\title{
It's all about that post; opportunities and challenges of sharing information online
}

Citation for published version (APA):

Aguirre Lopez, E. (2015). It's all about that post; opportunities and challenges of sharing information online. [Doctoral Thesis, Maastricht University]. Ipskamp drukkers. https://doi.org/10.26481/dis.20150626ea

Document status and date:

Published: 01/01/2015

DOI:

10.26481/dis.20150626ea

Document Version:

Publisher's PDF, also known as Version of record

\section{Please check the document version of this publication:}

- A submitted manuscript is the version of the article upon submission and before peer-review. There can be important differences between the submitted version and the official published version of record. People interested in the research are advised to contact the author for the final version of the publication, or visit the DOI to the publisher's website.

- The final author version and the galley proof are versions of the publication after peer review.

- The final published version features the final layout of the paper including the volume, issue and page numbers.

Link to publication

\footnotetext{
General rights rights.

- You may freely distribute the URL identifying the publication in the public portal. please follow below link for the End User Agreement:

www.umlib.nl/taverne-license

Take down policy

If you believe that this document breaches copyright please contact us at:

repository@maastrichtuniversity.nl

providing details and we will investigate your claim.
}

Copyright and moral rights for the publications made accessible in the public portal are retained by the authors and/or other copyright owners and it is a condition of accessing publications that users recognise and abide by the legal requirements associated with these

- Users may download and print one copy of any publication from the public portal for the purpose of private study or research.

- You may not further distribute the material or use it for any profit-making activity or commercial gain

If the publication is distributed under the terms of Article $25 \mathrm{fa}$ of the Dutch Copyright Act, indicated by the "Taverne" license above, 


\title{
IT'S ALL ABOUT THAT POST
}

\author{
Opportunities and Challenges \\ of Sharing Information Online
}

Elizabeth Aguirre 
Copyright Elizabeth Aguirre, Maastricht 2015

ISBN 978-94-6259-699-3

Cover design by: Jennifer Stead

Printing by: Ipskamp Drukkers

All rights reserved. No part of this publication may be reprinted or utilized in any form or by any electronic, mechanical or other means, now known, or hereafter invented, including photocopying and recording, or in any information storage or retrieval system, without permission from the copyright owner. 


\title{
IT'S ALL ABOUT THAT POST
}

\author{
Opportunities and Challenges \\ of Sharing Information Online
}

\section{DISSERTATION}

to obtain the degree of Doctor at Maastricht University, on the authority of the Rector Magnificus, Prof. Dr. L. L. G. Soete, in accordance with the decision of the Board of Deans, to be defended in public on Friday, 26 June 2015, at 10:00 hrs.

by Elizabeth Aguirre 


\section{PROMOTOR:}

Prof. Dr. J. C. de Ruyter

Prof. Dr. M. G. M. Wetzels

Prof. Dr. D. Grewal (Babson College)

\section{COPROMOTOR:}

Dr. F. D. Mahr

\section{BEOORDELINGSCOMMISSIE:}

Prof. Dr. G. Odekerken-Schröder (Chairman)

Prof. Dr. W. Gijselaers

Prof. Dr. A. Roggeveen (Babson College)

Prof. Dr. N. Stokburger-Sauer (University of Innsbruck) 
To my husband Jos 



\section{Acknowledgements}

It is surreal for me to be almost to the finish line, about to attain my doctorate. Even the stars could not have predicted this moment. My PhD journey has been a whirlwind experience, pushing me to extreme highs and lows, but because of everyone who believed in me, supported me, and challenged me, I survived it and came out a stronger and wiser person. I am proud of what I have accomplished within this dissertation and thankful to everyone who helped make this happen.

First and foremost, I express my eternal gratitude to my mentor and friend, Dr. Dominik Mahr. He pushed me beyond the boundaries of what I thought I could achieve, and he was there to support me when it seemed impossible. He was patient enough to sit through my many brainless conversations and go through some of my most terrible writing. Dominik, thank you for keeping me alive for the past few years, even if it was just to see me finish my PhD.

I also thank Prof. Dr. Ko de Ruyter for his generous support and guidance. His laissez-faire supervision style, coupled with his passion for fresh theories, allowed me the freedom to discover new topics within areas that I am truly interested in. His talent for writing helped transform my papers into something worth reading. Ko, it was a great pleasure to work with you. I enjoyed all our stimulating meetings and working together with you on your course.

I am grateful to Prof. Dr. Dhruv Grewal. His knowledge, expertise, and ability to transform raw ideas into publishable papers are remarkable. Dhruv, thank you for always welcoming me to Boston, for enlightening me when I was stuck in the mud, and for your dedication to guiding me through this $\mathrm{PhD}$ process.

Next, I am thankful to Prof. Dr. Martin Wetzels for his unconditional support. He was always approachable and ready to provide 
methodological insight. Martin, you have really helped move my $\mathrm{PhD}$ forward in so many ways, and for that I am extremely thankful!

I was also fortunate enough to work with my peers on some projects within my dissertation. Jan P., I'm glad that we had a chance to work together. It was great to brainstorm with you, and get excited about different parts of the project. Scott, thank you for taking care of me in Boston and outfitting me for our hike in New Hampshire. I had fun discussing new research ideas and methods with you, and I really have learned a lot from you.

I would like to express my gratitude to my committee members, Prof. Dr. Gaby Odekerken-Schröder, Prof. Dr. Wim Gijselaers, Prof. Dr. Nicola Stokburger-Sauer, and Prof. Dr. Anne Roggeveen for the time and effort they put into reading and evaluating this dissertation.

I also thank all my colleagues in the marketing department, who not only shared their expertise but who also made my time as a $\mathrm{PhD}$ candidate more fun. Specifically, I thank Kelly for believing that I could and should pursue a $\mathrm{PhD}$. It was she who first planted the idea in my head. Next, I thank Bram for always helping me with statistical questions when I needed it most. I also thank the current and former members of the L\&L team (Lieven, Eefje, Vincent, Wiebke, and Pieter) for their crazy ideas and funny conversations. It is a blast to come up with our quarterly newsletters together. I thank our "dynamic duo" of secretaries, Eefje and Pascalle, who together helped me through the university's complex administrative tasks, and who were always there for sincere conversations, and nice laughs. Last, I thank all the PhDs who took time off their own stressful PhDs to help me with mine, and who were also there to celebrate successes and console me during tough times. Niek and Anne, thank you for guiding me through the early years of my PhD. Jan M., Jan P., Matthias, Hannes, and Stephan, thank you for always offering to listen to my rants and helping me back on track when I was lost with my projects. Our parties were always epic, and Maastricht hasn't been the same since you all left! Katja and Nina, thank you for all the good times and the bad ones; for your great advice and your empathetic ears; and most of all, for helping me make one of the most important decisions of my life: picking a wedding dress. Jessie, thank you for always keeping me focused on the end-goal, and for always reminding me to still have fun. I miss our after-work drinks and bitterballen at 
Servaas! Stefania and Francisco, it was good to be officemates with you. It was also nice to see you both in Boston. Nadine, Vera, and Marleen, thank you for letting me randomly barge into your office every once in a while for human contact! Last, I would like to thank Ewa for not only always supporting her husband-even if he had to work nights and weekends on my dissertation-, but for also being very enthusiastic company that would brighten my day.

I would like to extend my gratitude to Ile and Robert, my paranymphs. They both helped prove a good distraction from the many long and hard days of my PhD. Ile, I enjoyed all our dog-walks and our good meals. It was really nice to get to know you at a more personal level. Robert, thanks for being an awesome year mate! We started our Masters at the same time, and so much has changed since! Thank you for being there when I needed help with anything under the sun from work-advice to a drink.

My visits to Boston were a big part of my $\mathrm{PhD}$ journey. I'd like to take this opportunity to thank everyone who welcomed me and took care of me during my time there. Jake, Trina, Chino, Vicka, and Kino, thank you very much for making me feel at home. It was great fun to experience Boston with you.

I want to say thank you to my family, who have been there to support me in this endeavor. Lola, you are the sweetest grandmother anyone can ask for. Thank you for your unconditional support and concern for my well-being. Mom, thank you for always being there for me no matter what. For always trying to do things to make me happy, even at your own expense. And of course, for sending me to Maastricht, which also helped me find myself and realize my full potential. Lastly, I want to thank the love of my life, Jos, for always believing in me. For bearing me when times were tough, and being the first one excited when things went well for me. His love and support helped me to persevere, and for that I dedicate this entire dissertation to him.

Elizabeth Aguirre, Maastricht 2015 



\section{Table of Contents}

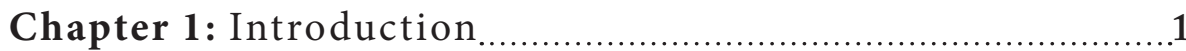

Chapter 2: Sharing is Rewarding ......................................11

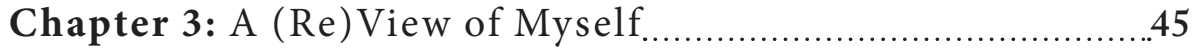

Chapter 4: Unraveling the Personalization Paradox.............75

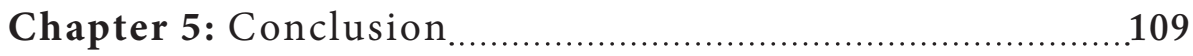

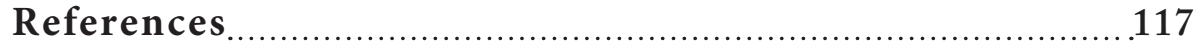

Appendix

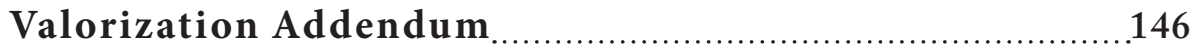

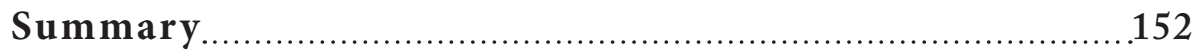

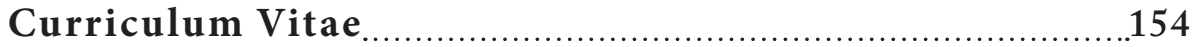





\section{List of Figures}

\section{Chapter 1}

Figure 1.1. Dissertation Overview

\section{Chapter 2}

Figure 2.1. Study 1a: Effects of Audience with Review Type on Choice of Cookie

Figure 2.2. Study 1b: Effects of Audience with Review Type on Willingness to Pay.

Figure 2.3. Study 3: Effects of Audience with Review Type in Praise versus No Praise.

Figure 2.4. Study 4: Effects of Audience with Review Type on $1 \mathrm{SD}$ above and below the mean of Self-Monitoring .........36

\section{Chapter 3}

Figure 3.1. Study 1: Interaction between Referral Manipulation and Learning Orientation on Number of Modules Taken.

Figure 3.2. Study 2: Interaction between Purpose and

Learning Orientation on Number of Modules Taken.

Figure 3.3. Study 3: Interaction between Perspective and Learning Orientation on Number of Modules Taken. 
Figure 3.4. Study 3: Interaction between Perspective and Learning Orientation on Number of Certainty Words. 68

\section{Chapter 4}

Figure 4.1. Prestudy 1: Click-Through Rates on Different Contexts 88

Figure 4.2. Prestudy 2: Percentage Change in ClickThrough Rates Due to Cookie Law in the Netherlands

Figure 4.3. Study 1: Effects of Information Collection with Less and More Personalization.... .93

Figure 4.4. Study 1: Mediated Moderation Model. .95

Figure 4.5. Study 2: Effects of Information Collection and Personalization in Different Contexts

Figure 4.6. Study 3: Effects of Information Collection in the Presence or Absence of an Icon on Click-Through Intentions 101

\section{Chapter 5}

Figure 5.1. Dissertation Overview 


\section{List of Tables}

Chapter 2

Table 2.1. Study 2: Means Standard Deviations, and Correlations. 28

Table 2.2. Study 2: Summary of Hierarchal Linear Model 29

Chapter 3

Table 3.1. Study 1: Summary of Zero Inflated Poisson Model 59

Table 3.2. Study 2: Summary of Zero Inflated Poisson Model 61

Table 3.3a. Study 3: Summary of Zero Inflated Poisson Model with Number of Modules as Dependent Variable 66

Table 3.3b. Study 3: Summary of Zero Inflated Poisson Model with Number of Certainty Words as Dependent Variable 67 



\section{CHAPTER 1 Introduction}




\section{Social Sharing}

"Social sharing is powerful enough to topple dictatorships and profitable enough to merit multibillion-dollar investments."

-Kitroeff (2014)

We live in an empowered and deeply connected society that propagates sharing and social interactions (Kaufman 2012). A growing number of individuals are drawn to social networking sites that allow them to share their experiences and engage in relevant content. For example, $58 \%$ of adults in the United States use Facebook, and $70 \%$ of them engage with the site daily (Duggan, Ellison, Lampe, Lenhart, and Madden 2015). As these social networking sites permeate the lives of the majority of the population, there is an explosion of activity that can be observed over the Internet: every minute 3.3 million posts are made on Facebook, 342,000 tweets on Twitter, and 60,000 comments on Instagram (Pennystockslab 2015). New developments have enabled billions of individuals to broadcast their thoughts and experiences, helped them reflect on these experiences, and enhanced their relationships with others (The New York Times 2011).

These developments have also created a myriad of opportunities for businesses to flourish. Firms such as Facebook and Amazon. com, for example, help customers by filtering this vast amount of information and providing them with tailored content in the form of product recommendations and targeted advertisements. These personalization strategies help drive their revenues: up to $20 \%$ of a website's revenue can be attributed to recommendation systems (Monetate 2012). Amazon.com is expected to earn $\$ 1.1$ billion from advertisements in 2015 (eMarketer 2013). A growing number of business-to-business (B2B) firms have started to integrate social media platforms to engage in conversations with their corporate partners and share knowledge (Channel Marketer Report 2014; Rapp, Beitelspacher, Grewal, and Hughes 2013). These initiatives can help drive partner engagement with a manufacturer's products (Kenton 2014), which is desirable because partners typically represent multiple product lines (Oracle 2009).

With the rise of new opportunities comes the emergence of new challenges for firms. With large amounts of consumer data being 
collected, customers find personalization practices increasingly intrusive (Aguirre et al. 2015; Angwin 2010). Recent evidence also suggests participation in social networking sites could be associated with lower self-control, resulting in unhealthy habits such as binge eating and higher credit card debt (Wilcox and Stephen 2013). With growing concern over socially responsible initiatives, companies are faced with the additional challenge of combatting the problems that arise from social networking.

In this dissertation, I investigate how sharing online affects the growing number of consumers who contribute content. I also provide firms and policy makers with strategies to help them manage the challenges that result from social networking. Unlike research that studies how online reviews affect the individuals who read them, this dissertation focuses on how reviewing affects the reviewers. To understand this phenomenon further, it is essential to gain deeper knowledge of the motivations that contribute to online information sharing. In the following section, I explore information disclosure as the overall theoretical perspective of this dissertation.

\section{Information Disclosure}

"We often talk about inventions like the printing press and the television-by simply making communication more efficient, they led to a complete transformation of many important parts of society. They give people more voice. They encouraged progress. They changed the way society was organized. They brought us closer together." - Mark Zuckerberg

It is prototypical for people to share personal information and express their thoughts and feelings to others (Omarzu 2000). This represents the defining characteristic of self-disclosure, which is the process of letting oneself be known to others (Mikulincer and Nachshon 1991) through the act of communicating personal information to them (Cozby 1973). Personal information can be descriptive or evaluative (expressing personal feelings and opinions) (Derlega, Metts, Petronio, and Margulis 1993) and messages can be shared to a small number of people or broadcasted to millions of people over the Internet (Barasch and Berger 2014). 
While sharing information is a ubiquitous phenomenon, it is a discretionary behavior; people make decisions about whether to disclose information and what information to disclose. Typically, these decisions hinge on both the conscious and subconscious goals of the discloser; they are made strategically to meet these goals. The disclosure decision model, developed by Omarzu (2000), aims to map the processes behind decisions to disclose information. It is based on the assumption that individuals decide what, how, and to whom they will disclose information, taking into account the social rewards and risks of disclosure. There are three stages in the model that lead to different types and different levels of disclosure.

The first stage of the model assumes individuals have different social goals when disclosing information. Some of these goals are relationship development, social validation, getting feedback and help, self-presentation (Derlega et al. 1993), and altruistic motives to help others and firms (Hennig-Thurau, Gwinner, Walsh, and Gremler 2004). When these goals are actualized through self-disclosure, individuals receive social rewards (Worthy, Gary, and Kahn 1969). However, varying situations and individual differences make some goals more salient because some people may place more importance on certain social rewards than others (Buss 1983).

The second stage of the model is making the necessary preparations to pursue the active goal. In this stage, individuals reflect on relevant information that helps them decide whether disclosure is an appropriate strategy to meet the goal. If so, they also select an appropriate recipient of the information (Omarzu 2000). This is an essential step, because it determines the content and form of the disclosure.

In the third stage of the model, individuals consider the subjective utility and risks of disclosing information that determines what is shared. While sharing information provides the discloser with a host of rewards, it also gives rise to some risks such as being rejected or being exploited, which leads to vulnerability (Moon 2000). A person's tolerance for vulnerability influences the intimacy level of their disclosure, making them more cautious about what they share (Derlega et al. 1993; Omarzu 2000).

Although self-disclosure has been studied for decades, it is a phenomenon that is intensified by the Internet. The Internet has 
provided opportunities for digital platforms to flourish and has enabled individuals to share with greater multitudes. It has empowered customers to speak out and voice their opinions, but it has also increased risk and made people more vulnerable.

In this dissertation, I shed light on a number of issues related to information disclosure within the online context. Although there is emerging research that looks at the motivations (Hennig-Thurau et al. 2004) of sharing specific content (Berger and Milkman 2012; Berger and Schwartz 2011) to a certain audience (Barasch and Berger 2014), as well as how this content influences the behaviors of this audience (Chevalier and Mayzlin 2006; Ludwig et al. 2013; Mudambi and Schuff 2010), research that considers how sharing affects the information discloser is lacking. Using the three stages of the disclosure decision model as a guide (Omarzu 2000), I address this gap in the research with three manuscripts.

Dissertation Overview
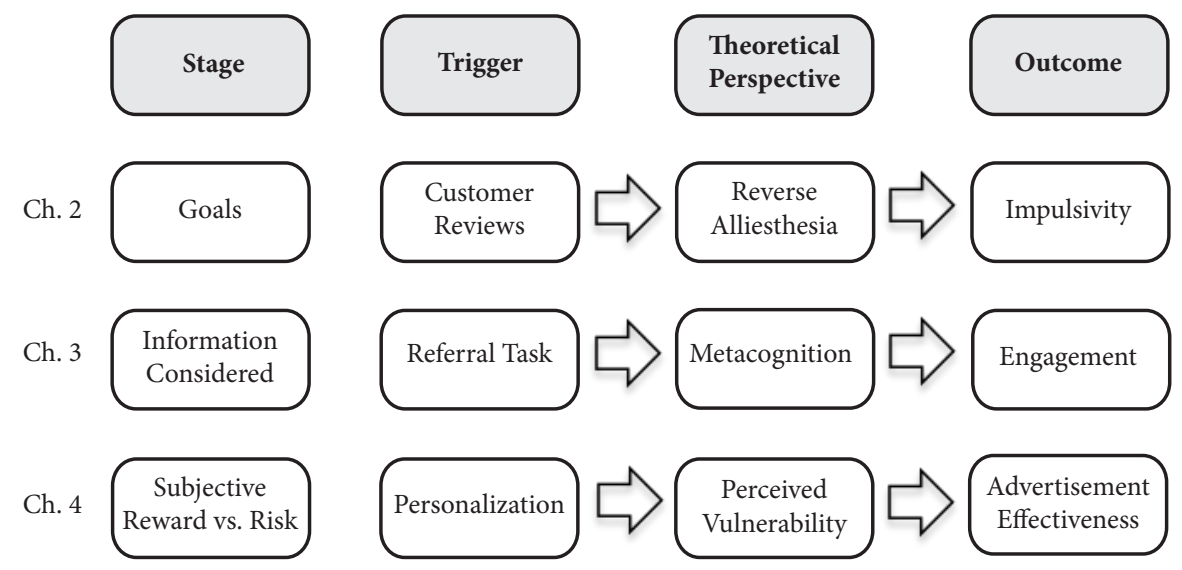

Figure 1.1

Dissertation Overview

This dissertation contains three distinct manuscripts that highlight how consumers are affected in each stage of Omarzu's (2000) disclosure decision model. In the first stage of the model, situational cues give rise to different social goals. In Chapter 2 of this dissertation, I investigate whether social cues inherent in customer reviews activate posters' goals to attain hedonic experiences. I explore whether these goals are especially salient among individuals who are sensitive to 
social cues, and whether they can be satiated through contact with rewarding experiences such as receiving praise.

In the second stage of the model, individuals reflect on the relevant information at hand to make decisions about their disclosure strategy. In Chapter 3 of this dissertation, I examine whether situational cues such as varying instructions in online tasks have an impact on what information is considered and reflected on (the activity known as metacognition), and assess its corresponding behavioral consequences. By specifically investigating learning environments within channel partner programs, I probe further to understand whether individuals' intrinsic abilities to engage in metacognition influence their drives to pursue additional learning.

In the third stage of the model, the individual takes into account the rewards as well as the risks of sharing. In Chapter 4 of this dissertation, I study how a firm's data collection strategy on social networking sites can determine whether individuals perceive the benefits of personalization or instead feel vulnerable. I further explore how cues that signal trust can mitigate the effects of vulnerability.

Chapter 2 Overview. Approximately seven million Americans, to date, have posted reviews on Amazon.com alone (McAuley and Leskovec 2013). Despite the popularity of online reviewing, little is known about how the review-writing process affects posters' behaviors. In Chapter 2, I address this research gap and attribute behavioral effects to the social rewards that reviewers attain from participating in this process. Sharing emotional information with others is in itself a rewarding behavior because it makes people feel positive about themselves and socially connected to their peers (Nielson 2012; The New York Times 2011). Research on reverse alliesthesia has found that experiencing such rewards may activate drive states focused on further reward seeking, even from different reward domains (Wadhwa, Shiv and Nowlis 2008). This activation makes individuals more impulsive (Kim and Zauberman 2013; van den Bergh, Dewitte, and Warlop 2008) and also makes them prefer more hedonic products (Li 2008). Because impulsive behaviors may have detrimental effects on consumer well being, such as increasing customer regret and debt (National Employment Savings Trust 2013), managers need to develop strategies to counteract this problem. This manuscript provides insights on the negative consequences 
that emerge from sharing information; it can be used as a starting point for managers to develop more specific guidelines to identify and provide targeted strategies to reviewers who are most vulnerable to detrimental effects.

Through a series of four experiments and a field study, I find sharing emotional reviews causes individuals to make more impulsive choices and have greater preferences for hedonic products compared to not sharing such reviews. By using boundary conditions, I am able to establish the mechanism behind this effect. I find this reward drive is more salient for individuals who are more sensitive to social cues. Further, I find it can be satiated by prior exposure to praise. Taken together, these results provide compelling evidence that the reviewwriting process may influence impulsive behaviors and hedonic choices and as a result pose a challenge to socially responsible managers. I provide several managerial implications for these findings and suggest strategies to mitigate the unintended effects of review writing.

Chapter 3 Overview. When people share information to others, $73 \%$ find they process the information more deeply, thoroughly and thoughtfully (The New York Times 2011). In Chapter 3, I investigate how the reflection brought about by writing reviews has an impact on partner engagement within manufacturer-partner relationships. I further investigate how two elements of review writing-the perspective taken and the purpose of the review-can influence this relationship. Particular to this context are enablement programs provided by manufacturers to equip their partners with knowledge and skills that may increase engagement with the manufacturer. This research targets lack of engagement (Maritz 2012), an issue faced by many $\mathrm{B} 2 \mathrm{~B}$ vendors, and provides a unique method of incorporating intrinsically motivating elements brought about by writing feedback within enablement programs.

Using experimental data collected from participants within an enablement program of a Fortune 100 information technology company, my findings that show writing feedback has an impact on partner engagement, exclusively among those who have a low learning orientation. Such partners have a low motivation to learn and are unable to recognize the deficits in their learning as they fail to reflect on their learning progress (Sheldon, Dunning, and Ames 2014). I find when such partners are tasked to reflect on pertinent 
information (for example, by writing for the benefit of a similar other or focusing the scope of their writing), they are more certain about the content of the feedback, which positively impacts their engagement behaviors in the long-term. Chapter 3 includes managerial insights on how to increase engagement among partners by prompting them to reflect on relevant aspects of their experiences through the process of writing feedback.

Chapter 4 Overview. In a study of over 15,000 global consumers, $51 \%$ picked "businesses using, trading, or selling my personal data without my knowledge or benefit" as a leading threat to their privacy (EMC $\left.{ }^{2} 2014\right)$. Although customers gain a lot of benefit from the personalized products and services firms provide (Vesanen 2007), they may also feel more vulnerable when firms use their personal information to feed this personalization process. In Chapter 4, I study this personalization paradox. Unlike other research in this area, I scrutinize firms' methods of data collection and analyze their influence on behavioral intentions to click on personalized advertisements. Currently, there are no strict standards in place that specify how firms should collect and use data (Goel 2014). Therefore, my findings may serve as a guide for both managers and government in understanding the consequences of various data collection strategies.

Using an exploratory field study on Facebook, as well as secondary data, I show personalization may not always lead to increased clickthrough behaviors, and firms experience sharp drops in click-through rates when customers realize firms used their information without their knowledge. In a series of three experimental studies, I find participants have greater intentions to click more (vs. less) personalized advertisements when firms overtly inform their customers of their collection strategies compared to when firms collected data covertly. I find this occurs because covert information collection makes customers feel more vulnerable. Through the use of trust-building strategies such as posting the advertisement on a credible website or utilizing information icons, firms can mitigate this feeling of vulnerability, leading to increased click-through intentions. Chapter 4 provides managers with insights that may help them with their personalization decisions, and informs governments of policies that may be beneficial to both consumers and firms. 


\section{Outline of the Dissertation}

This dissertation is based on three empirical studies described in Chapters 2, 3, and 4. While the overall theme of each of these studies is to investigate the effects of information disclosure in the online context, these studies can be read separately. Chapter 2 focuses on how writing customer reviews can trigger the reviewer to behave impulsively. Chapter 3 investigates how writing reviews has an impact on partner engagement within manufacturer-partner relationships. Chapter 4 shows some of the consequences that occur when firms collect and use the information that customers disclose to provide personalized advertisements. Finally, Chapter 5 concludes with a contemplation of the main findings, provides an overview of the implications, and offers some guidelines for future research. 



\section{CHAPTER 2 \\ Sharing is Rewarding}

Aguirre, Elizabeth, Scott Motyka, Dhruv Grewal, Dominik Mahr, Ko de Ruyter, and Martin Wetzels. "Sharing is Rewarding: The Effect of Sharing Experiences in Reviews on Reviewer Impulsivity," Working Paper. 


\begin{abstract}
Firms use product reviews to influence consumer behavior. They have developed several strategies to encourage customers to review products on their websites. Although there are many motivations that drive customers to review products, the act of sharing personal opinions is a rewarding experience in itself; it makes people feel socially connected to likeminded peers and positive about themselves. However, reverse alliesthesia theory suggests that such a rewarding experience may drive online reviewers to behave impulsively, which may have consequences on consumer well-being. With a growing number of customers transferring their loyalties to socially responsible firms, managers need to develop strategies to counteract this problem. Using different measures of impulsivity within four experimental designs, we demonstrate that sharing emotional information within the public realm of customer reviews, as opposed to expressing information in private, can lead participants to make impulsive decisions. This finding is further supported with a field study of Amazon.com reviewers. Because social approval provides receivers with rewards, we find firms can mitigate the occurrence of impulsive behaviors and their potential negative consequences by praising reviewers immediately after their writing tasks. However, not all individuals are equally affected; participants who are more sensitive to social cues seem particularly susceptible to this approach. These studies provide insight into the negative consequences that emerge from sharing information within social media, and highlight the need for industry associations to develop guidelines to protect reviewers who are potentially vulnerable to negative outcomes.
\end{abstract}


Reviews have emerged as a pivotal force in influencing customer purchase decisions (Weber Shandwick 2013). As a result, companies actively recruit consumers to post online reviews, and share their opinions and experiences with their peers (Essex 2011). While there are many motivations that drive customers to write reviews (Berger and Milkman 2012), it has been suggested that the very act of sharing opinions with others is a gratifying experience in itself, because it makes people feel positive about themselves and socially connected to likeminded peers (Nielson 2012; The New York Times 2011). Intriguingly, earlier research on gratifying experiences has shown they may cause consumers to engage in impulse buying (Tamir and Mitchell 2012; Wadhwa, Shiv, and Nowlis 2008). For companies, this finding sends a mixed signal. On one hand, it points towards untapped sales potential: massive numbers of online shoppers are engaged in writing reviews ( $\mathrm{PwC} 2012$ ). On the other hand, it recognizes that the scale and scope of reviewing presents a formidable challenge: impulse buying has been shown to have significant negative consequences, such as customer regret and waste of resources (National Employment Savings Trust 2013) as it causes individuals to prefer short term rewards over long-term benefits as well as vice over virtue products. Reviews are important to the success of many firms but there is also an undeniable need for companies to practice social responsibility. Consumers are transferring their loyalties to companies that care for their well-being (Kotler 2011). Therefore, firms should develop strategies based on in-depth behavioral insights to mitigate impulse buying and the unintended consequences of review writing.

To develop these insights, we turn to emerging reverse alliesthesia theory that suggests encounters with rewarding stimuli create a reward-drive state that heightens an individual's desire for instant gratification (Wadhwa, Shiv, and Nowlis 2008). Because sharing information with peers is inherently rewarding (Cozby 1973; Nitkin and Freund 2010), the central premise of this paper is that reviewing to a public audience can trigger reviewers to behave impulsively. Beyond introducing reverse alliesthesia as a theoretically derived explanation of impulsive behavior following the act of review writing, we advance extant knowledge by introducing a number of relevant contingencies that guide managers to regulate its negative consequences. More specifically, we aim to make three substantive research contributions. 
First, we extend current reverse alliesthesia theory by specifying what type of writing style used in writing reviews is particularly conducive to triggering impulsive behaviors. Characteristically, reviews are set within a public realm and often written in an affective tone (Ludwig et al. 2013). Such emotional expressions can provide an array of social rewards that strengthen their connectedness with others (Berger and Milkman 2012; Gable and Reis 2010). There is accumulating evidence that particularly hedonic stimuli, such as sexual images (Kim and Zauberman 2013; van den Bergh, Dewitte, and Warlop 2008), food and beverages (Wadhwa, Shiv, and Nowlis 2008), and opportunities for distinctiveness (Berger and Shiv 2011) have been found to increase impulsive behavior. However, it remains unclear whether the tone characteristic of customer reviews can be identified as a driving force of impulsive behavior. An important contribution of this paper, therefore, is to demonstrate reverse alliesthesia as a theoretical explanation of why writing reviews in an emotional style may lead to impulse buying behavior.

Second, current research demonstrates the reward-drive state is satiated upon exposure to reward and situational conditions can be created to mitigate this drive, reducing the likelihood of acting impulsively. Previous research has considered rewards such as money and hedonic products (e.g., candy bars) as a means to quench this reward drive. However, in practice, it is difficult for firms to integrate such strategies within review writing because they would have to compensate each reviewer after they have submitted their reviews, which could create negative perceptions (Streitfeld 2012). Nevertheless, praise is a potentially attractive alternative with rewarding characteristics that are well established in literature (Henderlong and Lepper 2002). Firms are currently using various forms of praise, such as social recognition and acknowledgement, to incentivize customers to write reviews; they could also be used as a tool to satiate the reward drive. Therefore, as a second research contribution, we explore how the use of praise can be identified as a boundary condition that mitigates the relationship between review writing and impulsive behavior.

Third, there is evidence that not all individuals are similarly affected by rewards (Sengupta and Zhou 2007). Some individuals find specific rewards more desirable than others; thirsty individuals, for example, find a beer more rewarding, particularly if they are alcoholic drinkers 
(Berger and Shiv 2011). Because sharing experiences through reviews is inherently social, we study individuals who are more sensitive to social cues, possessing a trait known as self-monitoring (Snyder 1974). Social contexts have remained largely unexplored within the theory of reverse alliesthesia; it is unclear how the self-monitoring trait determines the extent to which an individual is negatively influenced from writing a review. Therefore, as a third research contribution, we examine the contingency effects of individual differences in self-monitoring on the relationship between review writing and impulsive behavior.

In this paper, we begin by reviewing the literature on reverse alliesthesia and theorize how this body of knowledge is relevant to online review writing. Subsequently, we develop hypotheses on contingencies of writing reviews to gain more insights into the theory as it is applied to the online social context. We assess these hypotheses empirically through a series of experimental studies as well as a field study. We conclude with a discussion of the implications of our work for both research and practice.

\section{CONCEPTUAL BACKGROUND}

Rewards are not merely positive outcomes. They also possess a compelling force that directs attentional focus towards them, causing them to be "actively hungered" (Berger and Shiv 2011; Higgins 2006). However, rewards can also direct focus to unrelated rewards, because different rewards (e.g., food, money, and sex) activate the same reward regions of the brain and increase attention to and "wanting" of rewards (Berridge and Robinson 1998). This desire to attain rewards, caused by exposure to rewarding stimuli, is the foundation of the theory of reverse alliesthesia. The theory describes the activation of a reward drive that urges the individual to seek out other rewards (Wadhwa, Shiv and Nowlis 2008).

Building on this cornerstone theory, Berger and Shiv (2011) identify three characteristics of rewards. First, rewards go beyond the initial consumption cue and spill over into a broader array of domains. Sampling a tasty beverage not only increases the desire to 
consume more of the drink, but also intensifies preferences for other unrelated consumer products (Wadhwa, Shiv, and Nowlis 2008). This characteristic is also reflected in behaviors that result in impulsive choices and preferences ( $L i$ 2008). Exposure to rewarding stimuli heightens preferences for smaller, immediate rewards instead of larger, delayed rewards (Kim and Zauberman 2013; van den Bergh, Dewitte, and Warlop 2008) and vice options (e.g., movie tickets) over virtue options (e.g., bookstore coupons) (Li 2008). Second, the reward drive that triggers impulsive behaviors can be satiated by rewards from both within and without the initial reward domain. Exposure to money after sampling a tasty beverage diminishes the urge to seek out other rewards (Wadhwa, Shiv and Nowlis 2008). Third, rewards display drive-dependent attractiveness that extends to individual differences in reward desirability. Some rewards may trigger more impulsive behaviors than others, depending on individual and situational differences. Thirsty individuals, for example, find a beer more rewarding, particularly if they are alcoholic drinkers (Berger and Shiv 2011).

Individuals may obtain social rewards from sharing information with others (Baumeister 1982). However, this is not the case when the same information is expressed in private. Research shows online posters derive utility from sharing information to the public through social media (Toubia and Stephen 2013). Because humans are social creatures and place a high value on social interactions (Baumeister and Leary 1995), it is not surprising that sharing information online can be a gratifying experience in itself; such forms of sharing typically occur in the public sphere, resulting in information shared to a large number of people. However, the type of information that is shared may have an impact on how rewarding the sharing experience is because people find sharing personal opinions more inherently valuable than sharing facts (Tamir and Mitchell 2012).

In the online context, particularly customer reviews, people have the tendency to share two types of information: rational and emotional. Rational information refers to evaluative and factual content that is shared for self-enhancement purposes. Emotional information is comprised of expressions of personal feelings and opinions (Berger and Milkman 2012; Derlega et al. 1993). Typically, such information is shared to build social bonds (Peters and Kashima 2007) but at the same time it can also help people regulate their emotions and 
make sense of their experiences (Harber and Cohen 2005). Although sharing both rational and emotional information appears to have distinct social utilities, sharing emotional information is a more important predictor of intimacy than self-disclosure of facts and information (Laurenceau, Barrett, and Pietromonaco 1998). Sharing emotional information not only strengthens social bonds (Gable and Reis 2010; Peters and Kashima 2007; Rime 2007), but also signals to others that a person is open to a communal relationship (Clark and Taraban 1991) and leads individuals to be more liked (Collins and Miller 1994). Such relational benefits are important and highly valued especially among individuals who are sensitive to reward (van Prooijen, Karremans, and van Beest 2006), such as those who score highly on the self-monitoring trait. Such individuals have a stronger need to maintain social approval and carefully regulate their selfpresentation (Snyder 1974). They are more receptive to social cues (Becherer and Richard 1978).

\section{HYPOTHESIS DEVELOPMENT}

Sharing emotions with others is important as it communicates one's needs and plays a pivotal role in social interactions (Clark and Taraban 1991; van Kleef 2009). It can provide a wide variety of social rewards to the discloser and has a motivational reward value (Gable and Reis 2010). While emotions shared with others provide the discloser with social rewards, emotional information expressed in private provides no such rewards. In line with the theory of reverse alliesthesia, the social benefits that result from emotional communication to others, through customer reviews, may trigger a reward drive within the reviewer that causes them to engage in impulsive behaviors. However, this is not the case when emotions are expressed in private.

H1: Individuals engage in impulsive behaviors when they express emotional information to a public audience compared to when they express such information in private. 


\section{Praise}

Receiving praise is regarded as a social reward because it refers to positive evaluations of another's performance (Henderlong and Lepper 2002). Praise communicates social approval, builds self-esteem by focusing on personal abilities, and makes individuals feel pleased with their performances (Canavan-Gumpert 1977). Research studies have used rewards such as money and hedonic products (e.g., candy bars) to satiate the reward drive produced by exposure to rewarding stimuli (Wadhwa, Shiv and Nowlis 2008). Therefore, receiving praise can potentially satiate the impulsive drive that results from sharing emotional information to an audience through customer reviews.

H2: Providing praise to individuals satiates the impulsive behaviors that result from expressing emotional information to a public audience.

\section{Self-Monitoring}

Self-monitoring is a trait relating to sensitivity to social cues (Becherer and Richard 1978). High self-monitors have a stronger need to maintain social approval (Snyder 1974), and are more able to accurately perceive social cues than those who are low self-monitors (Gangestad and Snyder 2000). High self-monitors maybe more responsive to the social incentives that are derived from reviewing products online. Consequently, we predict the extent to which individuals who share emotional information increase their impulsive behaviors depends on their degree of self-monitoring. Individuals who are high selfmonitors are more sensitive to social cues and are therefore more likely to find the social sharing of emotions more appealing, leading to more impulsive behaviors. People who are low self-monitors are less likely to engage in impulsive behaviors because they are less concerned with social considerations.

H3: Individuals who are high (low) self-monitors (do not) engage in more impulsive behaviors when they express emotional information to a public audience than when they express such information in private.

We conducted a series of empirical studies to test these hypotheses. Studies $1 \mathrm{a}$ and $1 \mathrm{~b}$ establish that expressing emotional information to others through customer reviews increases impulsive choices 
and behaviors (H1). Study 2 incorporates field research carried out with Amazon.com reviewers to show these effects extend beyond the experimental setting. Study 3 investigates strategies firms can implement to offset the negative effects of review writing by assessing the effects of praise (H2). Study 4 examines individual differences in how review writing affects reviewer behavior (H3).

\section{STUDY 1A}

The act of writing a review is an inherently social phenomenon because reviewers expect others will read their reviews. However, to understand the behavioral effects of sharing information to others, it is necessary to contrast public reviewing with a condition in which participants are asked to express the same information in private. We apply these conditions in Study 1a, and delineate the types of information that are expressed: information that pertains to personal opinions and experiences (emotional) and information based on fact (rational). Because the purpose of Study $1 \mathrm{a}$ is to demonstrate the finding that simply sharing information does not result in greater impulsive behaviors is applicable only when emotional information is shared, we randomly assign participants to write an emotional review or a rational review (i.e., control).

As a measure of impulsive behaviors, we look at the behavior of participants in choosing between two products: vice products versus virtue products. Vice products (e.g., cakes) are hedonically more appealing than virtue products (e.g., salads), and selecting the former due to a sudden unplanned urge to immediately gratify oneself is regarded as an impulsive act (Sengupta and Zhou 2007; Wilcox and Stephen 2013). We examine whether participants engage in more impulsive behaviors (by selecting the vice product over the virtue product) when they share emotional information to a public audience compared to when they express this information in private $(\mathrm{H} 1)$.

Method

Design and procedure. Ninety-six participants from an online panel (66\% female; age $18-69$; mean $=36)$ participated in this 
experiment and were randomly assigned to a 2 (audience: public vs. private) $\times 2$ (review type: emotional vs. rational) between-subjects design. Two participants (2\%) were removed from the study ${ }^{1}$, leaving ninety-four entries for the analysis.

Participants watched a short video documentary, and were subsequently asked to write reviews. The instructions for the reviews varied between subjects. First, participants were asked to write either a personal review that was based on how the documentary made them feel (condition: emotional) or an objective review that was based on their opinion of the quality of the documentary (e.g., storyline, editing; control condition: rational). Second, all the participants were informed that their review would be shared with members of a film academy (condition: share) or were told that no one, not even the experimenters, would read it (condition: private; see Appendix A).

Measures. After writing the review, participants were informed that they would be participating in an unrelated study on decisionmaking. They were asked to imagine that they would have to choose between a chocolate chip cookie (vice item) and a granola bar (virtue item) (Wilcox and Stephen 2013). During the analysis, the word count of the review was used as a covariate to control for the effort spent on writing the review.

\section{Results}

Manipulation Checks. To test whether the manipulations worked as intended, participants answered two questions to indicate whether they provided an emotional or rational review. Participants in the emotional (vs. rational) condition reported lower scores to the statement "I wrote down an objective review of the movie clip" $($ Memotional $=4.70 ;$ Mrational $=6.02 ; t(92)=3.83 ; p<.001)$, and higher scores to the statement "I wrote down my personal feelings and attitudes towards the movie clip" (Memotional $=6.14$; Mrational = 3.76; $t(92)=-6.03 ; p<.001)$.

Participants completed two additional items to indicate whether or not they thought others would read their review. Participants in the public (vs. private) manipulation reported higher scores to the statement "I felt like I was sharing it with other people" $\left(\mathrm{M}_{\text {public }}=\right.$ $5.57 ;$ Mprivate $=4.91 ; t(92)=-1.84 ; p=.069)$, and lower scores to the 
statement "I felt that it would not be seen by others" $($ Mpublic $=2.72$; Mprivate $=4.19 ; t(92)=3.49 ; p=.001)$.

Choice. A logistic regression was used to test the predictions. The dependent variable was choice. Audience, review type, and their interaction were included as independent predictors, and word count as a covariate. The main effect of audience was not significant ( $\beta=-.44, p=.488)$, while the effect of review type was significant $(\beta=-1.26, p=.044)$, indicating that participants in the emotional condition were more likely to select the granola bar. Word count was not significant $(\beta<-.01, p=.158)$. More importantly, the review type by audience interaction was significant $(\beta=1.84, p=.034$; See Figure 2.1). To explore the interaction, we examined the effect of audience on those who wrote rationally or emotionally. In line with $\mathrm{H} 1$, we found that individuals who expressed emotional information to a public audience (vs. private expression) were significantly more likely to engage in impulsive behaviors by selecting the vice option (i.e., chocolate chip cookie; $z=2.31, p=.021$ ). Individuals who expressed rational information were not more likely to engage in impulsive behaviors when sharing this information to a public (compared to private expression) $(z=-.69, p=.490)$.

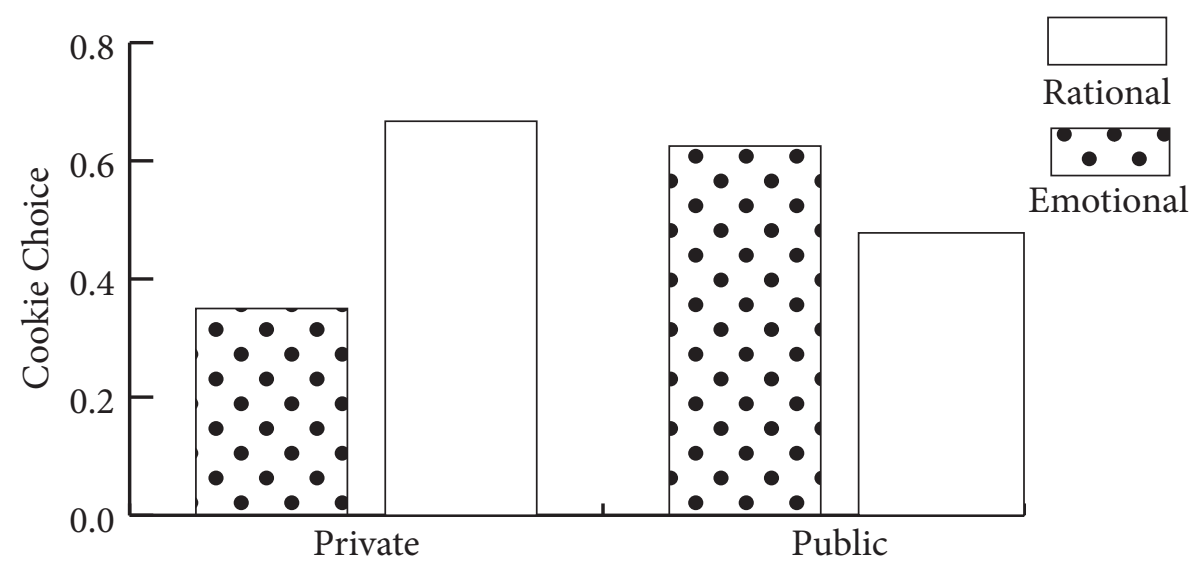

Figure 2.1

Study 1a: Effects of Audience with Review Type on Choice of Cookie 


\section{Discussion}

The results of Study 1 a provide evidence that publicly sharing emotional information through customer reviews (vs. private expression) leads participants to engage in impulsive behaviors (H1), specifically preferring vice options over virtue options. This finding provides evidence for the presence of reverse alliesthesia: sharing emotional reviews can trigger a reward-drive state as evidenced by impulsive choices. We ran an additional experiment to gain insight into the conventional writing styles of participants when they are not instructed to write in a particular manner. In this experiment, we found that participants had the tendency to write in an emotional manner, consequently exhibiting a similar drive for impulsive choices as participants in the emotional condition, but not in the rational condition. This suggests that individuals are naturally expressive and tend to write emotionally when writing product reviews, which is particularly troubling given the large amount of reviews online ${ }^{2}$.

To further generalize the findings of Study 1a, we vary the product type that is the focus of the review as it can influence the extent to which individuals write emotional information and the way in which writing affects impulsive behaviors. In Study 1 b, we introduce an entertaining movie, which we predict will generate more emotional responses than the neutral movie used in the first study. Moreover, we vary the measure of impulsivity by assessing customer willingness to pay for the product.

\section{STUDY 1B}

Online firms ask their customers to review different types of products; some are potentially more emotion-inducing than others. Previous literature shows participants are typically more likely to share their experiences with more entertaining products (Berger and Schwartz 2011). Therefore, Study $1 \mathrm{~b}$ tests whether the findings from the previous studies hold true by using an entertaining video trailer as the target of reviews. The study also considers participants' willingness to pay as a proxy for impulsive purchases, because it reflects a greater urge to own a product, and a higher product value (Vohs and Faber 2007). 


\section{Method}

Design and procedure. Two hundred and fifty-six participants from an online panel ( $56 \%$ female; age $19-71$; mean $=36$ ) participated in a 2 (review type: rational vs. emotional) $\times 2$ (audience: private vs. public) $\times 2$ (movie clip: neutral vs. entertaining) between-subjects design. Eight participants (3\%) were removed from the study ${ }^{3}$, leaving two hundred forty-eight usable entries. Participants were randomly assigned to one of eight groups, and were asked to write a rational (emotional) review about the clip that would (would not) be read by others.

Measure. Participants were asked to indicate the amount of money (in dollars) that they would be willing to pay for the movie clip. On a separate page, they were asked to provide a star rating for the movie clip, to be used as a covariate in the analysis to control for preference for the product. Similar to the previous study, the number of words used in the review were used as a covariate.

Results

Manipulation Checks. Similar to Study 1a, participants answered two questions to indicate whether they wrote a rational or emotional review. Participants in the rational (vs. emotional) manipulation reported higher scores to the statement "I wrote down an objective review of the movie clip" (Mrational $=6.02 ;$ Memotional $=5.15 ; t(246)$ $=-4.67 ; p<.001)$, and lower scores to the statement "I wrote down my personal feelings and attitudes towards the movie clip" (Mrational $=3.47 ;$ Memotional $=5.88 ; t(246)=10.51 ; p<.001)$. Participants also completed two items to indicate whether or not they thought that others would read their review. Participants in the public (vs. private) manipulation reported higher scores to the statement "I felt like I was sharing it with other people" $\left(\mathrm{M}_{\text {public }}=5.27 ; \mathrm{M}\right.$ private $=4.63 ; t(246)=$ $2.69 ; p=.008)$, and lower scores to the statement "I felt that it would not be seen by others" $\left(\right.$ Mpublic $=2.94 ; \mathrm{M}_{\text {private }}=4.18 ; t(246)=-4.81$; $p<.001)$.

Willingness to Pay. A three-way ANOVA with audience (private vs. public), review type (rational vs. emotional) and movie clip (entertaining vs. neutral) as independent variables and willingness to pay as the dependent variable was conducted with star rating and word count used as covariates. As predicted, no significant 
three-way interaction $(F(1,238)=.14 ; p=.710)$ was found. A closer look into two-way interactions revealed the predicted significant interaction between audience and review type $(F(1,238)=6.99$; $p=.009$; See Figure 2.2). This suggests that regardless of the type of film (entertaining or neutral), the effects that we have found in Studies $1 \mathrm{a}$ and $1 \mathrm{~b}$ remain relevant. For both films, participants who shared emotional information to a public audience (vs. expressing this information privately) reported a higher willingness to pay for the film they viewed. This is in line with findings from Hypothesis 1 . The main effects of audience $(F(1,238)=.18 ; p=.675)$ and review type $(F(1,238)=.08 ; p=.778)$ were not significant, while the main effect of the type of movie was significant $(F(1,238)=11.37 ; p=$ $.001)$. Both the covariates of star rating $(F(1,238)=172.98 ; p<.001)$ and word count $(F(1,238)=8.82 ; p=.003)$ had a significant impact on willingness to pay.

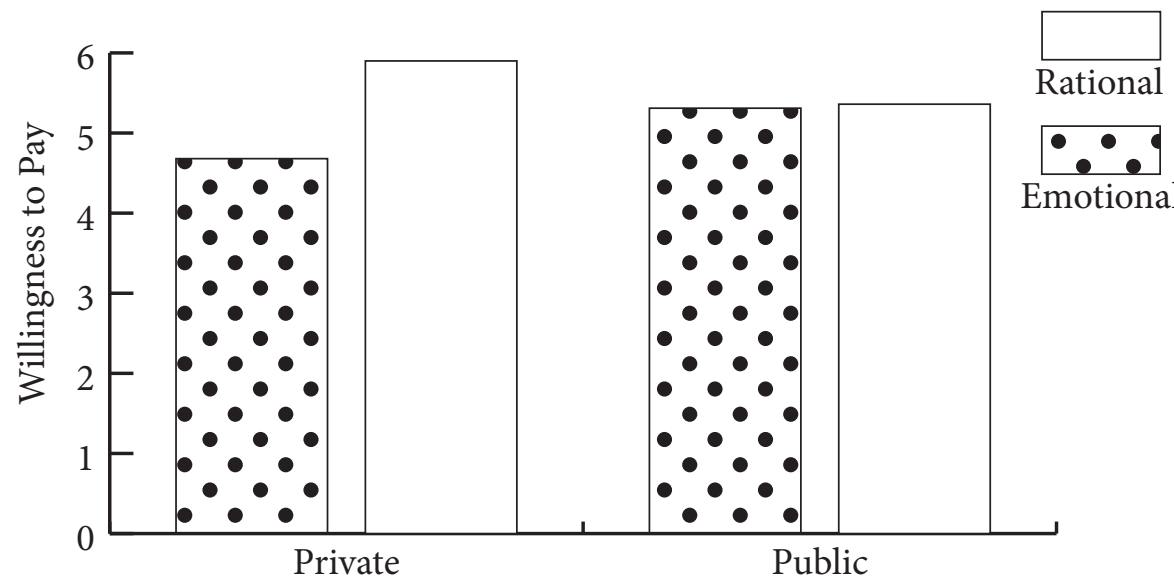

Figure 2.2

Study 1b: Effects of Audience with Review Type on Willingness to Pay

As there was no significant three way interaction, an additional twoway ANOVA was run with audience (private vs. public) and review type (rational vs. emotional) as independent variables and willingness to pay as the dependent variable, with star rating and word count used as covariates to shed light on the relationship. The interaction between audience and review type was significant $(F(1,242)=4.67 ; p$ $=.032$ ). Contrasts revealed that individuals who expressed emotional information to a public audience (vs. private expression) were willing to pay significantly more for the film $($ Mpublic $=5.31$; Mprivate $=$ 
$4.68 ; F(1,242)=5.33 ; p=.022)$. Individuals who expressed rational information were not more willing to pay for the film regardless of the audience (public or in private) $($ Mpublic $=5.36 ;$ M private $=5.90$; $F(1,242)=.71 ; p=.401)$. The main effects of audience $(F(1,242)=$ $.85 ; p=.358)$ and review type were not significant $(F(1,242)<.01$; $p=.950)$ but the covariate of star rating $(F(1,242)=163.41 ; p<$ $.001)$ and word count $(F(1,242)=12.06 ; p=.001)$ had a significant impact on willingness to pay.

\section{Discussion}

The goal of Study $1 \mathrm{~b}$ was to further extend the findings from Study 1 a by gaining insight into whether these findings still hold if participants write about more (vs. less) entertaining products. The results provide support for the applicability of these findings, and suggest that posting an emotional review can lead to impulsive behaviors (H1) regardless of the type of product being reviewed, as well as the quality of the product. Given that we have established sharing emotional information to others through customer reviews leads to impulsive choices and behaviors (Study 1a), and this occurs regardless of the type of product being reviewed (Study 1b), we conduct a field study (Study 2) to test whether reviewers report increased impulsive spending if they share more emotionally.

\section{(FIELD) STUDY 2}

A field experiment among Amazon.com users demonstrates the effects of writing reviews on impulsive purchases. In Studies 1a and $1 \mathrm{~b}$, we compare how sharing emotional information publicly versus expressing such information privately affects impulsive choices. In Study 2, our focus is solely on the public sphere because review writing is inherently social. In this experiment, we ask Amazon.com users to access their account information and provide information on the reviews they have written and subsequent purchases they have made. Through this unique research design, we find support for how the writing style of the review has an impact on impulsive behaviors. 


\section{Method}

Design and procedure. One hundred and fifty-one Amazon. com reviewers were recruited from an online panel ( $47 \%$ female; age $19-68 ;$ mean $=32)$. Three participants $(2 \%)^{4}$ were removed from the study, leaving one hundred and forty-eight entries for analysis.

Participants were first invited to participate in the questionnaire, and were informed prior to joining they would be requested to provide general and anonymous information about their product reviews and past purchases. Subsequently, they were presented with two screening questions that asked whether they had ever purchased a product on Amazon.com and whether they had ever posted a review on Amazon. com. If participants answered "no" to any of the questions, they were redirected to the end of the questionnaire. Participants who met these two criteria were asked to log into their Amazon accounts, and cut and paste information from the last five product reviews they had posted. Information requested included date of the review, star rating, title of the review, and verbatim text of the review. Next, they were asked to look through their past purchase histories and indicate the total dollar amount of products they purchased for the two week period following the writing of their reviews, as well as the total amount they spent on unplanned purchases during that time. They were instructed that if they had two reviews that overlapped within the two-week period, they should include only the purchases made before the next review was written, to ensure that purchases made could be attributed to the previous review. Finally, we asked them to indicate whether they truthfully provided information.

Measure. We calculated the percentage of money spent on unplanned purchases over the total amount spent during this period (i.e., percentage of unplanned spending) as our main outcome variable, and used it as a measure of impulsivity. A well-established and commonly used computer program, Linguistic Inquiry and Word Count (LIWC) (Pennebaker Conglomerates, Inc. n.d.) was used to analyze the number of affective and cognitive words in each review, used as our independent variables (Tausczik and Pennebaker 2010; Berger and Milkman 2012). The number of stars in the review, and word count were included as covariates in the analysis. 
Analytical Procedure. The data have a multilevel structure, in which a total of 433 reviews are nested within 148 participants. Typical OLS regression models are not suitable for this type of data because the data violates the assumption of independence of observations (Hox 2002). To account for this, we employed a Hierarchical Linear Modeling (HLM) (Raudenbush and Bryk 2002) with HLM 7 using full maximum likelihood estimation. Due to likely non-normality in the outcome variable (and to be conservative in our estimates), the effects were calculated using robust standard errors (Hox 2002). All predictor variables were entered using the natural X metric (uncentered) (Raudenbush and Bryk 2002), and all coefficients were entered as random effects.

The first level of analysis included the specific review characteristics and we did not include any variables at the second level. As a first step in the HLM analysis, we conducted a one-way analysis of variance with random effects (i.e., null model or intercept-only model in which no predictors were specified for either Level 1 or Level 2) to investigate whether the data was suitable for multilevel modeling (Garson 2012). The results indicated there was significant between-group variance $\left(x^{2}(147)=1217.98, p<.001\right)$. Moreover, the intraclass correlation coefficient (ICC) showed that $73 \%$ of the variance in percentage of unplanned spending is between the reviewers (Raudenbush and Bryk 2002). These results highlight the suitability of using multilevel modeling for the data.

We formulated the HLM models used for hypothesis testing with the following Level 1 (specific review characteristics) and Level 2 equations:

Level 1

$$
\begin{aligned}
& \text { UNPPERCS }_{i j}=\beta_{0 j}+\beta_{1 j^{*}}\left(\text { WC }_{i j}\right)+\beta_{2 j^{*}}\left(\text { STARS }_{i j}\right)+ \\
& \beta_{3 j^{*}}\left(\text { AFFECT }_{i j}\right)+\beta 4 j^{*}\left(\text { COGMECH }_{i j}\right)+r_{i j}
\end{aligned}
$$

Level 2

$$
\begin{aligned}
& \beta_{0 j}=\gamma_{00}+u_{0 j} \\
& \beta_{1 j}=\gamma_{10}+u_{1 j} \\
& \beta_{2 j}=\gamma_{20}+u_{2 j} \\
& \beta_{3 j}=\gamma_{30}+u_{3 j} \\
& \beta_{4 j}=\gamma_{40}+u_{4 j}
\end{aligned}
$$


where $i$ and $j$ represent each review and reviewer, respectively; UNPPERCS denotes percentage of unplanned spending; WC is word count; STARS refers to the star ratings; AFFECT is affective processes; and COGMECH represents cognitive mechanisms. Table 2.1 shows summary of means and SDs.

\begin{tabular}{|l|r|r|r|l|l|l|}
\hline Variables & Mean & SD & 1 & 2 & 3 & 4 \\
\hline LEVEL 1 & & & & & & \\
\hline 1. Word Count & 91.41 & 109.13 & - & & & \\
\hline 2. Stars & 4.14 & 1.24 & -.033 & - & & \\
\hline $\begin{array}{l}\text { 3. Affective } \\
\text { Processes }\end{array}$ & 6.83 & 4.53 & - & $.203^{\star *}$ & - & \\
\hline $\begin{array}{l}\text { 4. Cognitive } \\
\text { Mechanisms }\end{array}$ & 16.39 & 5.96 & .042 & $-.099^{\star}$ & $-.164^{* *}$ & - \\
\hline LEVEL 2 & & & & & & \\
\hline- & & & & & & \\
\hline
\end{tabular}

* No variables were included in Level 2

Table 2.1

Study 2: Means Standard Deviations, and Correlations

\section{Results}

Table 2.2 summarizes the HLM models and results. Note that we report unstandardized coefficients. As hypothesized, we find the greater the number of emotional words that are used in a review, the greater the amount of unplanned spending (our proxy for impulsivity) $\left(\gamma_{30}=.006, p=.053\right)$. We also find that decreasing use of cognitive words leads to an increase in the amount of unplanned spending $(\gamma 40$ $=-.006, p=.014)$. An interesting finding is that the lower the star rating, the greater the amount of subsequent unplanned spending $(\gamma 20$ $=-.016, p=.075)$-perhaps a method of mood regulation following a disappointing experience with a product. Length of the review (word count) did not significantly affect the percent of unplanned spending $(\gamma 10<.001, p=.769)$. 


\begin{tabular}{|c|c|c|}
\hline & $\begin{array}{l}\text { Null Model: } \\
\text { UNPPERCS } i j=\gamma_{00}+ \\
\mathrm{u}_{0 j}+\mathrm{r}_{\mathrm{ij}}\end{array}$ & 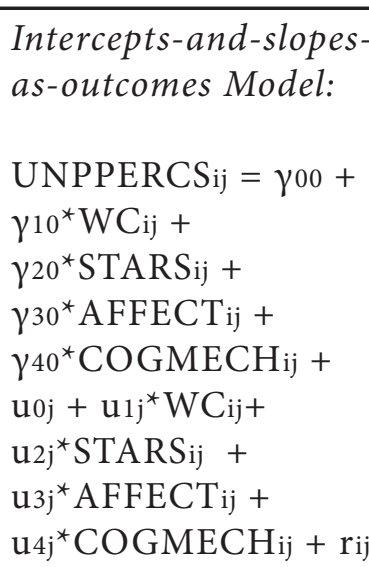 \\
\hline Fixed Effects & Coefficient (SE) & Coefficient (SE) \\
\hline $\begin{array}{l}\text { For INTRCPT } 1, \beta_{0} \\
\text { WORD COUNT, } \beta_{1} \\
\text { STARS, } \beta_{2} \\
\text { AFFECTIVE } \\
\text { PROCESSES, } \beta_{3} \\
\text { COGNITIVE } \\
\text { MECHANISMS, } \beta_{4}\end{array}$ & $0.253(0.031)^{* * *}$ & $\begin{array}{c}0.361(0.072)^{* * *} \\
0.000(0.000) \\
-0.016(0.009)^{*} \\
0.006(0.003)^{* *} \\
-0.006(0.002)^{* * *}\end{array}$ \\
\hline Random Effects & $\begin{array}{c}\text { Variance Component } \\
(S D)\end{array}$ & $\begin{array}{c}\text { Variance Component } \\
(S D)\end{array}$ \\
\hline $\begin{array}{l}\text { INTRCPT } 1, \mathrm{u} 0 \\
\text { WORD COUNT, u } 1 \\
\text { STARS, u2 } \\
\text { AFFECTIVE } \\
\text { PROCESSES, u3 } \\
\text { COGNITIVE } \\
\text { MECHANISMS, u4 } \\
\text { level-1, r }\end{array}$ & $0.121(0.347)^{* \star \star}$ & $\begin{array}{l}0.232(0.482)^{* * *} \\
0.000(0.001)^{* * *} \\
0.000(0.014) \\
0.000(0.004) \\
0.000(0.009) \\
0.039(0.196)\end{array}$ \\
\hline \multicolumn{3}{|l|}{ Model Fit } \\
\hline $\begin{array}{l}\text { Deviance } \\
\text { (Parameters) }\end{array}$ & $175.16(3)$ & $160.27(21)$ \\
\hline
\end{tabular}

${ }^{* * *} p<.01,{ }^{* *} p<.05,{ }^{*} p<.10$

Table 2.2

Study 2: Summary of Hierarchal Linear Model 


\section{Discussion}

Building on the findings from Studies $1 \mathrm{a}$ and $1 \mathrm{~b}$, we find support for our proposition that emotionally written reviews lead to impulsive behaviors (in this case, spending more money on unplanned products). Drawing from literature and studies conducted in Study 1, we believe this is due to the rewarding nature of disclosing emotionally laden content to a public audience. We also find a significant decrease in impulsive behaviors when individuals share rational or cognitive content with an audience. Another interesting finding is that lower star ratings yield increased amounts spent on unplanned purchases. This could be an individual's way to cope with a negative product experience: purchasing products makes the reviewer feel better (See, for example, Garg, Wansink, and Inman 2007). This effect has been well documented in literature. Because review writing has been shown to affect impulsive behaviors, firms can benefit from strategies designed to deter these effects. In Study 3, we consider a cost-effective strategy that firms can implement to offset the impulsive behaviors that may arise from writing reviews.

\section{STUDY 3}

After writing reviews, most reviewers are redirected to a confirmation page on which the firm acknowledges that a review has been posted. We believe such a page has the potential to mitigate the impulsive drive brought about by writing reviews; these types of pages provide firms with the opportunity to praise their reviewers. In Study 3, we test the effect of exposure to praise on impulsive choice to determine whether praise can satiate the reward drive created by sharing emotional reviews to a public audience $(\mathrm{H} 2)$.

Design and Procedure. Two hundred and forty-seven participants from an online panel $(65 \%$ Female; age $19-76$; mean $=35)$ participated in a 2 (audience: public vs. private) $\times 2$ (review type: emotional vs. rational) $\times 2$ (praise: no praise vs. praise) between-subjects design. Five $(2 \%)^{5}$ respondents were removed for various reasons, leaving two hundred and forty-two entries for analysis. The pattern of the results remained unchanged with the inclusion of these participants. 
Participants were invited to participate in this experiment, and were subsequently presented with a screening question that asked whether they had made a purchase on Amazon.com in the past six months. If participants answered "no" to this question, then they were redirected to the end of the questionnaire. Participants who met this criteria were asked to log into their Amazon.com accounts, and were redirected to a page that featured products that they had purchased but not yet reviewed. Participants were asked to select a product from the page that they had purchased within the past six months, and were told that they were to write a review on this product. They were randomly assigned to write a rational (emotional) review about the product and assigned to a private or public condition. Instructions on review type (rational vs. emotional) were adapted from that used in Study 1a. Participants assigned to the public condition were informed that they would be asked to share this review on Amazon.com, and were given instructions on how to do this. Those in the private condition were informed that we were developing an algorithm to evaluate the messages in reviews, and therefore no one would read the reviews that they had written.

After writing the review, participants were randomly assigned to a praise- and no praise-condition. Participants in the praise condition participated in an anagram task that praised their ability to find the correct number of solutions beyond the norm (Hicks, Hicks, and Mansfield 1969), while those in the no praise condition did not participate in this task. Afterwards, participants made eight monetary choices between a smaller-sooner or larger-later reward (e.g., $\$ 10$ tomorrow vs. $\$ 12$ in 25 days; $\$ 67$ tomorrow vs. $\$ 85$ in 70 days), which were summed such that higher values indicated more smaller-sooner choices. Subsequently, we calculated the word count and used this variable as a covariate in our analysis.

Results

Manipulation Checks. Similar to Study 1a, participants in the emotional (vs. rational) condition reported higher scores to the statement "I wrote down my personal feelings and attitudes towards the movie clip" (Memotional $=6.27 ;$ Mrational $=5.20 ; t(239)=-6.52 ; p<$ .001 ), and lower scores to the statement "I wrote down an objective review of the movie clip" (Memotional $=5.27 ;$ Mrational $=5.51 ; t(239)$ $=1.44 ; p=.077$ one-tailed). Moreover, participants in the public 
(vs. private) manipulation reported lower scores to the statement "I felt that it would not be seen by others" (Mpublic $=2.40 ;$ Mprivate $=3.15 ; t(240)=3.51 ; p=.001)$. Participants were presented with a slider question that asked them to indicate the extent to which they felt they shared information with others, anchored from 1-100 (1 $=$ did not share information; $100=$ shared information). In this question, participants in the public (vs. private) condition reported significantly higher values to the extent that they felt that they were sharing information $\left(\mathrm{M}_{\text {public }}=85.50 ;\right.$ M private $=76.81 ; t(240)=$ $-3.34 ; p=.001)$. Participants in the praise condition also answered a question in a similar slider with a scale from 1-100 that was about how rewarding the feedback they received from the anagram task was. A one-sample t-test revealed that these participants found the praise significantly more rewarding than the midpoint of the scale $(50 ;$ mean $=70.72 ; t(120)=9.35 ; p<.001)$.

Reward Choice. A three-way ANOVA was conducted with the summed choice of smaller-sooner rewards as a dependent variable with word count as a covariate. No significant main effects were identified for praise $(F(1,233)=2.53 ; p=.615)$, audience $(F(1,233)$ $=.340 ; p=.561)$ and review type $(F(1,233)=1.82 ; p=.178)$. The covariate word count was marginally significant $(F(1,233)=3.32$; $p=.070)$. All two-way interactions were non-significant: audience and review type $(F(1,233)=.516 ; p=.437)$, praise and audience $(F(1,233)=1.87 ; p=.173)$ and praise and review type $(F(1,233)=.03$; $p=.870)$. A significant three-way interaction was found $(F(1,233)$ $=3.89 ; p=.050$; See Figure 2.3).

Contrasts revealed that participants who were assigned to the no praise condition displayed similar results as those from Study 1. There was a significant two-way interaction between audience and review type $(F(1,233)=3.81 ; p=.052)$, in which participants who shared emotional information to a public audience displayed greater impulsive behaviors than those who expressed this information in private $\left(\mathrm{M}_{\text {public }}=4.23 ; \mathrm{M}_{\text {private }}=3.38 ; F(1,233)=3.21 ; p=.073\right)$. There were no differences in impulsive behaviors among participants who expressed rational information $\left(\mathrm{M}_{\text {public }}=3.07\right.$; $\mathrm{M}$ private $=3.63$; $F(1,233)=.95 ; p=.330)$.

Meanwhile, there was no two-way interaction between audience and review type among participants in the praise condition $(F(1,233)=.78$; 


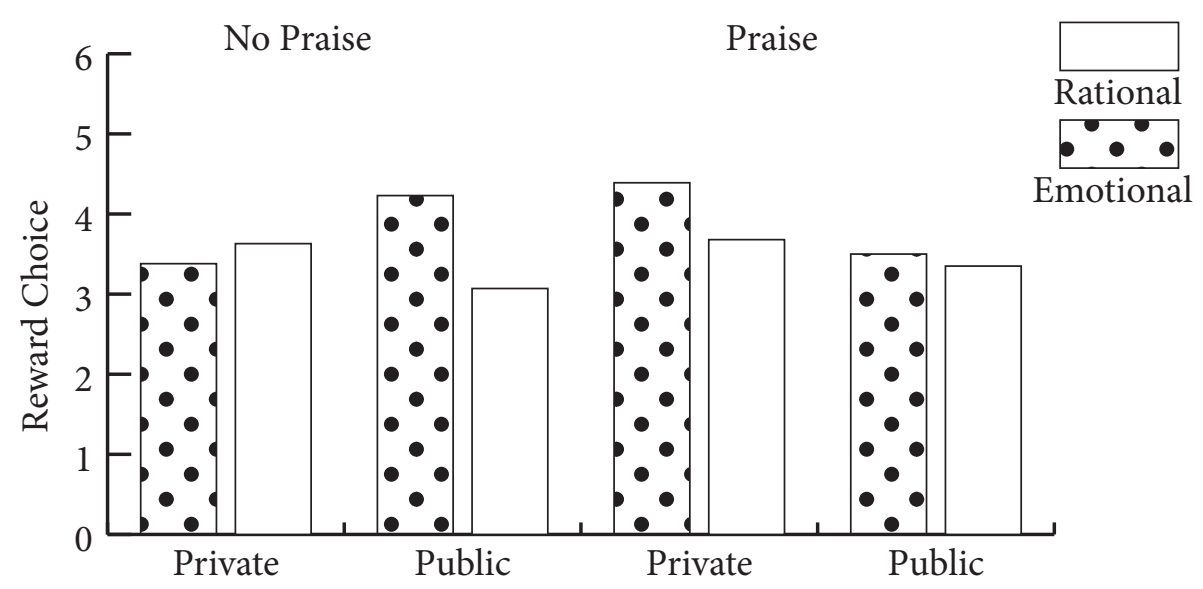

Figure 2.3

Study 3: Effects of Audience with Review Type in Praise versus No Praise

$p=.379 ; \mathrm{H} 2)$. No differences in impulsive behaviors were identified among participants who shared emotional $(\mathrm{M}$ public $=3.50 ; \mathrm{M}$ private $=$ $4.39 ; F(1,233)=2.70 ; p=.102)$ or rational (Mpublic $=3.35 ;$ Mprivate $=3.68 ; F(1,233)=.10 ; p=.753)$ information to a public audience compared to those who expressed this information in private.

\section{Discussion}

The findings of Study 3 provide further evidence of the rewarding nature of posting emotional reviews on the reviewers themselves. When no satiation was presented (i.e., no praise), participants experienced more impulsivity when they shared emotional information to a public compared to when they expressed this information in private (H1). However, when participants were exposed to another reward prior to the impulsivity measure, the differences between sharing emotional information to a public and expressing this information in private disappeared (H2). These findings are consistent with crossdomain satiation; we show an activated reward state can be satiated by the presence of another reward (Berger and Shiv 2011; Wadhwa, Shiv, and Nowlis 2008). These findings also provide evidence of a cost-effective strategy firms can undertake to mitigate impulsivity: providing praise to reviewers after they have written reviews. In the next study, we show individuals differ in the extent they are affected by review writing. This not only provides further evidence for our theory by demonstrating individuals who are more sensitive to social 
cues display more impulsive behaviors, but also shows not everyone may be equally affected by this impulsive epidemic.

\section{STUDY 4}

One quarter of consumers who purchase online also leave product reviews ( $\mathrm{PwC} 2012$ ). As we find in Studies 1-2, these consumers are particularly vulnerable to impulsive acts that can be detrimental to their well-being, unless firms implement strategies to avoid them (Study 3). In Study 4, we show not all consumers are vulnerable to the effects of sharing emotional information as they may differ in the extent to which they are sensitive to social rewards (Becherer and Richard 1978; Berger and Shiv 2011). Self-monitoring is a personality trait that is a good measure to indicate the extent to which individuals are sensitive to social cues (Gangestad and Snyder 2000), and as such, individuals who score high on this trait may perceive opportunities to share information to others as more rewarding then those who score low. Therefore, we investigate the extent to which individuals with differing levels of self-monitoring display impulsive behaviors as a result of sharing emotional information to others (H3). In this study, we measure impulsivity using a similar measure as Bennett (2009) that records donation amounts.

\section{Method}

Design and procedure. One hundred and fifty-eight participants (54\% female; age $18-64$; mean $=33)$ from an online panel participated in the study. Thirteen respondents were removed from the analysis $(8 \%)^{6}$, resulting in one hundred and forty-five respondents used for analysis. These respondents participated in a 2 (audience: public vs. private $) \times 2$ (review type: rational vs. emotional) between-subjects design.

Participants were shown a short video documentary. Similar to the previous studies, they were randomly assigned to one of four groups, and were asked to write a rational (emotional) review about the clip that would (would not) be read by others. Next, they were informed the experimenters were interested in learning more about the clip, 
but to give them time to reflect on their responses, they were to participate in an unrelated study regarding decision-making. They were asked to imagine a donation situation taken from Lee and Shrum (2012): "One in seven babies is born prematurely. Prematurity is the leading cause of newborn death. Join us in the fight to give every baby a healthy state. Donate Today!" They were asked to indicate the amount they would donate to the campaign if they had $\$ 100$ at their disposal, where greater donations correspond to greater impulsivity (Bennett 2009). Subsequently, respondents completed a Self-Monitoring Scale containing 25 true-or-false questions that measures differences in how individuals control and observe the self-presentation and behavior they display to others (Snyder 1974). However, three items were dropped during the analysis as these items had low correlations to the overall scale $(r<.2)$. Including these items, though, did not change the pattern of results. Word count was calculated from the reviews and used as a covariate in the analysis.

Results

Manipulation Checks. Similar to the previous studies, participants answered two questions to indicate whether they wrote a rational or emotional review. Participants in the emotional (vs. rational) manipulation reported lower scores to the statement "I wrote down an objective review of the movie clip" (Memotional $=5.10$; Mrational $=6.08 ; t(143)=4.01 ; p<.001)$, and higher scores to the statement "I wrote down my personal feelings and attitudes towards the movie clip" (Memotional $=6.08 ;$ Mrational $=3.61 ; t(143)=-8.20 ; p<$ $.001)$. They also completed two items to indicate whether or not they thought others would read their review. Participants in the public (vs. private) manipulation reported higher scores to the statement "I felt like I was sharing it with other people" (Mpublic $=5.73$; Mprivate $=4.69 ; t(143)=-3.42 ; p=.001)$, and lower scores to the statement "I felt that it would not be seen by others" $\left(\right.$ Mpublic $=3.09 ; \mathrm{M}_{\text {private }}=$ $3.82 ; t(143)=2.15 ; p=.033)$.

Donation Amount. A regression was conducted to test the effect of self-monitoring. Audience, review type, and the summed responses for self-monitoring $(\mathrm{M}=33.89, \mathrm{SD}=4.41, \min =23$, $\max$ $=44$ ), along with their interactions, were regressed on donation amount, and word count was included as a covariate. A marginal significant three-way interaction was found between audience, 

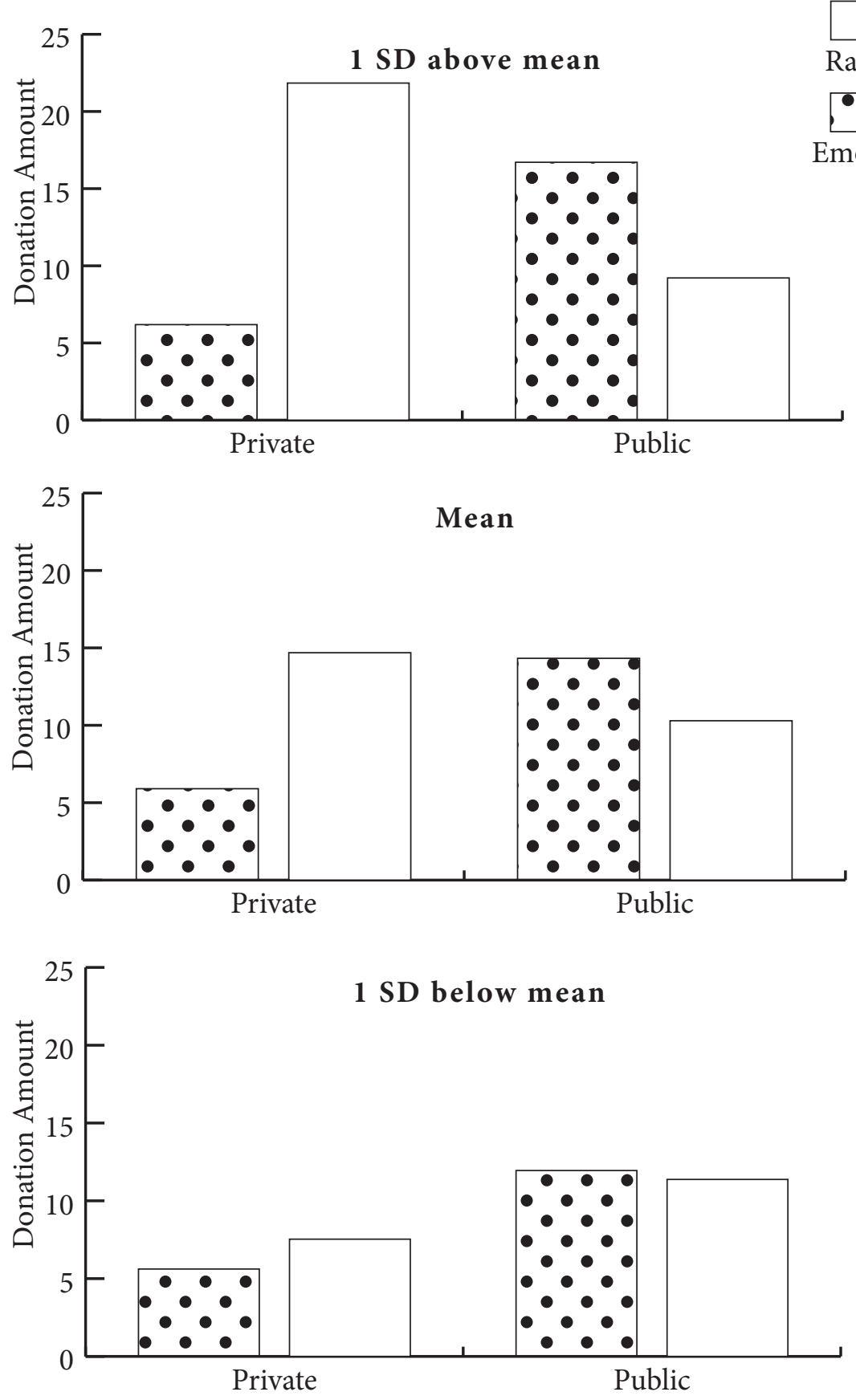

Figure 2.4

Study 4: Effects of Audience with Review Type on 1 SD above and below the mean of Self-Monitoring 
review type and self-monitoring $(\beta=.59 ; t(136)=1.78 ; p=.077)$. No significant two-way interactions were found with audience and review type $(\beta=-16.65 ; t(136)=-1.49 ; p=.139)$ and the interactions with self-monitoring and audience $(\beta=-.35 ; t(136)=-1.06 ; p=.292)$ or review type $(\beta=-.19 ; t(136)=-.59 ; p=.559)$. Also, there was no significant main effect for self-monitoring $(\beta=.50 ; t(136)=1.51$; $p=.134)$, audience $(\beta=12.81 ; t(136)=1.14 ; p=.256)$ and review type $(\beta=5.36 ; t(136)=.48 ; p=.634)$. Word count was significant $(\beta=-.03 ; t(136)=-3.87 ; p<.001)$.

As suggested by Spiller, Fitzsimons, Lynch, and McClelland (2013), it is useful to apply a floodlight (i.e., Johnson-Neyman) test to gain a better understanding of how a continuous variable moderates a $2 \times 2$ analysis. By running the analysis with the PROCESS SPSS application provided by Hayes (2013), we found there was a significant positive interaction between audience and review type for any model with self-monitoring higher than $33.21(\beta \mathrm{JN}=2.80, \mathrm{SE}=1.42, p=.050)$, but not for any model with self-monitoring lower than 33.21. Figure 2.4 plots the interaction with $1 \mathrm{SD}$ above and below the mean. This suggests that participants who are high self-monitors are more sensitive to the manipulations; we see starker differences between the groups.

\section{Discussion}

In support of Hypothesis 3, we find further support for our proposition individuals who vary in self-monitoring display differences in impulsive behaviors after writing emotional reviews. Our results show high self-monitors are more likely to engage in impulsive behaviors after sharing emotional reviews to others; this is not the case for low self-monitors. These findings are in line with research that shows high self-monitors are more sensitive to social cues (Becherer and Richard 1978), making the presence of the audience more salient and the act of sharing emotional information more socially rewarding. 


\section{GENERAL DISCUSSION}

In this research, we examine how sharing emotional information with others through customer reviews influences impulsive behaviors. Drawing on the theory of reverse alliesthesia, we propose the social context in which product reviews are naturally embedded, along with the consumer's propensity to share emotional content, creates a socially rewarding experience that has an impact on impulsive behaviors. In four studies, we test these propositions using a variety of established measures of impulsivity. We find consistent support for the propositions. When individuals share emotional information in their product reviews, they engage in more impulsive behaviors than when the same information is expressed in private (Study 1). This finding is also supported by a field study among Amazon.com reviewers (Study 2). We find firms can offset this effect by providing praise to their reviewers immediately after reviewing (Study 3 ). However, not all reviewers engage in impulsive behaviors after writing reviews, as individual differences exist in the extent to which they are sensitive to social cues (i.e., self-monitoring; Study 4).

\section{Implications for Theory}

Prior research on reverse alliesthesia has established that exposure to different rewarding stimuli may have an impact on impulsive behaviors (Wadhwa, Shiv and Nowlis 2008). Our results extend this theory by showing the social rewards (Berger and Shiv 2011) one accrues from sharing information to others lead to drive states similar to those previously documented (Kim and Zauberman 2013; Li 2008; van den Bergh, Dewitte, and Warlop 2008). Beyond this finding, this manuscript makes three key contributions to the research.

First, we examine the role of writing style in customer reviews to understand how it may impact reviewers' subsequent behaviors. This shifts the focus from traditional research on reviewing that investigates how reviews influence reader behavior (Chevalier and Mayzlin 2006; Ludwig et al. 2013). Our research demonstrates reviewers are more likely to make impulsive choices when they share emotional information. We attribute this finding to the theory of reverse 
alliesthesia, which proposes a reward drive is created upon exposure to rewarding stimuli. Because the act of writing emotional reviews is socially rewarding, it has the ability to strengthen connectedness with others (Laurenceau, Barrett and Pietromonaco 1998; Peters and Kashima 2007) and engage reviewers in impulsive behaviors.

Second, we investigate how praise serves as a strategy to offset behaviors that may result from review writing. As praise represents a positive feedback mechanism that communicates approval, it is socially rewarding, and therefore able to quench impulsive behaviors. These findings also provide new insights on how praise can be used to influence behavior in general. Although research has established praise is an effective tool in encouraging desirable behaviors (Henderlong and Lepper 2002), insights are scant on how praise can be used as a tool to discourage undesirable behaviors. With this manuscript, we show how applying social affirmation to the root cause of impulsivity can be used to regulate this undesirable behavior.

Third, our research highlights the importance of self-monitoring as a personality trait that determines the extent to which a reviewer acts impulsively. We provide additional support for the theory of reverse alliesthesia: individuals who are more sensitive to social cues are more likely to engage in impulsive behaviors. This finding also sheds light on a paradoxical relationship on a broader scale because self-monitoring can be conceptualized as an ability to control personal emotions within the public realm. However, despite having more control, we also see that within the private sphere, these same individuals engage in more impulse behaviors that suggest a loss of control.

\section{Implications for Managers}

This research examines the context of customer reviews, a popular feature for online retailers such as Amazon.com. These findings shed light on the negative consequences that may arise from the use of social media. As a growing number of consumers are jumping on this bandwagon, they become exposed to susceptibility to impulsive behaviors because they share their personal views with others. However, many customers remain unaware of the potential risks of social media participation, such as increased debt (Wilcox and Stephen 2013). Therefore, industry associations should develop more 
specific guidelines that members can implement on their platforms to help the public be more aware of their decisions. Our study shows reviewers who write in an emotional manner are susceptible to impulsive behaviors. Therefore, firms can develop tools that integrate text mining (text analytics) to better identify reviewers who are prone to writing in an emotional manner, and develop targeted strategies to manage them. As consumers increasingly turn to companies that care for their well-being (Kotler 2011), firms that choose to implement the guidelines and strategies proposed above should communicate that choice to their customers. Ideal communication channels are reliable media such as newspapers and television news programs that inform customers about the phenomenon and highlight the firm's initiatives in combating the problem.

One initiative a firm can implement is the integration of praise within their feedback systems, presented to customers immediately after they submit a review. One drawback, however, is customers may become accustomed to, or skeptical of, certain praise messages (Henderlong and Lepper 2002). Managers responsible for the social media functions of their companies must therefore take great care to make these messages as authentic as possible and tailor them to individual accomplishments. Because individuals derive social rewards from a variety of sources, managers can also consider other socially rewarding feedback such as acknowledging and thanking the reviewers for their contributions. These simple responses could be sufficient to deter impulsive behaviors.

Another initiative a firm can implement is the development of nonpublic channels that enable customers to communicate directly with the firm. Many firms already integrate similar systems, such as private chat functions or a simple "contact us" section, in their websites. While these systems are typically used to manage complaints, they can also be used as places for customers to express their personal feelings and opinions of products. Such insights not only help firms gain knowledge about their products, but also mitigate impulsive behaviors that stem from expressing the same information in a public forum. 


\section{Limitations and Areas for Future Research}

In this study, we limit our research scope to customer reviews. Because the Internet is flourishing from user-generated content that can be shared through social networking sites such as Facebook, collaborative platforms such as Wikipedia, micro-blogs such as Twitter, content communities such as YouTube, and many other forms of social media, further research could investigate whether sharing content on other platforms is perceived as equally rewarding, and, consequently, whether this leads to heightened impulsive behaviors. Additionally, because individuals share different information depending on the size of their audience (Barasch and Berger 2014), it would be interesting to determine how audience size affects the extent to which the sharing experience is rewarding.

Future research might also concentrate on other factors that mitigate impulsive behaviors. In this study, we looked at praise as a socially rewarding tool that can be used to offset this drive. However, the effectiveness of praise as a tool can differ between people, particularly with regard to what is praised and who provides the praise (Henderlong and Lepper 2002). A closer investigation of this area of research could help provide firms with more concrete solutions to the problems that arise from review writing.

Finally, Wilcox and Stephen (2013) find greater social network use is associated with greater impulsivity, particularly among those with strong ties. Our paper contributes to this area by showing active participation through posting on social networking sites may heighten impulsive behaviors. This finding has broad societal implications. Further research that delves into this area can help to develop our understanding of the consequences of social network use, and provide consumers with more awareness of the potential influences of social media. This awareness may help them have more control over their behaviors. 


\section{FOOTNOTES}

[1] One participant was removed because she took excessive time on the writing task survey (likely started something and left off to do something else), and another was removed because she did not take the writing task (i.e., review) seriously (simply wrote down an indecipherable word). Refer to page 20.

[2] We conducted an additional study to include a control group who were not instructed to write in a specific way $(n=170)$. All participants were randomly assigned to a 2 (audience: public vs. private) $\times 3$ (review type: emotional vs. rational, vs. control) betweensubjects design. The manipulations were similar to Study la, except participants in the control group were simply instructed to write a review, without any further directions. As a measure of impulsivity, participants made eight monetary choices between a smaller-sooner or larger-later reward, which were summed to produce a impulsivity scale (Li 2008). An ANOVA with audience and review type as independent variables and the impulsivity scale as a dependent variable with word count as a covariate reveals a significant twoway interaction between audience and review type $(F(163)=3.47 ; p$ $=.033)$. In support of Study $1 \mathrm{a}$, participants who shared emotional information to a public audience (condition: emotional) were more likely to engage in impulsive behaviors compared to participants who expressed the information in private $\left(\mathrm{M}_{\text {private }}=4.24 ; \mathrm{M}\right.$ public $=5.35$; $F(163)=3.37 ; p=.034$ one-tailed). The control condition exhibited similar results $\left(\mathrm{M}_{\text {private }}=4.67 ; \mathrm{M}\right.$ public $=5.55 ; F(163)=2.62 ; p=.068$ one-tailed), while this was not the case for participants who shared rational information $(\mathrm{M}$ private $=5.47 ; \mathrm{M}$ public $=4.60 ; F(163)=2.30$; $p=.132)$. There were no significant differences between the control and emotional condition in either private $(F(1,163)=.73 ; p=.394)$ or public $(F(1,163)=.10 ; p=.755)$ settings. However, significant differences existed between the control and rational condition in both private $(F(1,163)=2.02 ; p=.079$ one-tailed $)$ and public settings $(F(1,163)=2.53 ; p=.057$ one-tailed $)$. Refer to page 22 .

[3] Eight participants were removed because they took excessive time writing their reviews. Refer to page 23. 
[4] Three participants were removed because they indicated at the end of the questionnaire they did not provide correct information in either their reviews or their purchase information. Refer to page 26.

[5] One participant indicated an inability to write in the English, and was subsequently removed from the study. Three participants, who belonged to the public condition, indicated that they did not post their reviews on Amazon.com. One participant indicated that he/she was an Amazon Vine Member. Refer to page 30.

[6] Seven participants were removed because they did not seriously participate in the writing task (writing indecipherable text or simply cutting and pasting the instructions into the text box), two were removed because they took excessive time in the writing task, two were removed because they took excessive time completing the survey (likely started something and left off to do something else), and two were removed because they guessed the purpose of the survey. Refer to page 34 . 



\section{CHAPTER 3}

\section{A (Re)View of Myself}

Aguirre, Elizabeth, Dominik Mahr, Jan Pelser, Ko de Ruyter, Dhruv Grewal and Martin Wetzels. "A Re(View) of Myself: How Writing Reviews Drives Learning Participation in Channel Partner Programs," Submitted to Journal of Marketing. 


\begin{abstract}
Channel partner programs (CPPs) were developed to build the knowledge of individuals employed at partner firms and facilitate their social exchange. However, many CPPs suffer from low participation rates in their learning modules as manufacturers struggle to engage channel partners that are not innately driven to learn. Through a collaboration with a Fortune 100 information technology company, this article combines three experimental studies with archival data to explore whether reviewing learning modules strengthens engagement in further learning. Extending emerging theorizing on metacognition, the authors find that providing written referrals activates partners, who have a low learning orientation, to participate in additional modules. This occurs as writing reviews help these channel partners to reflect on their learning experience. The authors find two boundary conditions that direct the focus of their reflection: (1) writing for the benefit of peers rather than the manufacturer and (2) taking a focused rather than broad perspective of the learning content. A more focused reflection heightens their belief certainty about knowledge acquisition, which spurs them to pursue further learning.
\end{abstract}


Channel partners drive manufacturers' bottom lines and substantial levels of their total revenue-as much as $65 \%$, according to industry reports (Accenture 2010). High tech manufacturers such as SAP view employees of another firm such as Accenture as channel partners as they extend the manufacturer's sales force, and rely on them to expand sales in new industries and geographies (Paul 2013). Channel partner programs (CPP), originally established to stimulate sales, have evolved into a support ecosystem for knowledge building that includes initiatives such as learning modules and certification (Forrester 2013), as well as social functionalities, such as forums and virtual meeting rooms for knowledge exchange, collaborative learning, and social networking and peer support. Manufacturers accordingly have shifted their focus from incentivizing selling to enabling learning and rewarding the personal development of each channel partner through their participation in learning modules that develop their sales skills and product knowledge. Despite some elaborate and attractive incentives though, accumulating evidence suggests that learning modules in CPPs suffer from low participation rates and exhibit large discrepancies in partner engagement (Maritz 2012). Although some employees of channel partner firms recognize the value of professional development (CSO Insights 2014; Ford et al. 1998) and find participation authentically rewarding (Deloitte 2012), others remain unmotivated by personal growth and learning (Maritz 2012). Furthermore, research provides few insights into how to engage such unmotivated partners, which is a substantial problem for CPPs, whose success hinges on the active participation of partners. Incentive structures that motivate selling (Maritz 2013) do not seem effective for promoting the inherent value of learning or knowledge acquisition in CPPs (Lane4 2012). Considering that these programs account for the second highest expense for high-tech firms, after production costs (KPMG 2011), it is essential to understand how CPPs can engage unmotivated channel partners to learn.

Contemporary CPPs enhance social exchange and collaboration by facilitating referral systems in which channel partners can rate their experience (e.g., post hoc, real-time via Twitter) and write reviews about learning modules (Foirletta 2012). This established referral system practice suggests that sharing experiences increases transparency and has a decisive influence on the (buying) behavior of peer groups. A recent report by The New York Times (2011) suggests 
that sharing experiences with others is intrinsically rewarding and has the potential to intensify learning experiences, because sharing helps people appreciate their own personal development. Reviewing an experience and sharing it with others affects information processing, causing people to reflect on and realize the benefits of their learning; we propose that such referrals also might spur channel partners to learn more.

We thus explore recent theorizing on metacognition as a foundational basis for examining the impact of referrals on the learning engagement of channel partners. Metacognition pertains to thinking about thinking, which helps channel partners become aware of their learning processes (Jacobs and Paris 1987). Channel partners with low learning orientations (LO) struggle to engage in metacognition (Ford et al. 1998) and consequently experience difficulties in recognizing and seeking out learning opportunities for personal effectiveness (Sheldon, Dunning, and Ames 2014). Metacognitive interventions constitute effective tools that prompt people to reflect on their current state of learning; interventions that elicit fact-based responses (e.g., "How are $\mathrm{X}$ and Y related?" or "Who, what, where, and why?" questions during reading tasks) help people monitor and regulate their learning processes (Schmidt and Ford 2003; Somuncuoglu and Yildirim 1999). Referrals go beyond such direct transmissions of facts though, in that they contain a personal, subjective evaluation of the overall experience. The transmission of personal experiences is tailored to the audience and the scope of what is being shared, unlike facts that remain unchanged regardless of the context. Thus referrals should provide a sort of metacognitive intervention that activates reflection on personal experiences. While referrals may activate metacognition, it is unclear why this, in turn, may affect behavior. By examining the impact of referrals by channel partners on their own participation in CPPs, we contribute to nascent literature, in two key ways.

First, we examine different forms of referral systems to understand how they may drive learning engagement behaviors; more elaborate referrals systems (i.e., verbatim reviews) may trigger more reflective thinking than others (e.g., numerical or star ratings). Because channel partners with low $\mathrm{LO}$ are less able to engage in reflection (Ford et al. 1998), we also explore how these different forms of referral influence subsequent engagement behaviors by different channel partners. As another element of this contribution, we examine the boundary 
conditions that offer a more fine-grained view of when referrals are effective forms of engagement in learning programs. That is, we consider two central features of reviewing (Sporat, Driscoll, and Brizee 2012) - the beneficiary of the review (peers vs. manufacturer) and the perspective taken (broad vs. focused) - that direct the focus of the reflection, thereby enabling effective metacognition that fosters appreciation for the inherent value of learning, particularly among low LO channel partners.

Second, we probe the underlying mechanism by which feedback writing affects engagement by drawing on psychological certainty, a form of metacognition. Prior literature on belief certainty notes antecedents that directly affect it, such as information repetition and fluency of thinking (Tormala and Rucker 2007), yet it fails to explain why the metacognitive intervention of referrals may strengthen certainty. The introspective nature of self-reflection that referral writing activates may enhance a writer's understanding and evaluation of his or her personal experiences. Such sense-making resolves uncertainty and ambiguity about the learning experience and its contribution to the partner's own personal growth. Among channel partners with low LO, this task presents an opportunity to alter their value perceptions significantly and boost their convictions about learning. In turn, it could increase their behaviors dedicated to learning activities.

In the next section, we review related literature on metacognition and develop several hypotheses relevant to addressing the aforementioned research gaps. With a series of three experimental studies that are linked to archival data, we empirically assess these hypotheses, in collaboration with the CPP of a Fortune 100 high-tech manufacturer and solutions provider. We conclude with a discussion of the implications of our study for both research and practice.

\section{CONCEPTUAL BACKGROUND}

Metacognition refers to mental processes that help people monitor and evaluate their own personal thoughts. It implies having both knowledge and control over cognitive processes (Flavell 1979). A person who engages in metacognition is more aware of his or her 
competencies, learning progress, and thought processes (Somuncuoglu and Yildirim 1999), which facilitates further learning and improves performance (Anseel, Lievens, and Schollaert 2009). This selfawareness helps people recognize strengths and weaknesses in their learning that can motivate them to engage in activities that help them grow (Grant, Franklin, and Langford 2002; Sheldon, Dunning, and Ames 2014; Sitzmann and Ely 2010). However, because it demands considerable cognitive effort (VandeWalle et al. 1999), some people are more able to engage in metacognition than others (Dweck 1986).

Individuals with a low learning orientation ( $\mathrm{LO}$ ) are not innately driven to learn, and have difficulty motivating themselves to exert the necessary effort to engage in metacognition (Ford et al. 1998). As a result, they may fail to gain a rich understanding of their own thoughts and personal progress in learning situations, and they may be reluctant to seek activities to improve and develop themselves (Sheldon, Dunning, and Ames 2014). However, for individuals to perform effectively within a sales context, it is essential for them to continuously learn and apply their acquired knowledge and skills into their tasks (Sujan, Weitz, and Kumar 1994; Wang and Netemeyer 2002). Such an orientation towards learning is not only beneficial in the short-term, but also has long-term effects (Kohli, Shervani, and Challagalla 1998) that can even be manifested in a broader organizational setting (Bell, Mengüç, and Wuding 2010). Therefore, it is important to trigger such individuals with low LO to heighten their persistence to engage in more elaborate metacognition to help them become more involved in their personal development.

Although people with low LO possess poorer innate metacognitive skills, it is possible to activate metacognition in various learning situations through interventions that prompt reflection (Schunk 2005; Veenman, van Hout-Wolters, and Afflerbach 2006). For example, generic questions that elicit fact-based responses (e.g., "How does X affect Y?") stimulate learners to contemplate their own knowledge, which helps them identify their learning progress (Schmidt and Ford 2003). Such prompting to reflect also can occur through referral systems that require learners to make assessments about their personal knowledge and skill acquisition experiences. Two commonly used referral practices are rating and review writing. While both practices provide learners with a subject assessment of their experience, review writing is more elaborate as the learner 
explicates verbal representations of his or her thoughts and makes associations among different pieces of information. The process then enables the learner to make sense of and interpret the experiences, which influences in turn the way he or she thinks about them (Applebee 1984; Glogger et al. 2012; Klein 1999). Thus, writing a review should trigger metacognitive awareness that helps a learner obtain a deeper understanding and reduce uncertainty about his or her learning experiences, which builds stronger beliefs (Cho and MacArthur 2011; Klein 1999; Kuhrt and Farris 1990). Two elements of review writing, the purpose of the review and the perspective adopted, potentially influence the relevance of information being considered during metacognition and as a result, may help provide some focus on what is being reflected.

First, reviewers typically have an audience in mind that might benefit from the review, which defines the purpose of their writing task (Magnifico 2010). That is, the purpose of review writing relates closely to the beneficiary of the review, who might be similar or dissimilar to the reviewer; this distinction determines the content the reviewer considers for the review. When reviewers consider an audience that is similar to themselves, they tend to assimilate their point of view into the review, in a process called social metacognition (Jost, Kruglanski, and Nelson 1998). A review provided for the benefit of a similar other contains information that is personally relevant for the reviewer (Lerouge and Warlop 2006; Naylor, Lamberton, and Norton 2011), which is not the case for a dissimilar beneficiary. If channel partners review a learning module for their peers for example, they might write about the returns of their learning experience, such as how the content helped them complete their daily work tasks. If they review it for the manufacturer instead, channel partners likely specify areas of improvement and features that the manufacturer would find useful. Only the former type features issues that are at the heart of the channel partner's learning experience, such that they are more personally relevant than specific areas of improvement.

Second, reviews might vary in the breadth of topics discussed, such that they might take a broad or focused perspective on the matter (Applebee 1984), covering many or just a few issues related to the topic. For example, channel partners might take a broad perspective and review a learning module by considering its fit with other learning modules within their certification track. Alternatively, 
they might adopt a focused perspective and review specific aspects of the learning module that they just completed. This distinction is central to the notion of conceptual attention, according to which activation of different perspectives triggers distinct processing styles that affect how people attend to the available information (Förster 2012; Förster and Denzler 2012). Broad conceptual activations trigger global processing of information that activates more concepts in memory, which should prompt people to think about the bigger picture. Focused concept activations instead induce local processing that triggers them to focus on specific details of the subject matter at hand (Förster and Denzler 2012).

Overall, review writing triggers personal reflection, which prompts the reviwer to elaborate on and gain a more precise understanding of her or his thoughts (Li, Liu, and Steckelberg 2010). This elaboration might change the way the reviewer perceives the experience while also resolving ambiguity about its assessment and leading to stronger convictions about his or her beliefs (i.e., belief or attitude certainty; Rucker, Tormala, Petty and Briñol 2014). The more strongly they hold their beliefs, the more accessible they are in memory and thus the greater their influence over decisions and behaviors (Karmarkar and Tormala 2009; Wan et al. 2010). Because developing belief certainty requires reflection on whether the beliefs currently held are correct, it represents a form of metacognition (Dubois, Rucker, and Tormala 2011) that not only is persistent but also has the potential to shape desired behaviors over time.

\section{HYPOTHESIS DEVELOPMENT}

\section{Effects of Review Writing on Learning Participation}

Referral systems require participants to reflect and assess their past experiences. Although all referral systems exhibit this retrospective characteristic, they differ in the extent of deliberation required; verbatim reviews are more elaborate than numerical or star ratings. Writing reviews requires a more extensive reflection that pushes the reviewer to evaluate the experience critically, which can invoke metacognition (Magnifico 2010), facilitate learning and improve 
performance (Anseel, Lievens, and Schollaert 2009). Thus, review writing can serve as a metacognitive intervention that helps reviewers become more self-aware, and, in turn, potentially increase learning engagement and reduce attrition in learning programs (Sitzmann and Ely 2010).

In CPPs, review writing serves as a tool to activate metacognition, which could trigger channel partners to reflect on their learning experiences and motivate them to participate in learning programs. Channel partners with low LO might benefit from review writing, in that they might come to recognize the value of learning programs for their professional development, especially if metacognition triggers them to realize that they have not met established learning goals (Sheldon, Dunning, and Ames 2014). Metacognition then could pave the way to purposeful behavioral change (Grant, Franklin, and Langford 2002), leading channel partners with low LO to increase their participation in learning activities. However, because channel partners with high LO already display an inherent willingness to improve (Dweck and Leggett 1988), we argue that those with high LO monitor their learning progress and practice metacognition regardless of whether they engage in review writing.

H1: Review writing (vs. rating) activates low learning-oriented channel partners to pursue further learning, but not for high learningoriented channel partners.

\section{Boundary Conditions: Effects of Review Writing Elements on Learning Participation}

Purpose. Reviewers have an audience in mind (Magnifico 2010), when they write their reviews, because they consider how its content might affect an external party. When the audience is similar to the reviewer, the reviewer tends to draw on his or her opinions and experiences when making inferences about others' thinking (Lerouge and Warlop 2006), which is in line with research on social metacognition (Jost, Kruglanski and Nelson 1998). As such, when channel partners are primed to think that other partners will benefit from their reviews, they adopt a self-focus. However, if these partners believe dissimilar others will benefit from the reviews, they may not engage effectively in this metacognitive process as they may not probe their personal experiences to the same extent. 
Channel partners with high LO are active in metacognition, and do not benefit from further interventions like that from writing (Schmidt and Ford 2003). However, channel partners with low LO could benefit from the self-focus that writing for a similar other provides because it could help them probe their personal learning experiences, which is not the case when they write a review for the benefit of a dissimilar other. Typically such channel partners lack the motivation to meet the cognitive demands of metacognition (Ford et al. 1998), therefore prompting them to write about their learning experiences could stimulate reflection that could result in increased learning engagement and reduced attrition in learning programs (Sitzmann and Ely 2010). Activated metacognition enables them to assess the quality of their personal engagement with learning, and gain insights on the value of learning programs (Ford et al. 1998).

H2: Review writing for an audience of similar others (vs. an audience of dissimilar others) activates low learning-oriented channel partners to pursue further learning, but not high learningoriented channel partners.

Perspective. It takes significant effort to sift through and connect disparate information when writing a broad review because more associations are activated within memory (Evans, Kirby, and Fabrigar 2003). Channel partners with high LO have sufficient inherent motivation to exert effortful global processing, but partners with low LO do not (Schmidt and Ford 2003; Somuncuoglu and Yildrim 1999). Therefore, we anticipate that when low LO partners invoke global processing by writing a broad review, they struggle to identify essential information to make sense of their learning experience. Disparate information that is not directly associated with their learning experience distracts them from gaining insights through review writing.

In contrast, if channel partners with low LO must write a focused review, their local processing gets triggered by writing about concrete concepts that also are immediately associated with their learning experience (Förster and Denzler 2012). The clear boundaries enable them to focus on relevant information, facilitating reflection that is directed toward developing a greater understanding of the experience. Such sensemaking may help these partners alleviate ambiguity about their assessments and strengthen their certainty about their 
learning experience (Tormala and Rucker 2007). Thus, when low LO channel partners write focused reviews, they consider information directly related to their learning experience and effectively engage in metacognition. This reflective process helps channel partners make sense of their learning experiences and strengthens their certainty about the gains they have accrued from the learning module, which should increase their determination to continue to pursue new learning modules. Therefore, low LO channel partners should be more engaged to take additional modules when they write a focused review as compared to when they write a broad review. At the same time, as channel partners with high LO monitor their learning progress and practice metacognition regardless of whether they engage in review writing, they should remain unaffected when they write either a broad or focused review.

H3: Writing a focused review (vs. broad review) activates low learningoriented channel partners to pursue further learning, but not high learning-oriented channel partners.

To test these predictions, we conducted a series of studies with the global channel partners of one of the world's best known technology brands, to assess whether reviewing a learning module increased the total number of subsequent learning modules completed by channel partners with low LO (Study 1). We also considered whether varying the focus of the review writing task would alter the results, according to the purpose of the review (Study 2) or the perspective taken (Study 3).

\section{RESEARCH SETTING}

For this Fortune 100 manufacturer, its CPP plays a key role in its go-to-market strategy, because it regards its channel partners as extensions of its sales force. Through these channel partners, the manufacturer has been boosting sales performance each year, and these partners are increasingly critical to its growth. As a means to ensure continued success, this CPP enables the partners to operate effectively within the business ecosystem, by providing them with the resources to expand their capabilities and deliver value-added 
services. Incentive programs are tied to this manufacturer's CPP to encourage their participation as well.

The manufacturer's award-winning CPP is internationally renowned and available in more than 100 countries, in dozens of languages. Within this CPP, channel partners receive invitations to participate in learning modules and also may become certified. Currently, approximately 15,000 partners have pursued certification. The learning modules have high market value and represent a tool that the manufacturer uses to build channel partner loyalty. The condensed, cutting-edge material is designed to strengthen partners' business acumen and deepen their core competencies and expertise related to the manufacturer's services.

\section{STUDY 1}

With Study 1 we examine whether the effects of the method of providing referrals (i.e., writing about the learning module or rating the module) on partner engagement over time is moderated by the LO of the participating channel partner $(\mathrm{H} 1)$. As a measure of partner engagement, we collect archival data on the number of learning modules that the channel partner completed in the subsequent three months. We asked each channel partner to provide a referral about one learning module they had completed, either by writing a review or by offering a rating, and observed how this action affected the number of modules they had taken after three months.

We conducted a pretest with bachelor's degree students from a university and found initial evidence for H1 (see Appendix B). A regression, with interest in pursuing further studies as the dependent variable and referral type (reviewing vs. rating), LO, and their interaction as independent variables, revealed significant main effects for both referral manipulation $(\beta=3.85 ; t(102)=2.131$; $p=.035)$ and LO $(\beta=.72 ; t(102)=3.094 ; p=.003)$, suggesting that reviewing (vs. rating) and having higher LO both increased students' interest in pursuing additional learning. We also found a marginally significant interaction between referral and LO at a $10 \%$ level $(\beta=-.56 ; t(102)=-1.759 ; p=.082)$; a Johnson-Neyman test 
further revealed significant positive effects of reviewing on interest in further learning among all participants with LO scores less than $5.9\left(\beta_{\mathrm{JN}}=.53 ; t=1.983 ; p=.050\right)$ but not for those with LO scores above 5.9. That is, students with low LOs who wrote reviews about a previous course were significantly more interested in pursuing a master's degree than those who simply rated the course. We found no differences among participants with high LO. Thus we gained initial evidence that writing a review can heighten learning engagement.

\section{Design, Participants, and Procedure}

The experimental design for Study 1 involved eighty-eight channel partners that had subscribed to the learning program within the manufacturer's CPP; in return for their participation, they earned points in the manufacturer's incentive program. By random assignment, participants either wrote a review or provided a rating of a learning module. We excluded three participants from the analysis: one who explained he could not write in the language of the experiment, another who was assigned to the review condition but did not write a review, and a third participant who did not take the experiment seriously (e.g., inputting an HTML address when asked to indicate age). Thus the sample consisted of eighty-five participants (Mage = 38 years; Msales_experience $=10$ years; $8 \%$ female) .

These participants considered a dropdown menu of modules offered by the program and selected one they had completed in the previous six months. Next, they were instructed to provide a written review in the space provided or rate the module on a 1-10 scale. Participants also completed a shortened, four-item version of a LO scale (Elliot and Church 1997; $\alpha=.85$ ). For the analysis, we used the average of the four items, such that higher values indicated higher LO. We also incorporated three control variables for the model estimation: sales experience, the effort the respondents perceived was necessary to complete the referral task, and user type (reseller or distributor), to ensure our findings were due to the manipulation. Three months after the experiment, we collected behavioral information about the number of modules each participant completed after the experiment. 


\section{Results}

We estimated H1 using a zero-inflated Poisson (ZIP) model, because the number of modules represented count data, and we found a considerable amount of zero values (53\%). Vuong (1989) tests confirmed the applicability of this model for our data. The dependent variable was the number of modules completed after the experiment; the independent variables were the referral manipulation (reviewing $=1$; rating $=0), \mathrm{LO}(\mathrm{M}=6.06 ; \mathrm{SD}=.76 ; \mathrm{min}=4, \max =7)$, and their interaction. Moreover, we included sales experience, perceived task effort, and user type as covariates.

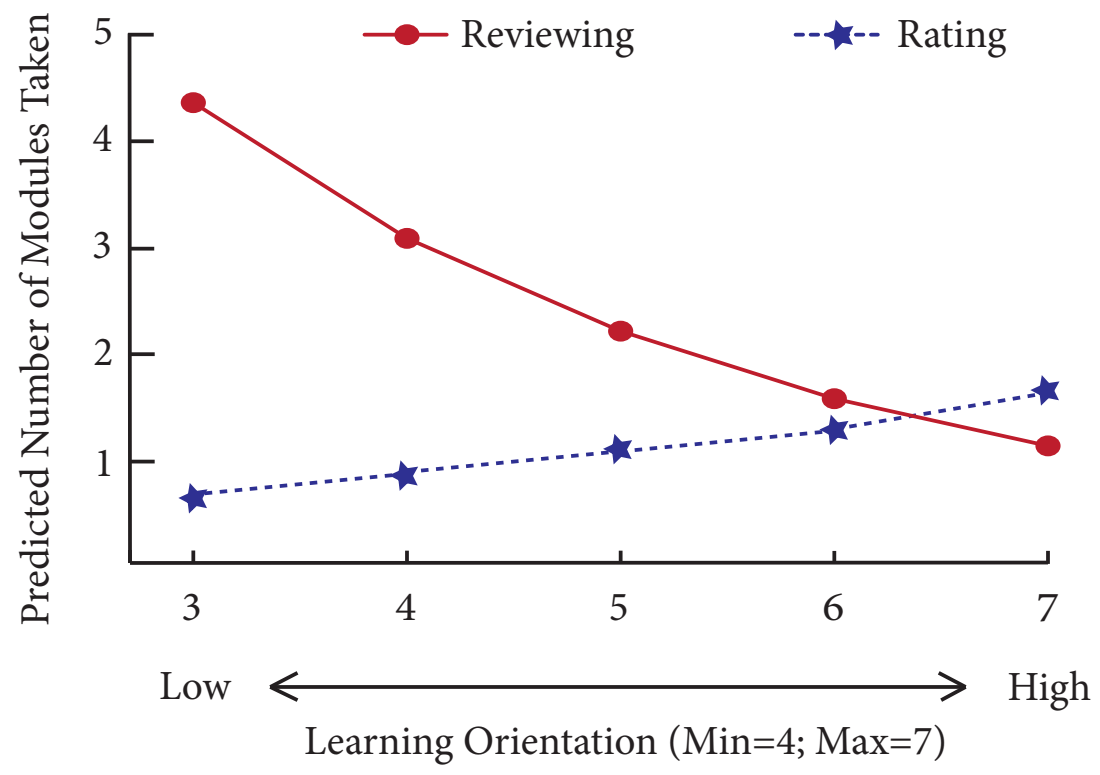

Figure 3.1

Study 1: Interaction between Referral Manipulation and Learning Orientation on Number of Modules Taken

As the results in Table 3.1 show, we found a marginally significant main effect for the referral manipulation $(\beta=3.32$; incident rate ratio $[\mathrm{IRR}]=27.59 ; p=.06$ ). The IRR results (Long and Freese 2006) suggested that providing written reviews increased the number of modules subsequently completed, by a factor of 27.59 , with all other variables held constant. However, we found no significant effect of LO $(\beta=.19 ; \mathrm{IRR}=1.20 ; p=.33)$. In support of $\mathrm{H} 1$, the interaction between referral and LO was significant at $10 \%(\beta=-.53$; IRR $=$ $.59 ; p=.07$; Figure 3.1$)$. Writing a review led low LO participants 


\begin{tabular}{|l|c|r|}
\hline & \multicolumn{2}{|c|}{ Number of Modules } \\
\hline & $\begin{array}{l}\text { Unstandardized } \\
\text { Coefficient (SE) }\end{array}$ & IRR \\
\hline Constant & $1.90(1.41)$ & 27.59 \\
\hline $\begin{array}{l}\text { Referral (rating =0; } \\
\text { reviewing = 1) }\end{array}$ & $3.32(1.79)^{*}$ & 1.20 \\
\hline Learning orientation (LO) & $0.19(0.19)$ & 0.59 \\
\hline Referral $\times$ LO & $-0.53(0.29)^{*}$ & 0.90 \\
\hline Sales experience & $-0.11(0.02)^{* * *}$ & 0.84 \\
\hline Perceived task effort & $-0.18(0.05)^{* * *}$ & 0.62 \\
\hline $\begin{array}{l}\text { User type (distributor }=0 ; \\
\text { reseller = 1) }\end{array}$ & $-0.48(0.30)$ & \\
\hline $\mathrm{N}$ & $85($ non-zero $=40 ;$ zero $=45)$ \\
\hline Log-likelihood & -142.59 \\
\hline $\begin{array}{l}\text { Bayesian information } \\
\text { criterion }\end{array}$ & 320.72 \\
\hline $\begin{array}{l}\text { Akaike information } \\
\text { criterion }\end{array}$ & 301.18 \\
\hline
\end{tabular}

${ }^{* * *} p<.01 .{ }^{* *} p<.05 .{ }^{*} p<.10$.

Table 3.1

Study 1: Summary of Zero Inflated Poisson Model

to engage in more learning programs compared with providing a rating, but this difference did not arise among high LO participants.

\section{Discussion}

Firms invest substantially in developing their learning programs, largely to encourage channel partners to participate actively and thereby increase their skills and product knowledge, which should translate into more sales. Our first study reveals that writing reviews on a module can drive less motivated channel partners to complete more learning modules during the subsequent three-month period than providing ratings on the modules. We posit that this finding emerges because the review writing process activated metacognitive thinking, which triggered partners with low LO to evaluate their learning experience. This could potentially alter their value perceptions and boost their convictions resulting in a greater sense of certainty. However, writing reviews did not have an effect on channel partners 
with high LO, potentially due to ceiling effects. We were able to identify, though, a significant and positive main effect of review writing (vs. rating), which suggests that writing about one's learning experience can lead to an increase in the number of modules taken. As review writing has the capability to trigger metacognitive thinking, Study 2 investigates a boundary condition that could shed light on how to direct the focus of the review to optimize metacognition.

\section{STUDY 2}

In Study 2, we seek to understand how highlighting the purpose of the writing tasks, and specifically who benefits from the review, might affect the activation of metacognitive thinking. When the beneficiary is perceived as similar, it may activate self-reflection, because the reviewer assumes that his or her thoughts and preferences are in line with those of the beneficiary (Lerouge and Warlop 2006), which is not the case when the beneficiary is perceived as dissimilar. Therefore, prompting channel partners with low LO to write a review for a similar other (e.g., business partner peers) may induce metacognition, which in turn could affect their participation in new modules; prompting them to write a review for a dissimilar other (e.g., manufacturer) should not increase their participation in new modules, as we predicted in $\mathrm{H} 2$.

\section{Design, Participants, and Procedure}

The experimental design included partners who subscribed to the same global learning program as Study 1. Sixty-four partners participated in exchange for points from the manufacturer's incentive program; none of them participated in Study 1. Unlike Study 1, all participants were required to write a review, and the random assignment indicated whether they wrote a review for the benefit of either their peers or the manufacturer that hosted the learning program. Three participants were removed from the analysis (4\%): one who wrote incomprehensible gibberish, and two identical entries, suggesting the same person participated in the experiment twice. The remaining sixty-one entries entered our analysis (Mage $=39$ years; Msales_experience $=10$ years; $18 \%$ female $)$. 
Similar to Study 1, participants wrote a review and completed the four-item LO scale $(\alpha=.92)$. Sales experience, perceived task effort, and user type were the covariates, and we again collected behavioral information after three months.

Results

We estimated another ZIP model, confirmed as appropriate by a Vuong (1989) test. The dependent variable was the number of modules completed three months after the manipulation; the independent variables were the purpose manipulation (similar others or peers = 1 ; dissimilar other or manufacturer $=0)$, $\mathrm{LO}(\mathrm{M}=5.82$; $\mathrm{SD}=.93$; $\min =3, \max =7$ ), and their interaction. Sales experience, perceived task effort, and user type were the covariates.

\begin{tabular}{|l|c|r|}
\hline & \multicolumn{2}{|c|}{ Number of Modules } \\
\hline & $\begin{array}{l}\text { Unstandardized } \\
\text { Coefficient (SE) }\end{array}$ & IRR \\
\hline Constant & $-1.44(0.88)^{*}$ & 0.24 \\
\hline $\begin{array}{l}\text { Purpose (manufacturer }=0 ; \\
\text { peers = 1) }\end{array}$ & $6.06(1.33)^{* * *}$ & 427.07 \\
\hline Learning orientation (LO) & $0.22(0.14)$ & 1.25 \\
\hline Purpose $\times$ LO & $-0.92(0.23)^{* * *}$ & 0.40 \\
\hline Sales experience & $0.04(0.01)^{* * *}$ & 1.04 \\
\hline Perceived task effort & $0.19(0.06)^{* * *}$ & 1.21 \\
\hline $\begin{array}{l}\text { User type (distributor }=0 ; \\
\text { reseller }=1)\end{array}$ & $0.37(0.18)^{* *}$ & \\
\hline $\mathrm{N}$ & $61($ non-zero $=35 ;$ zero $=26)$ \\
\hline Log-likelihood & -159.48 \\
\hline $\begin{array}{l}\text { Bayesian information } \\
\text { criterion }\end{array}$ & 351.85 \\
\hline $\begin{array}{l}\text { Akaike information } \\
\text { criterion }\end{array}$ & 334.97 \\
\hline
\end{tabular}

${ }^{* * *} p<.01 .{ }^{* *} p<.05 .{ }^{*} p<.10$.

Table 3.2

Study 2: Summary of Zero Inflated Poisson Model

The results in Table 3.2 suggest that writing for the benefit of similar others increased the number of modules channel partners took 
during the subsequent three-month period $(\beta=6.06$; $\mathrm{IRR}=427.07$; $p<.001)$, compared with writing for a dissimilar other. However, LO did not affect this measure $(\beta=.22$; IRR $=1.25 ; p=.11)$. As we predicted in $\mathrm{H} 2$, the interaction between the purpose manipulation and LO was significant $(\beta=-.92$; IRR $=.40 ; p<.001$; Figure 3.2$)$, such that low LO participants who focused on similar others were more likely than their counterparts who targeted dissimilar others to complete more modules later, whereas this difference did not arise among participants with high LO.

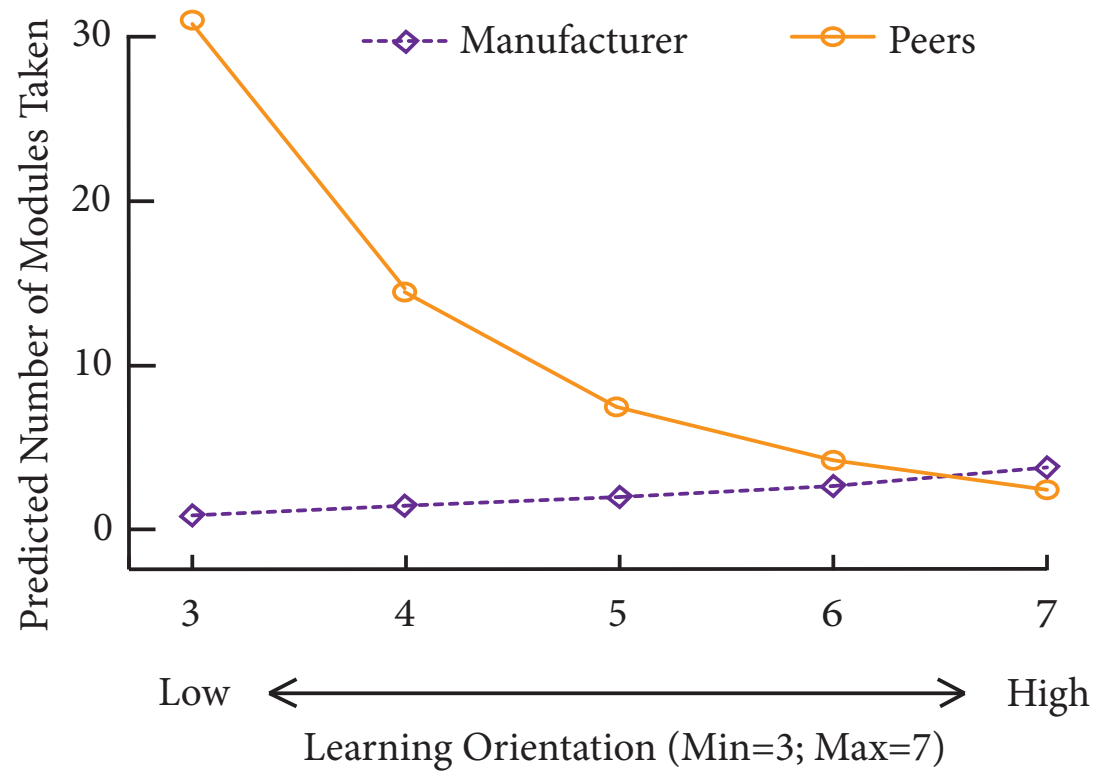

Figure 3.2

Study 2: Interaction between Purpose and Learning Orientation on Number of Modules Taken

\section{Discussion}

With Study 2, we found support for H2, because channel partners with low LO who write reviews directed toward similar others are more likely to pursue additional learning modules than are those who write reviews for dissimilar others, while this difference was not evident among channel partners with high LO. This finding is in line with the concept of social metacognition, such that low LO channel partners use their self-knowledge to proxy for the thoughts of others similar to themselves. As a result, these partners tend to express their own personal experiences within the review, which 
helps them to make sense of their own learning experiences that could decrease their uncertainty and lead to greater engagement in learning modules.

Considering the beneficiary of the review writing task enabled us to clarify how reviewing can lead channel partners to complete additional learning modules. We found that not all review writing effectively enhances engagement, but only those that help the channel partner focus their writing on self-relevant information. To gain additional insights, we explore another variable that might influence the metacognitive effect of writing in motivating people to pursue further learning, namely, the perspective taken in the review.

\section{STUDY 3}

To illustrate that not all forms of reviewing activate the metacognitive thought necessary to drive increased learning, in Study 3 we vary the perspective taken by the channel partners. This perspective might be broad or focused and thus relate to global or local processing styles, respectively. With a broad perspective, the channel partner accounts for more information, which might overwhelm those with low LO, and make it difficult for them to retrieve relevant information related to their learning experience. With a focused perspective, channel partners can easily process relevant information and effectively reflect on their learning experience. Therefore, those with low LO should be more willing to participate in new modules. As channel partners with high LO already engage in metacognition, they should be indifferent to how they write the review (H3). Additionally, we explore whether the elaboration triggered by metacognitive thought could in fact help resolve ambiguities related to the learning experience, and thereby strengthen the channel partner's certainty beliefs, which could explain their changes in behavior. Thus, in this study, we test the mediating role of certainty, using an objective measure of the number of certainty terms in the review. 


\section{Design, Participants, and Procedure}

The experimental design of Study 3 included partners who subscribed to the same global learning program but had not participated in either of our previous studies. A total of sixty-five partners participated, in exchange for points from the manufacturer's incentive program. The design was similar to that for Study 2, except that participants were randomly instructed to write a broad review about how the module fit with their overall learning program or a focused review about the module itself. We excluded five participants from the analysis ( $8 \%)$ : one wrote no reviews, another indicated that he had 100 years of sales experiences, which is unlikely, one indicated that he could not write in the language of the experiment, and two with incomplete entries. Thus the sample contained sixty participants $($ Mage $=40$ years; Msales_experience $=11$ years; $20 \%$ female $)$.

The procedure was similar to that of Studies 1 and 2. Participants selected a module they had completed from a dropdown menu, then provided a written review in the space provided. They also completed the four-item LO scale $(\alpha=.91)$. We used their sales experience, perceived referral task effort, and their user type (distributor or reseller) as covariates.

Three months after the experiment, we collected behavioral information about the number of modules each participant completed. Using the linguistic inquiry and word count (LIWC; Pennebaker Conglomerates, Inc. n.d.) method, a well-established linguistic text-mining program (Ludwig et al. 2013; Tausczik and Pennebaker 2010), we analyzed the percentage of certainty words (e.g., confident, correct, definite, absolute) that appeared in the review, to investigate whether changes in certainty beliefs could explain why channel partners with low LO participated in more learning modules when they were triggered to engage in metacognition.

\section{Results}

Similar to Studies 1 and 2, the estimation used a ZIP model. The Vuong (1989) tests confirmed its appropriateness for our data. Table 3.3 a contains the model estimates; we included the perspective manipulation ( 1 = focused review; $0=$ broad review $), \operatorname{LO}(M=6.08$; $\mathrm{SD}=.79 ; \mathrm{min}=3.50, \max =7.00)$, and their interactions, as well as sales experience, perceived task effort, and user type as covariates. We 
found a significant main effect for the perspective manipulation ( $\beta$ $=4.45 ; \mathrm{IRR}=85.26 ; p=.03)$; generally, taking a focused perspective when writing a focused review increased the number of modules subsequently taken, compared with writing a broad review. The level of LO again did not affect the number of modules $(\beta=.30$; IRR $=1.34 ; p=.28)$. In support of $\mathrm{H} 3$, we uncovered a significant interaction between the perspective and $\mathrm{LO}(\beta=-.82 ; \mathrm{IRR}=.44 ; p=$ .02 ; Figure 3.3), such that low LO participants who wrote a focused review completed more modules in the subsequent three-month period than did those who wrote a broad review. No differences arose across high LO participants.

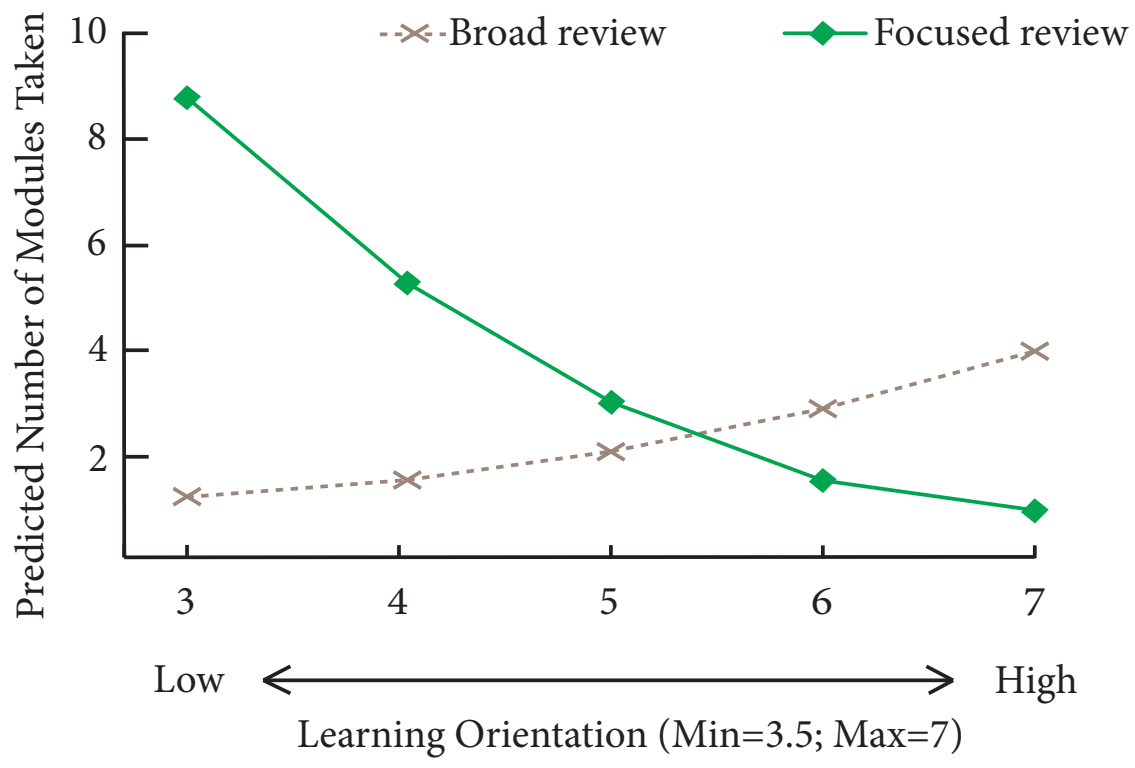

Figure 3.3

Study 3: Interaction between Perspective and Learning Orientation on Number of Modules Taken

To understand the mechanisms driving these results, we analyzed the effect of our variables on the number of certainty words used within the written review. Table $3.3 \mathrm{~b}$ contains the model estimates. We again used the ZIP regression, because the count data featured many zero values $(60 \%)$. The estimation of the number of certainty words in the analysis relied on the same variables (perspective manipulation, LO, their interaction, sales experience, perceived task effort, and user type). As we show in Table 3.3b, both the perspective manipulation $(\beta=13.15$; IRR $=512,935.7 ; p<.001)$ and $\mathrm{LO}(\beta=$ 


\begin{tabular}{|l|c|r|}
\hline & \multicolumn{2}{|c|}{ Number of Modules } \\
\hline & $\begin{array}{l}\text { Unstandardized } \\
\text { Coefficient (SE) }\end{array}$ & \multicolumn{1}{|c|}{ IRR } \\
\hline Constant & $-1.52(1.75)$ & 0.22 \\
\hline $\begin{array}{l}\text { Perspective (broad =0; } \\
\text { focused = 1) }\end{array}$ & $4.45(2.09)^{* *}$ & 1.34 \\
\hline Learning orientation (LO) & $0.30(0.27)$ & 0.44 \\
\hline Perspective $\times$ LO & $-0.82(0.34)^{* *}$ & 1.03 \\
\hline Sales experience & $0.03(0.01)^{* * *}$ & 13.01 \\
\hline Perceived task effort & $0.01(0.05)$ & \\
\hline $\begin{array}{l}\text { User type (distributor }=0 ; \\
\text { reseller }=1)\end{array}$ & $1.34(0.29)^{* * *}$ & \\
\hline $\mathrm{N}$ & $60($ non-zero $=32 ;$ zero $=28)$ \\
\hline Log-likelihood & -123.92 \\
\hline $\begin{array}{l}\text { Bayesian information } \\
\text { criterion }\end{array}$ & 280.60 \\
\hline $\begin{array}{l}\text { Akaike information } \\
\text { criterion }\end{array}$ & 263.84 \\
\hline$* * * p<.01 .{ }^{* *} p<.05 .{ }^{*} p<.10$. & \\
\hline
\end{tabular}

Table 3.3a

Study 3: Summary of Zero Inflated Poisson Model with Number of Modules as Dependent Variable

1.66; IRR $=5.19 ; p<.001)$ were significant: Respondents who wrote in a focused manner or had a higher LO used more certainty words. We also found a significant interaction between these variables such that channel partners with low LO who wrote a focused review used more certainty words compared to those who wrote a broad review $(\beta=-2.21 ;$ IRR $=.11 ; p<.001$; Figure 3.4$)$. Interestingly, we also found that channel partners with high LO also used more certainty words when they were asked to write a broad review compared to when they were asked to write a focused review.

To test whether an increase in certainty words brought about by metacognition could explain the changes in behavior of low LO channel partners, we conducted a test of mediated moderation, following the procedure recommended by Muller, Judd, and Yzerbyt (2005), and estimated three ZIP regressions. First, we used the number of modules as the dependent variable and the perspective manipulation, 


\begin{tabular}{|l|c|r|}
\hline & \multicolumn{2}{|c|}{ Number of Certainty Words } \\
\hline & $\begin{array}{l}\text { Unstandardized } \\
\text { Coefficient }(S E)\end{array}$ & \multicolumn{1}{|c|}{ IRR } \\
\hline Constant & $-7.79(2.56)^{* * *}$ & 0.00 \\
\hline $\begin{array}{l}\text { Perspective (broad }=0 ; \\
\text { focused = 1) }\end{array}$ & $13.15(2.62)^{* * *}$ & $512,935.70$ \\
\hline Learning orientation (LO) & $1.66(0.39)^{* * *}$ & 5.19 \\
\hline Perspective $\times$ LO & $-2.21(0.42)^{* * *}$ & 0.11 \\
\hline Sales experience & $-0.02(0.01)^{* *}$ & 0.98 \\
\hline Perceived task effort & $-0.25(0.07)^{* * *}$ & 0.78 \\
\hline $\begin{array}{l}\text { User type (distributor }=0 ; \\
\text { reseller }=1)\end{array}$ & $1.35(0.35)^{* * *}$ & 3.89 \\
\hline $\mathrm{N}$ & $60($ non-zero $=24 ;$ zero $=36)$ \\
\hline Log-likelihood & -131.75 \\
\hline $\begin{array}{l}\text { Bayesian information } \\
\text { criterion }\end{array}$ & 296.24 \\
\hline $\begin{array}{l}\text { Akaike information } \\
\text { criterion }\end{array}$ & 279.49 \\
\hline$* * * 01 .{ }^{* *}<<.05 .{ }^{*} p<.10$. & \\
\hline
\end{tabular}

Table 3.3b

Study 3: Summary of Zero Inflated Poisson Model with Number of Certainty Words as Dependent Variable

LO, their interaction, sales experience, perceived task effort, and user type as independent variables. The interaction was significant $(\beta=-.82 ;$ IRR $=.44 ; p=.02)$. Second, the next ZIP contained the number of certainty words as the dependent variable and the same independent variables; again, the interaction was significant $(\beta=-2.21$; IRR $=.11 ; p<.001)$. Third, adding the number of certainty words and its interaction with $\mathrm{LO}$ to the first model revealed a marginally significant effect of certainty on the number of modules $(\beta=.49$; $\operatorname{IRR}=1.63 ; p=.09)$. The interaction between perspective and LO also remained significant $(\beta=-1.16$; IRR $=.31 ; p=.001)$, though it had a smaller impact in this model. These findings indicate that certainty mediates the impact of focused (vs. broad) review writing on the number of modules completed. 


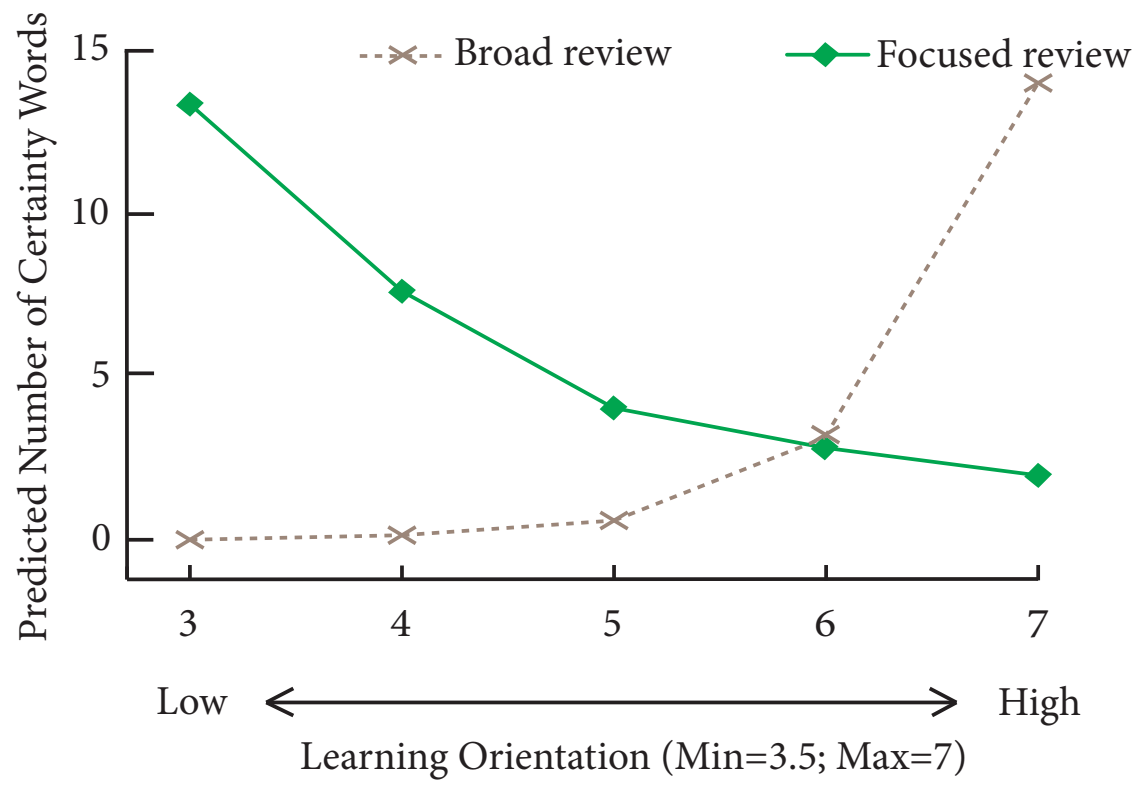

Figure 3.4

Study 3: Interaction between Perspective and Learning Orientation on Number of Certainty Words

\section{Discussion}

Engaging in metacognition is an effortful activity that channel partners with low LO experience difficulties in (Ford et al. 1998). Writing a review about a learning module provides such channel partners with a task that requires them to reflect on their learning experiences with that module, which in turn affects their participation with future learning modules. However, as we discovered in Study 2, not all review writing tasks increased their participation, but only those that were particularly relevant for the channel partner, which was when they wrote a review that would benefit their peers. Similarly, in Study 3, we find that a focused review writing task that relates directly to their specific learning experience is most effective in driving future participation behaviors. We argue that peripheral information, even if relevant, may serve to distract these low LO channel partners, hindering them from fully understanding their experience. As a result, they are less motivated to pursue similar learning experiences. Additionally, we find evidence of the role of certainty in explaining why channel partners with low LO participated in more learning modules when they were triggered to 
engage in metacognition. We believe that metacognitive activities help channel partners to understand their learning experience, which in turn increases their certainty beliefs and as a result encourages accordant behaviors.

\section{GENERAL DISCUSSION}

We have examined the role of learning as an instrument for businessto-business engagement-and particularly how reflection on learning experiences, through referral systems, can drive engagement of individuals employed at partner firms. Drawing on metacognition theory, we attribute this drive to the role of review writing, such that it engages channel partners with low LO to become more self-aware of their learning experience, which results in a heightened pursuit of additional learning programs (Study 1). In further support of this proposition, we discover that only certain forms of review writing actually engage partners with low LO. Specifically, partners with low LO who provide a review for similar others are better able to retrieve relevant information about their learning experience, because they assume that their peers have preferences similar to their own. This effect leads to a heightened pursuit of additional learning programs (Study 2). Moreover, partners who write in a more focused manner can better identify relevant information about their learning experience, which increases their certainty about what they have learned and their pursuit of additional learning (Study 3 ). These effects of reviewing are persistent, in that belief certainty exerts a lasting, strong impact on behaviors over a period of three months (Wan et al. 2010).

\section{Implications for Theory}

The findings of this manuscript advance extant research in two main ways. First, this article represents the first examination of referral systems as tools for engagement that is in line with the shift to enablement and long-term channel-partner relationships (Li and Dant 1999; Rapp, Ahearne, Mathieu, and Schillewaert 2006). We extend the focus beyond a traditional view of channel partner feedback as input that the manufacturer uses to improve the quality of its products and services (Golder, Mitra, and Moorman 2012; Voss et al. 2004). 
Our research highlights how the process of review writing activates metacognition, which influences the enduring learning behaviors adopted by channel partners with low LO. By considering who they write for and how they write, we demonstrate additional support for the activation of metacognition, in that channel partners prompted to reflect on self-relevant information related to their experiences with the learning program displayed a higher propensity to complete additional learning modules. Thus, our research introduces the previously unexamined positive consequences of widely used review writing tasks, thereby opening the theoretical realm to include both the direct benefits of channel partner feedback through improved service and the indirect benefits that result from behavioral and motivational transformations. These theoretical implications also likely encompass the relationships between firms and customers, in which setting referral systems might help embed customers within the organization (Bhattacharya and Sen 2003). In this case, customers gain an opportunity to participate actively with the organization and also enter into a reflective process that enables them to recognize the benefits of continued participation, strengthening their motivation to engage with the organization.

Second, we demonstrate that the metacognitive activity of belief certainty drives the effects of review writing on engagement. When low LO channel partners write reviews, they gain a deeper understanding that helps them make sense of their learning experience. In turn, they become more certain about their feelings and more willing to engage in additional learning. Prompted self-reflection strengthens beliefs about the personal gains brought about by the learning program and its inherent value, resulting in increased partner participation in learning programs over time. These findings support previous literature about the enduring effects of strong beliefs (Karmarkar and Tormala 2009; Wan et al. 2010) and also provide new evidence that elaborating on personally relevant information, brought about by the metacognitive intervention of review writing, can serve to strengthen certainty. Thus our study provides a novel link between metacognitive interventions and belief certainty, and it suggests innovative ways to activate it. Our use of text mining methods (i.e., LIWC) substantiates the mediating role with objective measures; manufacturers have access to simple, unobtrusive means to identify varying levels of belief certainty and assess their partners' engagement. Similarly, 
these findings provide evidence of the importance of considering metacognition as a mediating mechanism to explain the effects of relationship-specific investments on financial outcomes. Investments in training programs particularly within eLearning environments may help build relationship bonds with channel partners that translate to improved sales (Palmatier, Dant, Grewal, and Evans 2006; Rapp, Beitelspacher, Schillewaert, and Baker 2012). However, channel partners also must have a clear understanding of the personal value embodied by these relationship-specific investments. We identify other mechanisms that can strengthen interorganizational relationships, beyond trust and commitment (Palmatier, Dant, and Grewal 2007).

\section{Implications for Managers}

By enabling channel partners to meet dynamic growth opportunities in a market, CPPs have a strategic influence on manufacturers' overall success. Our findings suggest several ideas for increasing engagement and promoting CPPs through the use of referral systems. First, manufacturers should consider incorporating intrinsic motivators that might supplement their existing incentive programs. Extrinsic incentive programs that reward partners with luxury items or vacation destinations to participate in learning modules might help motivate partners, but they also can be matched easily by competitors (Lane4 2012) and generally lack elements that create engaging, meaningful experiences (Deloitte 2012). As we have shown, encouraging channel partners to reflect on what they have learned helps them understand the personal benefits they have gained from a learning program. Therefore, we recommend that manufacturers incorporate review systems into their learning modules to prompt channel partners to review modules after taking them. This simple, powerful means to nurture reflective thinking offers notable benefits for partner engagement over time.

Second, partners are heterogeneous, with varying learning motivations and different evaluations of certain rewards (Deloitte 2012); these traits can signal their willingness to engage in learning programs. Although reflective thinking brought about by writing reviews is a powerful behavioral motivator, it is limited, in that it is effective only for partners that are not already intrinsically motivated to learn. To optimize the behavioral outcomes of reviewing, manufacturers should find ways to focus on essential information within the reviews, relevant 
to low LO partners' personal experience with learning modules, in the task instructions. Similar to suggestions put forward by ZS Associates (2014), we recommend that the review task be customized to appeal to different segments of channel partners with distinct needs. For example, manufacturers could identify different segments, such as those with low LO, through a survey question, then invite certain channel partners to review modules while highlighting the benefits of these reviews for their peers.

Third, manufacturers should encourage their partners to draw conclusions about how learning programs have helped them, to increase their certainty. Reflective thinking is a key method, but certainty could also increase if channel partners read negative and positive appraisals from other business partners or discern that a majority of other business partners hold similar perspectives (Rucker et al. 2014). Other methods for increasing certainty include sending e-mails that affirm what the channel partners learned a few days after they have completed a learning module or sharing the thoughts expressed by other channel partners about the learning module. Because of its strong, lasting impact on engagement, manufacturers should measure certainty, possibly using unobtrusive text mining methods similar to those in our study, to gain information to help them evaluate and predict their partners' behaviors.

Fourth, managers can advance the social functionalities of their CPPs to facilitate knowledge exchanges among business partners. They could develop and maintain communities that help channel partners discuss their experiences with the CPPs. This platform would not only foster reflective thinking, as channel partners share their experiences, but also boost the degree of certainty among other channel partners, when they encounter testimonials from their peers.

\section{Limitations and Avenues for Further Research}

With this study of how referral systems can increase individual engagement, we limit our research scope to engagement in a learning program, which likely has cascading effects on objective outcomes, such as sales. Further research should investigate other relationship outcomes that might result from metacognition, such as sales or increased lead generation. Beyond learning, other managerially relevant contexts might be considered too, such as the impact of 
referral systems in business-to-consumer settings (e.g., online customer reviews on ecommerce and social networking sites). Such investigations would enrich our theoretical understanding, by providing evidence of whether metacognition drives engagement behaviors, not just to pursue additional learning but also to increase share of wallet or word of mouth.

Other research might concentrate on motivators for metacognition other than review writing, such as providing comparative information that benchmarks people's performance on learning tasks against an average or sending trivia questions related to the subject matter to help them think about how much they have learned. We have focused on the effects of review writing after a three-month period; other research might investigate the dynamic effects of these interventions to detail how and when they diminish over time. Comparative studies of multiple interventions also could shed light on which strategies are most effective for engaging partners over time. These insights would provide more delineated understanding of the mechanisms behind the interventions and thus reveal new theoretical knowledge.

Finally, the metacognitive activity of writing reviews can drive intrinsic motivations; in other circumstances, it might also trigger external drivers, such as social acceptance, particularly if the review platform enables the writer to showcase him- or herself. Understanding other motivations associated with writing reviews could expand the theoretical foundations for research in this area, as well as suggest more insightful and sophisticated applications of this simple and effective tool for manufacturers.

Overall, we find that reviewing learning modules can drive channel partners with low LO to take on additional learning, particularly when they must consider specific information for the benefit of their peers. We attribute this finding to the activation of metacognition that helps channel partners see the value of the programs, which concurrently increases their certainty. These findings have implications for new methods of engagement, and they also provide a cost-effective solution that managers can implement for their CPPs. 



\section{CHAPTER 4}

\section{Unraveling the}

\section{Personalization Paradox}

Aguirre, Elizabeth, Dominik Mahr, Dhruv Grewal, Ko de Ruyter, and Martin Wetzels (2015), "Unraveling the Personalization Paradox: The Effect of Information Collection and Trust-Building Strategies on Online Advertisement Effectiveness," Journal of Retailing, 91 (1), 34-49. 


\begin{abstract}
Retailers gather data about customers' online behavior to develop personalized service offers. Greater personalization typically increases service relevance and customer adoption, but paradoxically, it also may increase customers' sense of vulnerability and lower adoption rates. To demonstrate this contradiction, an exploratory field study on Facebook and secondary data about a personalized advertising campaign indicate sharp drops in click-through rates when customers realize their personal information has been collected without their consent. To investigate the personalization paradox, this study uses three experiments that confirm a firm's strategy for collecting information from social media websites is a crucial determinant of how customers react to online personalized advertising. When firms engage in overt information collection, participants exhibit greater click-through intentions in response to more personalized advertisements, in contrast with their reactions when firms collect information covertly. This effect reflects the feelings of vulnerability that consumers experience when firms undertake covert information collection strategies. Trust-building marketing strategies that transfer trust from another website or signal trust with informational cues can offset this negative effect. These studies help unravel the personalization paradox by explicating the role of information collection and its impact on vulnerability and click-through rates.
\end{abstract}


Retailers use sophisticated, personalized marketing strategies that exploit consumer data to influence purchase decisions (Hawkings 2012), so much so that these data have become the "life-blood of retail" (National Retail Federation n.d., p. 20). Many online retailers partner with publishers such as Google and Yahoo that collect consumer data, then use the collected information to present personalized advertisements (Angwin 2012). In addition, with the spread of social networking sites, retailers-which represent the largest sector of Internet advertising spending, accounting for $22 \%$ in 2011 (Interactive Advertising Bureau 2012)-have entered into these media spheres to present consumers with more targeted advertising. Facebook thus became the most popular ad publisher in 2011, with a $31.2 \%$ market share (comScore 2011), but also has come under close scrutiny of its advertising practices and covert data collection methods (Singer 2010). These trends suggest the need for retailers to find more sustainable methods of data collection and use (McCann Worldwide 2011).

Advocates of covert data collection techniques contend that the consumer benefits from them, because the data collection does not disrupt their online surfing experience (Milne, Bahl, and Rohm 2008), whereas granting consent to each data collection encounter would force users to take 2.5 times longer to complete online tasks (Interactive Advertising Bureaux Europe 2011) and disrupt the flow of their shopping (National Retail Federation n.d.). Yet consumers may experience discomfort when they receive personalized advertisements (Tucker 2012), because it prompts them to realize their information has been collected without their consent. For example, when the U.S. retailer Urban Outfitters launched a website that personalized each customer's experience by gender, customers instantly recognized the personalization and confronted the clear knowledge that the retailer had collected their information without their awareness. They reacted by accusing Urban Outfitters of being "too close for comfort" and making illegitimate uses of their data, which quickly led Urban Outfitters to abandon the personalization strategy (Singer 2012). Thus, despite evidence that response rates improve with greater personalization, such efforts also could increase consumer discomfort, leading to lower response rates. This phenomenon gives rise to what we refer to as the personalization paradox: Personalization can be both an effective and an ineffective marketing strategy, depending 
on the context. The effects of various data collection methods on this paradox remain unclear, though retailers using online advertising could benefit from recommendations about which tools or marketing communication to use to avoid or minimize the negative effects of personalization.

Current research offers little guidance; it mostly emphasizes consumers' reactions to the delivery of personalized services (Sundar and Marathe 2010; Tam and Ho 2006), without accounting for the information collection process needed to personalize services or consumers' reactions. Literature on covert marketing practices provides some insights though. For example, Miyazaki (2008) studies disclosures of the use of cookies, a common covert information collection technique, and finds that when consumers realize a cookie is going to be installed (e.g., after notification on web browsers) but receive no prior disclosure in privacy statements, they exhibit lower behavioral intentions toward the website. Although personalization can signal greater relevance and increase customer adoption (Tam and Ho 2006), no research indicates whether it triggers negative reactions similar to those prompted by an explicit cookie notification (Miyazaki 2008).

Furthermore, research that addresses the mechanism underlying negative reactions to data uses tends to rely on cognitive reasoning, such that customers weigh the pros and cons of allowing firms to use their data (Awad and Krishnan 2006). Yet in many cases, consumers form attitudes quickly, instinctively, and without in-depth thinking, in reaction to a stimulus (Shiv and Fedorikhin 1999). Such affective responses strongly influence retail shopping experiences (Arnold and Reynolds 2009) and consumer judgments (Avnet, Pham and Stephen 2012). Milne, Bahl, and Rohm (2008) suggest that consumers may experience an affective sense of vulnerability in response to covert information collection, but empirical tests of this proposition or its implications for consumer behavior are lacking. In addition, customers likely accept feelings of vulnerability in environments marked by trust (Urban, Amyx, and Lorenzon 2009), and various retailer-driven marketing strategies seemingly might increase customer trust (Bart et al. 2005; Kim and Kim 2011; Pan and Zinkhan 2006). Such trustbuilding strategies in turn might offset the negative reactions brought about by feelings of vulnerability. 
This article seeks to make three main contributions. First, using evidence from exploratory field studies on Facebook and secondary data, we corroborate the existence of the personalization paradox and probe the interdependencies among the collection and use of data for personalization and their impact on consumer behavior in social media settings. This effort represents a response to calls for more empirical generalizations related to personalization strategies in retailing (Grewal et al. 2011). With new insights into the personalization paradox, we find that employing covert data collection undermines the beneficial impact of increased relevance on advertising effectiveness. Second, we conceptualize consumers' perceived vulnerability as a negative influence on the experience of personalization in social media-mediated environments. Drawing on psychological ownership theory, we propose that vulnerability occurs when personalization provokes discomfort, because the consumer comes to a sudden realization of the covert data collection. This conceptualization offers an affective alternative to the common cognitive rationale for low click-through rates on online ads, namely, as due to privacy concerns. In turn, we operationalize consumer vulnerability with a newly developed, robust, five-item measure and validate its impact on advertising effectiveness. Third, we test the impact of two trust-building strategies-transferring trust from the media context or signaling trust with cues-that may offset the experience of vulnerability. If the personalized advertisement appears on a trustworthy website, its credibility can mitigate the negative effect of covert data collection. Similarly, information icons that systematically inform customers about how their information is being collected and used provide trust-building cues that can reduce the negative impacts of covert data collection.

\section{CONCEPTUAL BACKGROUND}

\section{Personalization}

Personalization refers to a customer-oriented marketing strategy that aims to deliver the right content to the right person at the right time, to maximize immediate and future business opportunities 
(Tam and Ho 2006). The strength of this strategy is that it requires a minimum amount of effort by the customer, who relies mostly on the marketer to identify and meet his or her needs (Montgomery and Smith 2009). This central aspect of personalization provides a stark contrast with customization, which occurs when the consumer specifies the elements of his or her preferred marketing mix (Arora et al. 2008).

Firms routinely practice personalization, both offline and online. In face-to-face service encounters, firms encourage employees to adjust their behaviors toward each customer, such as referring to a customer by name or modifying the service offering to accommodate customers' needs (Shen and Ball 2009). The applicability of personalization expands significantly in online environments too. Search engines, such as Google and Yahoo, can refine each user's search results by incorporating prior search information; online retailers, such as Amazon.com and Barnes \& Noble, provide personalized recommendations based on collaborative filtering, that is, on a user's similarity to other users and their preferences (Montgomery and Smith 2009). Online advertisers also issue behaviorally targeted advertisements, reflecting a user's online behavior (Goldfarb and Tucker 2011).

This ability to incorporate users' past behaviors also enables online firms to personalize services more accurately, with advantages for both the firms and their customers. Briefly, customers enjoy improved products and services, a better preference match (Vesanen 2007), reduced cognitive overload, and convenience (Ansari and Mela 2003). Firms can better service their customers, which increases customer satisfaction (Rust and Chung 2006) and loyalty (Ansari and Mela 2003), and better manage customers' perceptions of their responsiveness (Song and Zinkhan 2008). Moreover, they might gain competitive advantages (Murthi and Sarkar 2003), charge higher prices (Vesanen 2007), and improve their profitability (Rossi, McCulloch, and Allenby 1996; Zhang and Wedel 2009). In an online advertising context, firms also benefit from greater recall, higher content evaluations, and more purchases (Tam and Ho 2006), such that personalized advertisements appear twice as effective as similar, impersonal versions (Tucker 2014). 
Murthi and Sarkar (2003) specify three personalization stages: learning, matching, and evaluation. In the learning stage, firms collect and analyze customer data to understand their needs and preferences. The matching stage involves applying this information to personalize a customer's experience; for our study context, it implies presenting a customer with a personalized advertisement. Finally, evaluating the effectiveness of the personalization strategy demands consideration of the learning and matching stages. In online settings, this last stage translates into evaluating the effectiveness of the personalized strategy with measurable instruments, such as click-through rates.

Because personalization inherently involves adapting to customer needs, it is essential for firms to learn about customers. The strategies that firms employ to collect such data differ in the degrees to which consumers are aware of how and when their information gets collected. We thus delineate two data collection strategies: overt and covert (Murthi and Sarkar 2003; Sundar and Marathe 2010).

\section{Information Collection}

When firms engage in overt information collection strategies, consumers know their data are being collected (Sundar and Marathe 2010), because the firm has made a conscious effort to inform them. The underlying assumption is that continued use of the services, after this information provision, creates an ad hoc consent to the data collection. For example, The Economist's website clearly informs readers about its use of cookies; an information box appears in the header of each page (www.economist.com). Privacy advocates stress the importance of information transparency and consent, but practitioners tend to argue that excessive consent requests could be detrimental to consumers' surfing experiences (Interactive Advertising Bureaux Europe 2011). For example, the "irritating" nature of the Dutch "cookie law" led to suggestions to rescind the requirement that websites obtain permission from visitors to use cookies every time they visit a site (DutchNews.nl 2013).

Covert information collection strategies instead occur when firms collect data without consumers' awareness, often by unobtrusively gathering information while the consumer browses the Internet (Milne, Bahl, and Rohm 2008; Montgomery and Smith 2009). The 
unobtrusiveness of this form of data collection helps the firm gain unbiased data, and thus a richer customer understanding that it can use to tailor its services (Verhoef et al. 2010). It also benefits consumers, by not interfering with their surfing experience. Because consumers are not informed of each discreet instance of information collection, the ad hoc consent assumed in overt information collection settings cannot apply (John, Acquisti, and Loewenstein 2011). Consumers' demands for more openness thus pose a challenge to firms that prefer to continue to practice covert strategies (Turow et al. 2009).

\section{Link Between the Personalization Paradox and Information Collection}

Personalization requires the collection and use of consumer data to make inferences about their preferences (Montgomery and Smith 2009). Although Internet users generally realize that firms, such as social networking sites, collect their information, they often become aware of these discreet instances only if the firm overtly informs them that it is doing so. When firms do not inform their customers about their data collection efforts, an advertisement that contains distinct, personal information may cue customers that their information has been collected, without their consent. Milne, Bahl, and Rohm (2008) suggest that exposure to such cues results in negative customer reactions and thus to harms to the firm's reputation and future business. For example, customers might perceive that the firm is acting in its own self-interest, which would lower their perceptions of its benevolence and value offering (Shen and Ball 2009). We expect the effect of personalization on consumers' click-through intentions to be moderated by their awareness of the collection of personal data. Moreover, the positive benefits of personalization should accrue when the firm engages in overt, as opposed to covert, information collection.

H1: When firms engage in overt information collection, more personalized (cf. less personalized) advertisements enhance click-through intentions, but not when firms engage in covert data collection. 


\section{Cognitive Theories}

Two literature streams related to privacy and reactance seek to explain the negative consequences of personalization using cognitive approaches. First, investigations of privacy feature various considerations, including the importance of regulatory and parental interventions for limiting underage disclosures (Lwin, Stanaland, and Miyazaki 2008) and the effects of privacy on retailer quality perceptions (Wolfinbarger and Gilly 2003). The application of privacy theories to explicate personalization outcomes often emphasize the trade-off between the benefits of personalization and the costs of privacy. In this cost-benefit analysis, consumers act as rational economic agents, who consider both the risks and benefits prior to disclosing their information and form perceptions of the personalized service (Awad and Krishnan 2006; Chellappa and Shivendu 2010; John, Acquisti, and Loewenstein 2011; Pavlou 2011). This rational assessment and deliberate decision process suggest that sharing private information is a cognitive, rather than affective, concept.

Second, personalized messages can lead users to perceive threats to their freedom, in terms of their ability to avoid being closely observed by a firm (Brehm 1966). In response to this threat, customers may exhibit reactance and attempt to reattain their restricted freedom (Fitzsimons and Lehmann 2004). In light of this, White et al. (2008) find that higher levels of personalization are less effective if customers receive no justification for why their information has been used. Building on this finding, Tucker (2014) shows that introducing privacy controls increases the effectiveness of personalized advertisements by reducing reactance. Reactance "describes a strategy that consumers use to avoid complying with a persuasion attempt but does not directly characterize the cause of discomfort associated with a privacy invasion" (Tucker 2012, p. 2). Therefore, we turn to psychological ownership theory and describe an affective process that might explain the discomfort and ultimately the paradox.

\section{Psychological Ownership and Vulnerability as an Affective Alternative}

Psychological ownership is a state in which a person has a sense of ownership over external objects (Pierce, Kostova, and Dirks 2001), because of his or her strong cognitive and affective attachment to 
them (Avey et al. 2009). These owners then perceive a right to gain information about the objects and a voice in decisions that affect them (Pierce, Kostova, and Dirks 2001). Violations of these expectations produce strong negative emotions; removal of the possessed objects causes people to feel acute loss, such that they may be "personally annihilated" (James 1981, p. 280) or sense a loss of self (Belk 1988).

Vulnerability arises when consumers lack of a sense of control over the situation and experience a state of powerlessness, brought about by marketplace imbalances (Baker, Gentry, and Rittenburg 2005). Consumers may feel vulnerable if firms engage in certain actions that make them feel exploited (Andreasen, Cooper-Martin, and Smith 1994). Such an experience is marked by strong emotional intensity, caused by the acute threat to their self-concept, such that the individual even could feel as if her or his security and well-being were at risk (Baker, Gentry, and Rittenburg 2005; Pierce, Kostova, and Dirks 2001). In contrast with cognitive theory-based predictions, feelings of vulnerability emerge subconsciously and may be hard to express, despite their strong impact. Research also indicates that this feeling of vulnerability may shape privacy concerns, which suggests the potential relationship between these constructs (Bandyopadhyay 2009; Dinev and Hart 2004).

When customers recognize covert information collection, through exposure to highly personalized advertisements, they likely perceive a loss of control and experience feelings of vulnerability. Vulnerability is highly undesirable, so consumers avoid objects associated with it. In contrast, when customers receive details about information collection strategies prior to their exposure to highly personalized advertisements, they are less likely to perceive a loss or experience feelings of vulnerability, because they have granted implied consent, through their awareness. We thus posit that the influence of personalized advertisements on consumers' click-through intentions depends on their awareness that personalization is taking place. When consumers become aware of covert information collection only through their exposure to a highly personalized advertisement, they sense greater vulnerability and express lower click-through intentions in response to highly personalized advertisements; when they are exposed to overt information collection, they do not experience feelings of vulnerability and indicate greater click-through intentions. 
H2: When firms engage in covert information collection, more personalized (cf. less personalized) advertisements increase feelings of vulnerability, but not when firms engage in overt data collection.

\section{Trust-Building Strategies}

Trust, as "a psychological state comprising the intention to accept vulnerability based on positive expectations of the intentions or behaviors of another" (Rousseau et al. 1998, p. 395), is especially important online, due to the vast information asymmetries and customer uncertainty inherent to the Internet (Stewart 2003). For example, consumers cannot ascertain how retailers use information about their shopping behaviors on websites. Without any means to determine whether a firm is acting in their own best interests, consumers may remain unwilling to grant firms more control over the interaction (Bart et al. 2005; Urban, Amyx, and Lorenzon 2009). Online advertisers therefore pursue various strategies, such as relying on a particular website's credibility or using signaling cues, to build more trust in their advertisements, which then should improve clickthrough rates.

Online advertisers can take advantage of a trustworthy website by capitalizing on the potential spillover of trust from the website to an advertisement. Consumers tend to believe that advertisements follow the norms of the websites on which they appear (Stewart 2003), so if a web surfer trusts a particular website, he or she likely assumes that the assurances and safeguards related to the site also pertain to the advertisements on the site. In turn, they are more likely to accept a sense of vulnerability to trustworthy websites (Pavlou, Liang, and Xue 2007). If such websites feature highly personalized advertisements, we expect that consumers accept this form of vulnerability, despite the covert data collection, and exhibit higher click-through intentions than they would in response to an advertisement on an untrustworthy website. That is, we predict that vulnerability decreases click-through intentions only if consumers are exposed to highly personalized advertisements on an untrustworthy website. 
H3: When firms engage in covert data collection, more personalized advertisements decrease click-through intentions if the advertisement appears on a less trustworthy (cf. more trustworthy) website, due to their increased feelings of vulnerability.

Alternatively, firms might seek to increase consumer trust through cues that signal their benevolence and reliability (Kim and Kim 2011). The Internet Advertising Bureau UK (2011) urges firms to incorporate icons to inform users about data collection and usage practices; such icons could increase trust perceptions (Pan and Zinkhan 2006), benevolence and integrity beliefs (Schlosser, White, and Lloyd 2006), and behavioral intentions (Wang, Beatty, and Foxx 2004). When advertisers incorporate icons directly into an advertisement, consumers may experience more trust and become more willing to accept vulnerability, such that they will click on a highly personalized advertisement that contains a trust-building cue, despite their recognition of covert data collection attempts by the firm.

H4: When highly personalized advertisements contain trust-building cues, click-through intentions do not differ whether the information has been collected overtly or covertly.

To establish empirical evidence of the predicted personalization paradox, we undertook an exploratory field study on Facebook (Prestudy 1) to demonstrate the differential effects of personalization. We also gathered secondary data about a personalized advertising campaign (Prestudy 2) that attributed the decrease in effectiveness to covert information collection. As in-depth analyses, we conducted three experimental studies: Study 1 examines the impact of the interaction between information collection and personalized strategies on click-through intentions, revealing a central role of vulnerability in reducing the effectiveness of personalization. In Study 2, we investigate whether website credibility can offset the negative effects of vulnerability, and in Study 3, we consider the effectiveness of the industry-advocated solution of incorporating information icons into the advertisement. 


\section{PRESTUDY 1}

A field experiment on Facebook provides some insights into the personalization paradox. Retailers often sell both services and products, so for this field experiment on Facebook, we selected a brand in each category: a well-known financial services brand and a familiar dog food brand sold in the Netherlands. The experiment featured three advertisements. The first contained no personalization; the second was moderately personalized, targeting people who indicated that they liked financial services or dogs; and the third was highly personalized, with content that reflected both liking of financial services or dogs and the participants' demographic characteristics (i.e., age, gender, location). The advertisements ran for five days on Facebook, during which we collected the aggregated click-through rates (CTR).

\section{Results}

The results for the financial services brand showed significant increases in CTR when participants received more relevant advertisements, reflecting their indicated preferences (CTRno_personalization $=.017 \%$, CTRmoderate_personalization $=.077 \% ; z=-4.61, p \leq .001)$. However, when participants received a targeted advertisement with specific personal information, the CTR significantly decreased (CTRmoderate personalization $=.077 \%$, CTRhigh_personalization $=.032 \% ; z=3.15, p=$ .002; see Figure 4.1, Panel a). Similar findings emerged for the dog food brand, with significant CTR increases from no to moderate personalization (CTRno_personalization $=.047 \%$, CTRmoderate_personalization $=.064 \% ; z=-1.38, p=.084$, one-tailed) but significant decreases from moderate to high personalization (CTRmoderate_personalization $=$ $.064 \%$, CTRhigh_personalization $=.033 \% ; z=2.60, p=.009$, two-tailed; see Figure 4.1, Panel b).

\section{Discussion}

These findings offer evidence of the personalization paradox. Observing consumers' behaviors in the real world, we find that they react differently to advertisements with varied personalization levels. 
Some personalized advertisements are effective, but others fail to induce desired behaviors, such as clicking on the advertisement. The realization that personalization's effects are not entirely straightforward highlights the need to explicate its functioning in different contexts, to gain insights into best management practices. Information collection strategies largely determine the personalization process, so we investigate how such strategies affect customers' reactions to personalized advertisements.

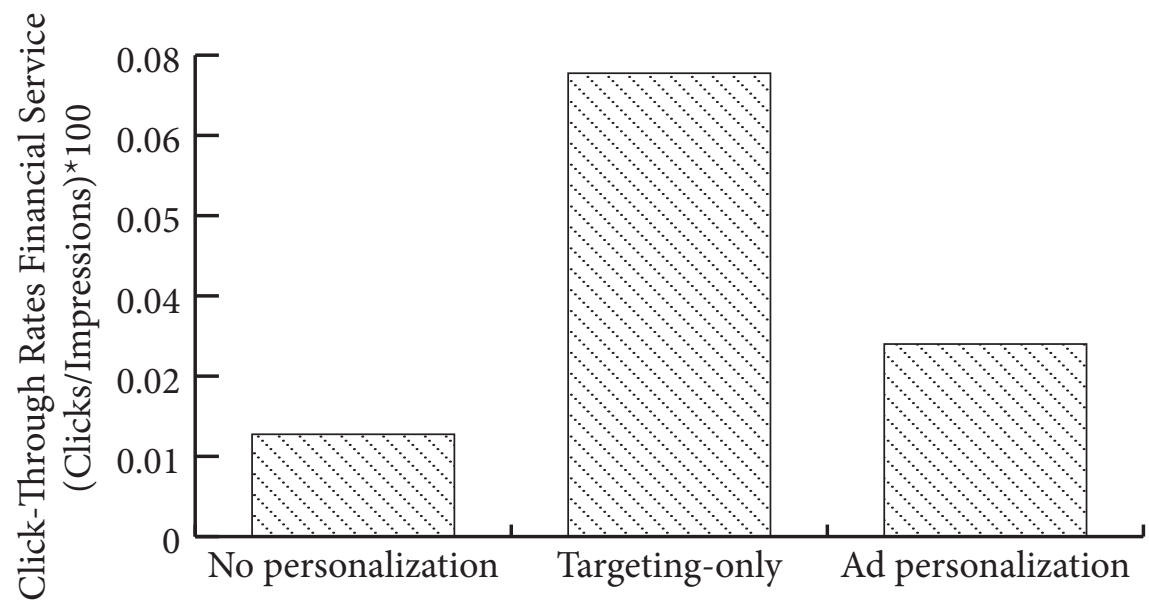

a. Financial Services

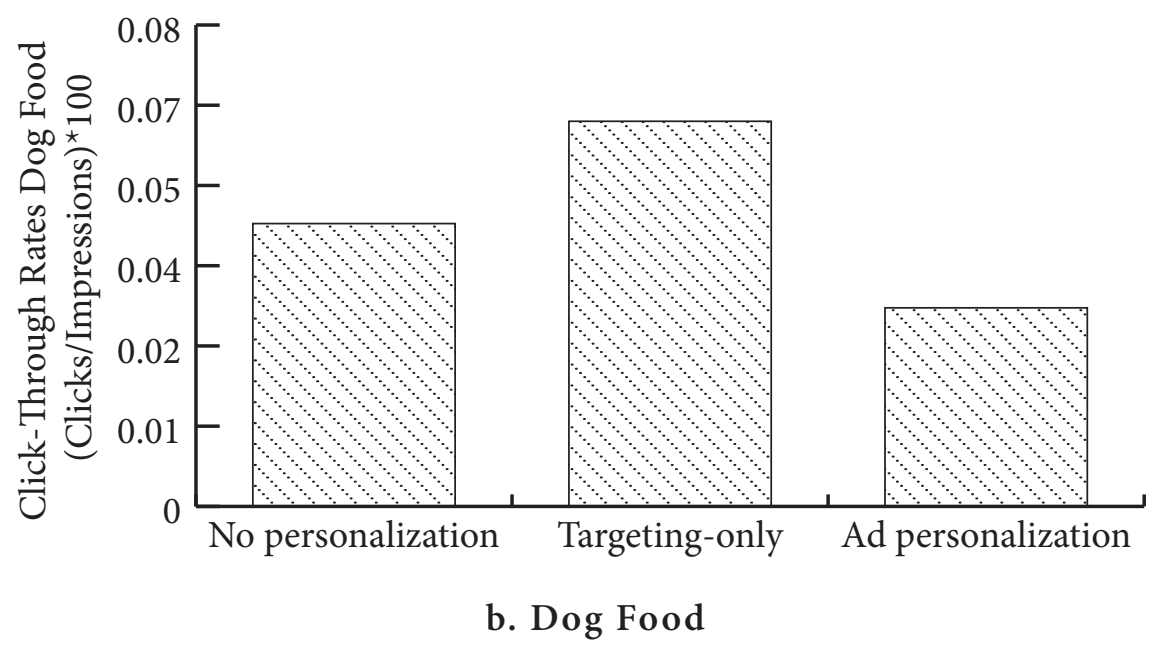

Figure 4.1

Prestudy 1: Click-Through Rates on Different Contexts 


\section{PRESTUDY 2}

In early January 2013, the Dutch government began enforcing its "cookie law," which obliged all websites to inform visitors of their cookie usage policies and receive express permission (DutchNews.nl 2013). Online visitors suddenly confronted evidence of the extent to which their information was being collected, similar to the effects of receiving a highly personalized advertisement. Therefore, reactions to the enforcement of the cookie law might mimic the reactions to the recognition of covert information collection. Accordingly, we acquired the CTR for a personalized advertising campaign run by a Dutch financial services provider over the course of a year. Midway through the campaign, the government began enforcing the cookie law, which created a natural comparison of CTR before and after enforcement.

Specifically, we modeled CTR as exponential functions of the explanatory variables:

$C T R t=\exp \left[\alpha+f(t)+I_{t}{ }^{*} k(t)+\varepsilon t\right]$,

where CTRt indicates the click-through rate (clicks/impressions) on day $t(i=1,2, \ldots, 381)$; $\alpha$ is the intercept to be estimated; $f(t)$ refers to the function that captures the baseline fluctuations, whose parameters must be estimated; $I t$ is an indicator equal to 1 if day $t$ occurred after the cookie law was enacted, and 0 otherwise, for which parameters need to be estimated; $k(t)$ captures the incremental change in CTR due to the enactment of the cookie law, for which the parameters must be estimated; and $\varepsilon t$ is a normally distributed error term.

The results of the analysis (see Figure 4.2) show that CTR significantly drops from the baseline immediately after the introduction of the cookie law (-11\%); after nine weeks, the CTR rebounds, exceeds the initial baseline, and then continues to increase thereafter. That is, right after the initial enforcement of the cookie law, customers reacted negatively to indicators that sparked their realization that their information was being collected without their consent. However, as time passed and people grew accustomed to the data collection, they apparently began to appreciate the transparency provided by the cookie information and increased their CTR. To specify the 
mechanism that drives this phenomenon, we embarked on a series of studies to test the effect when customers consider personalized advertisements, which may create responses similar to those prompted by the Dutch cookie law.

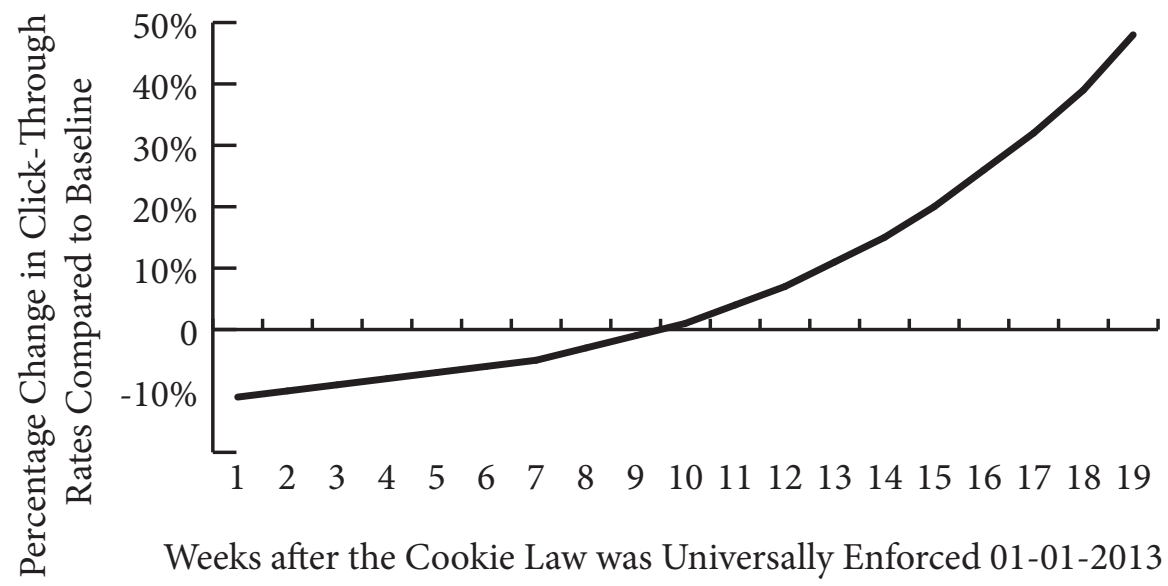

Figure 4.2

Prestudy 2: Percentage Change in Click-Through Rates Due to Cookie Law in the Netherlands

\section{STUDY 1}

With Study 1, we seek to untangle the personalization paradox by testing the predicted interaction effect (personalization $\times$ information collection) by which more personalized advertisements increase click-through intentions when firms openly inform customers of the information collection. We also test whether more personalized advertisements increase perceived vulnerability if firms fail to inform customers of this collection. For these tests, we selected Facebook as the setting, considering the importance of promotions through social media (Shankar et al. 2011) and Facebook's vast popularity (comScore 2011). In a pretest, we identified financial services as an appropriate category to advertise online; respondents perceived their financial information as very sensitive. 


\section{Method}

Design and procedure. One hundred thirty-seven participants from an online panel who were familiar with Facebook completed the survey. Seventeen participants did not meet the quality requirements set in advance (i.e., too little or excessive time examining the advertisement manipulation ${ }^{1}$, too little or too much time completing the survey, such that the respondent appeared to have started and then left off to do something else), so we excluded them from the analysis. (These standards remained constant across all three of our main studies.) Thus, 120 respondents participated in a 2 (less vs. more personalized advertisement) $\times 2$ (overt vs. covert information collection) between-subjects design.

The participants were informed that they would complete a comprehension task to test their ability to recall and understand text presented in two newspaper articles. The first article contained the information collection manipulation; the second was a filler article. After reading each article, the respondents answered three filler questions that tested their comprehension. The varying last paragraph in the first article served to manipulate the study conditions (see Appendix C): Respondents in the overt condition read that Facebook users were aware that Facebook used their data to create personalized advertisements; respondents in the covert condition read that Facebook users were unaware of this usage. Next, we told the respondents that they would be participating in a different study, in which they would imagine that they needed a car loan to purchase a new car and therefore sent a message to a friend through Facebook to ask for information about car loans (see Appendix D). The scenario explained that after sending the message, they would be redirected to Facebook's homepage. This page contained an advertisement either slightly (less personalized) or closely (more personalized) related to the scenario.

Measures. After reviewing the advertisement, participants responded to a click-through intention measure and a five-item perceived vulnerability measure, both on seven-point Likert scales ("strongly agree" to "strongly disagree"). A single item assessed clickthrough intentions: "I would like to click on the advertisement to get further information." Perceived vulnerability was measured using a multi-item, self-reported scale, which we developed for this study 
(see Appendix E) using the suggested procedures for multi-item scale development (Netemeyer, Bearden, and Sharma 2003). Respondents indicated the extent to which the advertisement made them feel "exposed," "unprotected," "susceptible," "unsafe," and "vulnerable" $(\alpha=.88)$.

Results

Manipulation check. Participants completed four items (Dijkstra 2005) to indicate the level of personalization in the advertisement ("This advertisement is directed to me personally"; "I recognize my personal situation in this advertisement"; "This advertisement takes into account the problem I faced"; "This advertisement takes into account my personal situation"; $\alpha=.93$ ). They identified the more personalized condition as significantly more personalized than the less personalized version (Mless $=4.32$, Mmore $=5.00 ; t(118)=-2.53, p$ $=.013)$. Respondents in the overt condition also agreed more strongly with the statements, "Facebook users grant Facebook access to their personal information" (Movert $=5.84, M_{\text {covert }}=4.69 ; t(118)=-4.01, p$ $<.001)$ and "Facebook users are aware that information about them is collected" (Movert $\left.=5.34, M_{\text {covert }}=3.34 ; t(118)=-6.85, p<.001\right)$.

Click-through intentions. We validated our prediction using a between-subjects analysis of variance (ANOVA) with click-through intentions as the dependent variable and personalization, information collection, and their interactions as the independent variables. The main effect of personalization was significant $(F(1,116)=7.79$, $p=.006)$, but that of information collection was not $(F(1,116)=$ 1.87, $p=.174)$. As Figure 4.3, Panel b shows, the personalization $\times$ information collection interaction effect on click-through intentions was significant $(F(1,116)=4.64, p=.033)$, in support of H1. Followup contrasts revealed no difference in click-through intentions when respondents in the covert manipulation received a more rather than less personalized advertisement $($ Mless $=2.94$, Mmore $=3.16 ; F(1,116)=$ $.22, p=.641)$. However, when respondents in the overt manipulation viewed a more personalized advertisement, they reported greater click-through intentions $($ Mless $=2.67$, Mmore $=4.38 ; F(1,116)=$ $11.44, p=.001)$. Thus, the more personalized advertisement in the overt condition increased click-through intentions, but in the covert condition, we found no changes. 


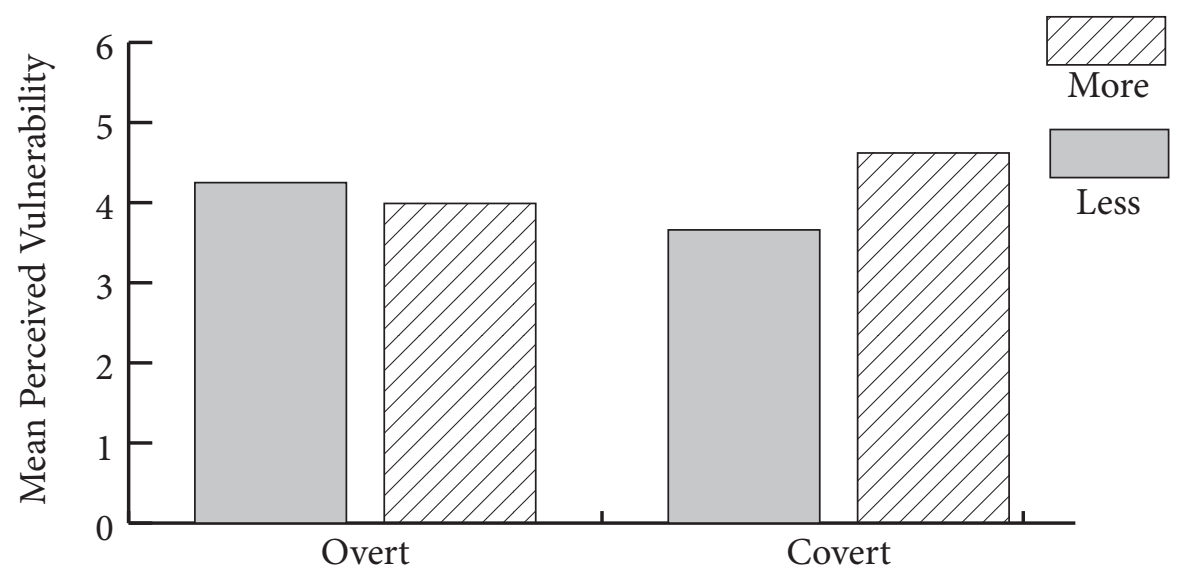

a. Perceived Vulnerability

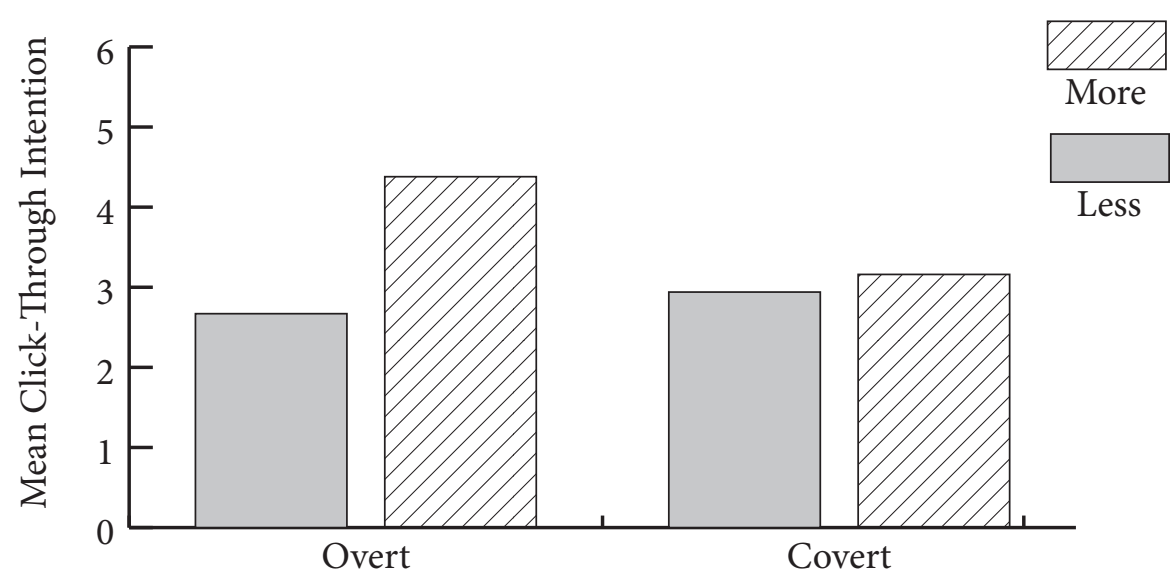

b. Click-Through Intentions

Figure 4.3

Study 1: Effects of Information Collection with Less and More Personalization

Perceived vulnerability. To examine respondents' perceived vulnerability, we used another between-subjects ANOVA, with perceived vulnerability as the dependent variable and personalization, information collection, and their interactions as the independent variables. Neither main effect, of personalization $(F(1,116)=1.92$, $p=.168)$ or information collection $(F(1,116)=.01, p=.946)$, was significant. However, Figure 4.3, Panel a reveals a significant personalization $\times$ information collection interaction effect on 
perceived vulnerability $(F(1,116)=5.88, p=.017)$, in support of $\mathrm{H} 2$. Respondents in the covert condition perceived more vulnerability in the more personalized condition (Mless $=3.66$, Mmore $=4.62 ; F(1,116)=$ $7.80, p=.006)$, whereas respondents in the overt condition perceived no difference in vulnerability (Mless $=4.25$, Mmore $=3.99 ; F(1,116)$ $=.50, p=.479)^{2}$.

Mediation. To determine if perceived vulnerability mediated the effect of the personalization $\times$ information collection interaction on click-through intentions (Muller, Judd, and Yzerbyt 2005; Preacher, Rucker, and Hayes 2007), we ran three regression models. First, the regression with click-through intentions as the dependent variable and personalization, information collection, and their interaction as the independent variables demonstrated a significant personalization $\times$ information collection interaction effect on click-through intentions $(\beta=.37, t(116)=2.15, p=.033)$. Second, a regression with perceived vulnerability as the dependent variable and the same independent variables indicated a significant personalization $\times$ information collection interaction effect, this time on perceived vulnerability $(\beta=$ $-.31, t(116)=-2.42, p=.017)$. Third, adding perceived vulnerability and the interaction between perceived vulnerability and information collection to the first model revealed a significant effect of perceived vulnerability on click-through intentions $(\beta=-.36, t(114)=-2.82$, $p=.006)$. This regression also showed that the interaction between personalization and information collection was no longer significant $(\beta=.25, t(114)=1.45, p=.150)$. The magnitude of the personalization $\times$ information collection interaction decreased from $\beta=.37(t(116)$ $=2.15, p=.033)$ to $\beta=.25(t(114)=1.45, p=.150)$. The conditional indirect effects (Preacher, Rucker, and Hayes 2007) confirmed the mediating role of perceived vulnerability for the covert condition $(z=-2.00, p=.045)$ but not for the overt condition $(z=.66, p=$ $.510)$. Thus, vulnerability mediated the effects of personalization and information collection on click-through intentions, and participants in the covert condition expressed lower click-through intentions because they felt vulnerable ${ }^{3}$, as we summarize in Figure 4.4.

\section{Discussion}

These results provide evidence of the personalization paradox. In some conditions, personalization leads to greater click-through intentions; specifically, and consistent with our prediction, more 


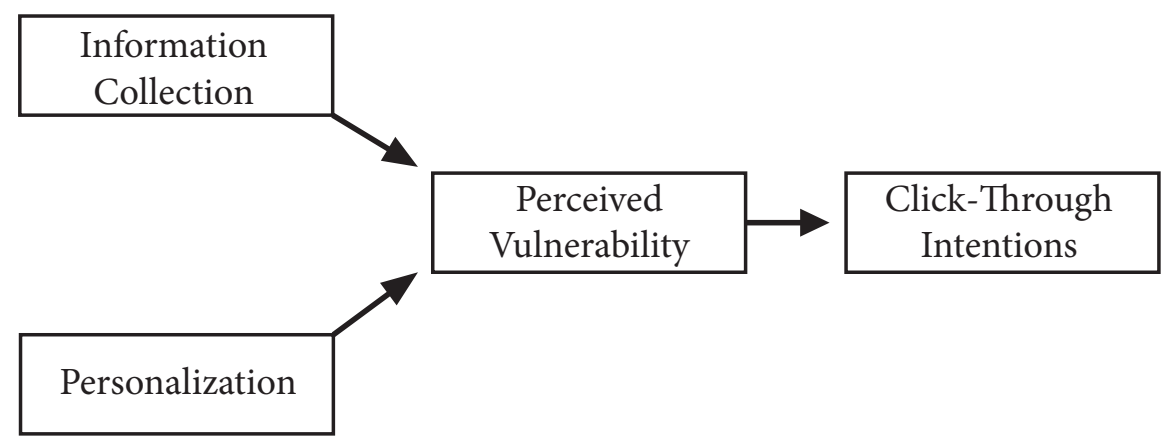

Figure 4.4

Study 1: Mediated Moderation Model

personalization increases click-through intentions when firms overtly collect consumer data to provide personalized services. When firms covertly collect data though, consumers feel more vulnerable when they realize their information has been collected without their permission, which decreases their click-through intentions. Because decreasing this sense of vulnerability can increase the effectiveness of personalized advertising, we next consider how retailers might establish trust as a means to counter the negative effects.

\section{STUDY 2}

The credibility of a website that contains an advertisement strongly influences that advertisement's effectiveness, by determining consumers' perceptions of its value (Aaker and Brown 1972), their attitudes toward the advertisement, and their behavioral intentions (click-through, purchase) (Choi and Rifon 2002; Shamdasani, Stanaland, and Tan 2001). Trust is particularly vital for managing situations that involve vulnerability and potential transactions (Gupta, Yadav, and Varadarajan 2009). Because trust transfers from a website to the advertisements it hosts (Stewart 2003), the setting should influence the effectiveness of a personalized advertisement; McCann Worldwide (2011) cites Facebook as among the least trusted online brands though. In Study 2, to test the prediction that personalized advertisements decrease click-through intentions when firms engage 
in covert data collection if the advertisement appears on a less trustworthy website, we use the popular CNN news website as a more trustworthy site and Facebook as the less trustworthy version. The mediation effects of vulnerability should emerge among participants who view an advertisement on Facebook but not for those who view the same advertisement on CNN.

\section{Method}

Design and procedure. Two hundred fifty-one participants from an online panel who were familiar with Facebook participated in a 2 (less vs. more personalized advertisement) $\times 2$ (overt vs. covert information collection) $\times 2$ (Facebook vs. CNN) betweensubjects design. We used a screening procedure to test their attention and motivation: Participants answered an open-ended question by indicating which website featured the advertisement, and anyone who provided incorrect responses was excluded $(n=25)$. Twenty-seven participants did not meet the preset qualifications and were removed from the analysis, and five participants were excluded because they admitted they did not read the articles. Thus, 194 participants were included in the analysis.

The procedure was similar to that for Study 1: Respondents read two articles, the first of which contained the information collection manipulation. Then they imagined themselves in a car-buying scenario and viewed an advertisement that related either slightly or closely to the scenario. In addition, the advertisement appeared on either Facebook's or CNN's website.

Measures. We measured click-through intentions with a single item, "I would like to click on the advertisement to get further information," using a seven-point Likert scale ("strongly agree" to "strongly disagree"). Then we asked participants to respond to the five-item vulnerability measure from Study $1(\alpha=.93)$.

\section{Results}

Manipulation check. Respondents completed the four items ( $\alpha=$ .90) related to how personalized they considered the advertisement and the two questions about Facebook users' awareness of and consent to information collection. The manipulations again worked as intended, according to the comparisons of more versus less personalized 
advertisements $($ Mless $=4.25$, Mmore $=5.83 ; t(192)=-10.07, p<.001)$ and overt versus covert conditions (awareness Movert $=5.26$, Mcovert $=3.43 ; t(192)=-7.59, p<.001$; consent $M_{\text {overt }}=5.99, M_{\text {covert }}=4.54$; $t(192)=-6.96, p<.001)$. We also asked respondents to indicate the extent to which they trusted Facebook and CNN, using a semantic differential measure ("untrustworthy-trustworthy"). A paired samples t-test revealed that $\mathrm{CNN}$ was significantly more trustworthy than Facebook $($ Macebook $=4.08, \operatorname{MCNN}=4.57 ; t(193)=-3.96, p<.001)$.

Click-through intentions. A between-subjects ANOVA with personalization, information collection, context, and their interactions as independent variables and click-through intentions as the dependent variable revealed a significant main effect for personalization $(F(1,186)=31.95, p<.001)$ but no significant main effect for information collection $(F(1,186)=1.01, p=.315)$ or context $(F(1,186)=1.69, p=.196)$. The two-way interaction between personalization and information collection was marginally significant $(F(1,186)=3.29, p=.071)$, whereas the two-way interactions between context and personalization $(F(1,186)=.32$, $p=.572)$ and context and information collection $(F(1,186)=.04$, $p=.835)$ were both insignificant. The three-way interaction of the independent variables also was not significant $(F(1,186)=1.18, p=$ .278). However, analyzing each context independently, we found that participants displayed lower click-through intentions when highly personalized advertisements, collected covertly, appeared on the less trustworthy website compared with the more trustworthy one ${ }^{4}$. Even though the three-way interaction was not significant, it did not negate the possibility of finding indirect effects through perceived vulnerability (Hayes 2009). Therefore, we explored the mediating role of vulnerability on the relationship between the interaction and click-through intentions.

Mediation. To understand how perceived vulnerability affects click-through intentions in the three-way relationship of personalization, information collection, and context, we conducted a mediation analysis and tested for indirect effects by bootstrapping with 1000 draws using the PROCESS Model 11 (Hayes 2013). We thus confirmed an indirect effect of personalization, through perceived vulnerability, when participants belonged to the covert condition and saw a personalized advertisement on Facebook $(\beta=-.20)$, for which the $95 \%$ confidence interval (CI) excluded zero $(-.45,-.04)$; the same 


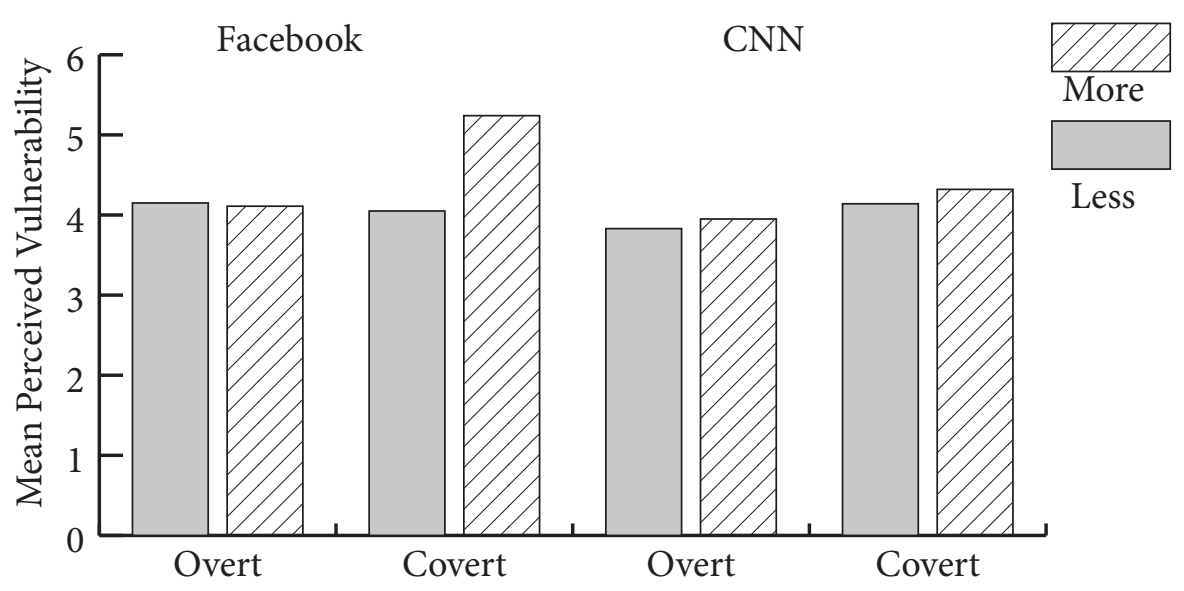

a. Perceived Vulnerability

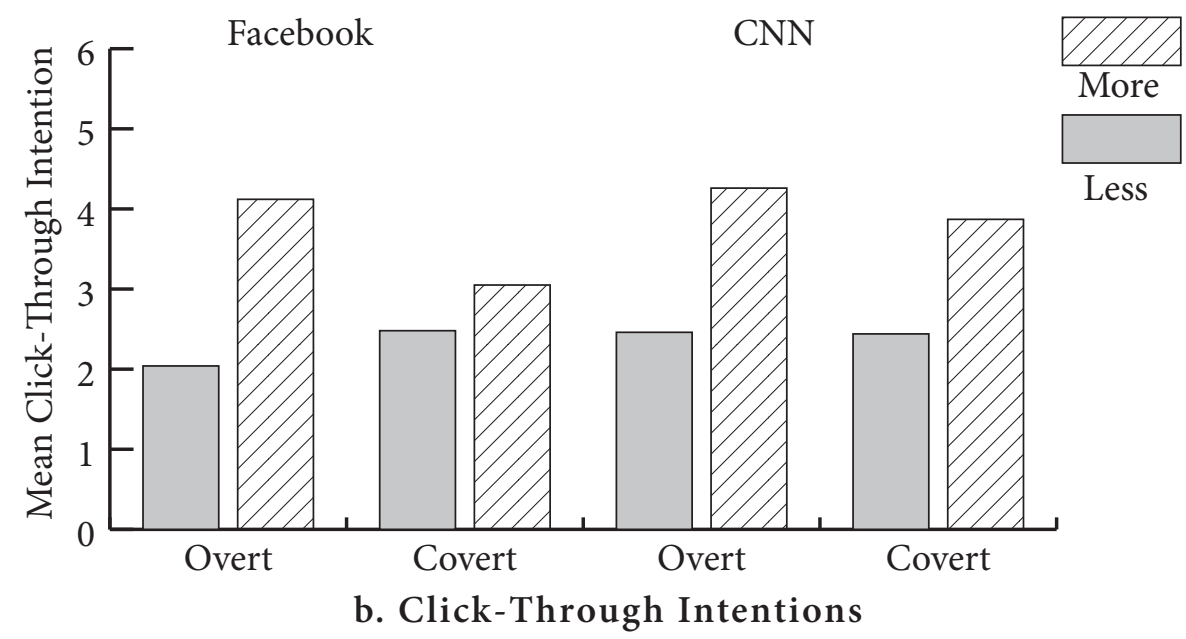

Figure 4.5

Study 2: Effects of Information Collection and Personalization in Different Contexts

effect did not emerge for CNN $(\beta=-.03)$, and the 95\% CI included zero $(-.18, .10)$. For participants in the overt condition, perceived vulnerability did not mediate the influence for either Facebook $(\beta=$ $.01 ; 95 \%$ CI $(-.13, .19))$ or CNN $(\beta=-.02 ; 95 \%$ CI $(-.21, .16))$. Therefore, when firms covertly collect data and present highly personalized advertisements, customers feel vulnerable (see Figure 4.5, Panel a) and express lower click-through intentions (Figure 4.5, Panel b) if 
the advertisements appear on an untrustworthy website but not if they show up on a trustworthy website, in support of $\mathrm{H} 3$.

\section{Discussion}

Study 2 pertains to the differential effects of the medium of an advertisement. We find that the credibility of the website can mitigate the negative effects of covert data collection, in that the results persisted for respondents viewing an advertisement on Facebook, whereas people who viewed the advertisement on $\mathrm{CNN}-$ a more trustworthy website-indicated different click-through intentions. If they were exposed to covert information collection, respondents indicated higher click-through intentions for the more personalized advertisement on the trustworthy site, where they did not feel vulnerable. But Facebook attracts approximately $66 \%$ of the U.S. population (Nielson 2013), and retailers prefer to reach this vast market, so other strategies are needed to offset the vulnerability effect.

\section{STUDY 3}

In response to increasing pressures regarding industry data collection practices, the U.K. Internet Advertising Bureau introduced a selfregulatory program that uses icons to inform users about data collection and usage practices associated with each advertisement, as well as an opt-out mechanism (Internet Advertising Bureau UK 2011). Firms appear to consider this icon an effective means to prevent government regulations, yet to the best of our knowledge, no research has tested its effectiveness empirically. Information icons can signal benevolence and integrity beliefs (Schlosser, White, and Lloyd 2006), two key elements of trust, so we posit that they also might offset the negative effects of covert data collections.

\section{Method}

Design and procedure. One hundred forty participants from an online panel who were familiar with Facebook completed the survey. Seventeen respondents did not meet the preset requirements, leaving a sample of 123 participants in the 2 (overt vs. covert information 
collection $) \times 2$ (icon present vs. absent) between-subjects design. The procedure was similar to that for Study 1: Respondents read two newspaper articles, the first of which contained the information collection manipulation, and then imagined themselves in a car-buying scenario before receiving a highly personalized advertisement. This advertisement contained either no icon or an icon that specified about how their data would be collected, provided an opportunity to learn more about the policies, and offered opt-out choices.

Measures. We used a seven-point Likert scale ("strongly agree" to "strongly disagree") to measure click-through intentions with a single item: "I would like to click on the advertisement to get further information."

\section{Results}

Manipulation check. The manipulations were successful. Respondents in the overt condition agreed more strongly that Facebook users knew about information collection $($ Movert $=5.06$, $M_{\text {covert }}=3.32 ; t(119)=-5.13, p<.001 ;$ two participants did not complete the manipulation checks) and provided consent (Movert $=$ $\left.6.08, M_{\text {covert }}=4.70 ; t(119)=-4.66, p<.001\right)$, and respondents in the icon condition agreed more with the statement, "The ad directed me to more information about Facebook's data use policies" (Micon $=4.47$, Mno_icon $=2.59 ; t(119)=-5.69, p<.001)$.

Click-through intentions. A between-subjects ANOVA featured information collection, icons, and their interaction as independent variables and click-through intentions as the dependent variable. There were no significant main effects but a significant interaction effect $(F(1,119)=4.75, p=.031$; see Figure 4.6). In line with our previous findings, paired contrasts revealed that respondents exposed to the covert (vs. overt) manipulation had significantly lower click-through intentions when they did not see an information icon (Movert $=4.00$, $\left.M_{\text {covert }}=2.96 ; F(1,119)=5.48, p=.021\right)$. However, when respondents were presented with an information icon, the differences in clickthrough intentions between the overt and covert conditions became insignificant $\left(\right.$ Movert $\left.=3.43, M_{\text {covert }}=3.77 ; F(1,119)=.58, p=.448\right)$, in support of $\mathrm{H} 4$. Additional contrasts revealed that respondents in the covert condition who received the information icon expressed significantly higher click-through intentions, at a $10 \%$ significance 
level $\left(\mathrm{Micon}_{\mathrm{i}}=3.77, \mathrm{Mno}_{\mathrm{icon}}=2.96 ; F(1,119)=3.08, p=.082\right)$. We found no differences between respondents in the overt condition who received or did not receive the information icon $(\mathrm{Micon}=3.43$, Mno_icon $=4.00 ; F(1,119)=1.73, p=.190)$.

Discussion

The findings support the conjecture that when firms covertly collect data from customers and use the information to provide highly personalized advertising, it has negative consequences, such as lower click-through intentions. However, if firms take the initiative to inform customers about their data collection procedures, this negative effect disappears, likely because proactive information provision signals the firms' benevolence and reliability (Kim and Kim 2011), increases trust, and thus minimizes the negative effects of covert data collection. That is, firms can mitigate the negative effects of their covert data collection strategies by providing information and control to users at the moment the personalized advertisement appears.

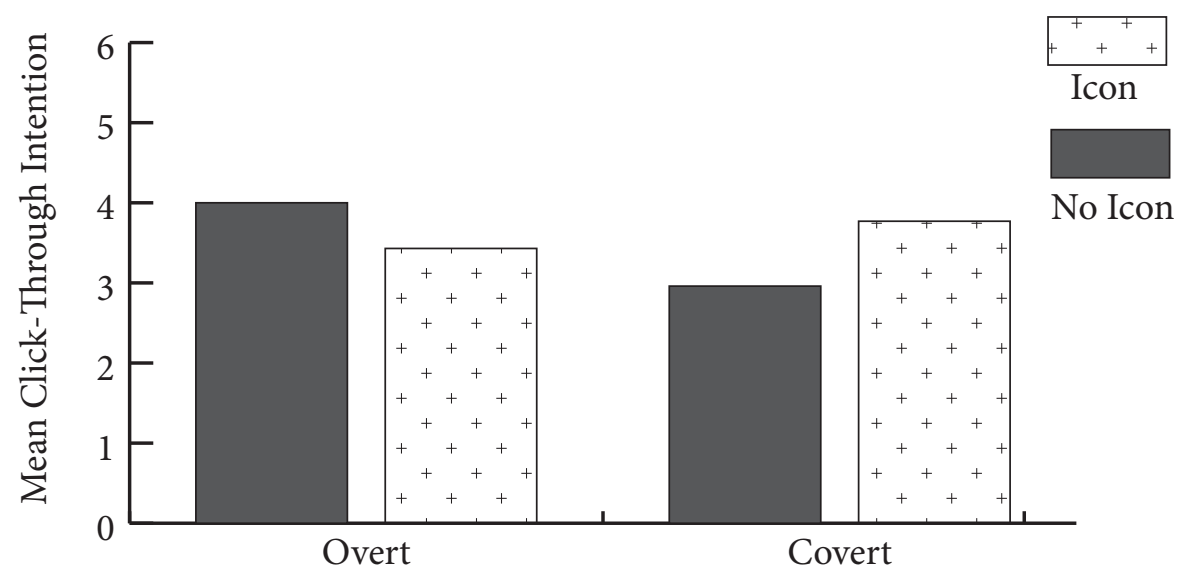

Figure 4.6

Study 3: Effects of Information Collection in the Presence or Absence of an Icon on Click-Through Intentions 


\section{GENERAL DISCUSSION}

With this research, we respond to calls for more empirical generalizations that provide a better understanding of personalization strategies (Grewal et al. 2011). Consistent with prior research (Tam and Ho 2006), we demonstrate that personalization leads to greater click-through intentions-when firms practice overt information collection strategies. When firms practice covert strategies, clickthrough intentions do not change (Studies 1-2), because respondents who were previously unaware of the information collection felt more vulnerable in the face of a highly personalized advertisement. These findings shed light on the personalization paradox and explain why personalization is not always effective. We also demonstrate that the outcomes vary, depending on the credibility of the website on which advertisements appear (Study 2) and the presence of trust-building cues (Study 3).

\section{Implications for Theory}

This study contributes to extant research in three main ways. First, we examine the interaction between information collection and its personalization uses. Prior research offers opposing views of personalization effectiveness (Tam and Ho 2006; White et al. 2008); our field test, secondary data, and main study results help reconcile the debate. When firms openly inform their customers that data collection has taken place, customers find the self-referential and relevant content of the personalized advertisements more useful, so their behavioral intentions improve (Tam and Ho 2006). When consumers are not informed though, customers reject the personalized content and exhibit lower behavioral intentions (White et al. 2008). Even if the firm only informs the customer about its information collection practices as the consumer views the advertisement, the negative reaction disappears. Thus, customer awareness and its accompanying ad hoc consent have central influences on personalization effectiveness.

Second, we show that rejections of personalized services often stem from feelings of vulnerability, which arise when consumers confront a personalized cue. Previous research has relied predominantly on 
reactance theory to explain this phenomenon (Tucker 2014; White et al. 2008), thus ignoring affective responses (Tucker 2012). By applying the theory of psychological ownership, we clarify the influence of an affective vulnerability experience and test its mediating effect. The results reveal mediation, in support of the robustness of these outcomes. Moreover, in line with research on psychological ownership (Pierce, Kostova, and Dirks 2001), we show that ensuring a consumer's right to information and voice in pertinent decisions significantly reduces feelings of vulnerability. This empirical demonstration of vulnerability and its ramifications for personalization strategies extends research on personalization and psychological ownership. Specifically, our findings reveal a central role of vulnerability-which we operationalize with a new scale-in explaining backlash due to personalization. We also offer an initial empirical investigation of the effects of affective consumer responses on personalized services in social networks.

Third, we test the impact of two trust-building strategies that may offset the experience of vulnerability. Faced with information asymmetry, customers rely on trust heuristics to evaluate personalized advertisements (Kim and Kim 2011), so trust-building strategies can counteract the negative effects of covert data collection. If the personalized advertisement appears in a credible context or incorporates information icons that signal trustworthiness, consumers tend to assume they can trust the source.

\section{Implications for Retailers}

The National Retail Federation attributes the growth of online retail sales to retailers' increased ability to use customer information to deliver relevant, targeted marketing. In addition to its theoretical implications, our study offers valuable insights for firms engaging in such online personalization. Retailers, as the most active group using such advertising strategies, should recognize that personalization is not always effective and strategically vary their personalization efforts by carefully selecting which pieces of information to use. For example, firms might rely on information that is generally relevant to a customer but not overly or personally targeted, particularly if they have gathered this latter information from online social network communications. The firms should carefully assess the level of information sensitivity and how closely that information ties to 
each consumer's identity. Both elements likely determine consumer acceptance of a personalization strategy.

We also recommend transparency about when and how consumer data is being collected. Increased media attention and the spread of personalization practices mean that consumers are increasingly aware that firms collect their information, online and offline. When they receive personalized advertising, these consumers likely express more skepticism toward the retailer, especially if it cites information they did not explicitly consent to provide. Consumers believe that they own such personal information, so if retailers gain access to it, they must inform customers about their data collection strategies and seek implied consent, in the form of consumers' continued usage. Customers must be conscious of this decision, which implies that retailers should be proactive in providing comprehensible, visible notifications of their information collection practices.

Despite the importance of such information policies, it is difficult to implement proactive communications in all circumstances and across the various complex relationships on the Web (e.g., among online publishers, retailers, and data brokers). For targeted advertising in social media, firms thus might benefit from placements on trustworthy websites or from the use of an icon, similar to the one in Study 3, included directly in the advertisements. The icons have been advocated by industry associations as a best practice solution (Internet Advertising Bureau UK 2011) but not universally implemented yet. Such actions help build trust though, which has a direct correlation with recommendation intentions, loyalty, and share of wallet (IBM Institute for Business Value 2012). Our findings indicate the need for wider adoption; such tools can offset negative reactions to personalized advertising, enhance website credibility, and make personalized advertising more acceptable.

\section{Limitations and Avenues for Further Research}

The limitations of this study stem largely from the experimental context we used to test our predictions. First, respondents considered a hypothetical buying scenario. Although the scenario resembled reality, consumer decision making in the real world may differ. Second, it is difficult to say whether the results generalize to other contexts, especially those in which the personalization implies different levels 
of information sensitivity (Mothersbaugh et al. 2012). Moreover, online publishers other than Facebook could produce different results. Further research should address these generalization issues.

Additional research also could delve into customer responses to online and offline personalization strategies. Offline data collection typically occurs when the customer tenders a physical loyalty card; online data collection is less transparent, and the nature of online personalization enables retailers to react to the provided information in real time (Dekimpe et al. 2011), with minimal time between data collection and use. These features could affect how customers react to distinct online and offline personalization strategies, which is an interesting avenue for research. As technological innovations constantly push the acceptable boundaries of information collection, it also would be worthwhile to conduct a longitudinal study to gain insights into any changes in what customers define as acceptable.

More research also could explicate the concept of psychological ownership and its influence over consumer behavior. Shu and Peck (2011) argue that this theory can explain many endowment effects documented in prior literature, yet related research remains limited. It would be helpful to determine which personality traits or demographic characteristics might correlate with psychological ownership. We also call for research into potential variations in ownership perceptions toward personal information that cannot be controlled, such as age, gender, and health, compared with that which can be controlled, such as an address, level of education, or financial information.

Finally, the ever-increasing value of advertising through social media ( $\$ 3.8$ billion in 2011; Kharif 2012) suggests the need for more investigations of related issues. Research might consider the role of other network members and their potential influence on the effectiveness of advertising in social media networks. As technology advances, customers can exchange information more easily in real time; a user viewing an advertisement on a social media channel thus may be simultaneously interacting with others. Does this dynamic environment affect advertising success? The size of a network and the strength of the ties within that network also could influence this emerging phenomenon. 


\section{FOOTNOTES}

[1] A prestudy with 108 students in a laboratory setting established the minimum $(11.20 \mathrm{sec})$ and maximum $(29.05 \mathrm{sec})$ time needed to examine the manipulation containing the advertisement. Refer to page 91.

[2] A two-cell post-control condition resulted in no significant differences for the covert conditions pertaining to either clickthrough intentions or vulnerability. Refer to page 94.

[3] We conducted an additional study $(n=39)$ to examine the effects of a cognitive response measure (i.e., privacy) along with the affective response (i.e., vulnerability). All participants saw the covert manipulation but were randomly assigned to view either the less or more personalized advertisement. In addition, the order of the vulnerability and privacy measures were randomized, to avoid order effects. The privacy measure came from Tolchinski et al. (1981; $\alpha=$ .816). The results were substantially the same, with no significant differences between the less and more personalized advertisements for click-through intentions $(p=.507)$, as well as no differences for privacy $(p=.298)$, but a significant difference for vulnerability ( $p$ $=.043$, one-tailed). Refer to page 94 .

[4] Among respondents who viewed the advertisement on Facebook, we found a significant interaction between personalization and information collection $(F(1,92)=4.25, p=.042)$, in support of $H 1$. Click-through intentions among participants in the covert condition remained the same, regardless of the level of personalization (Mless $=2.48$, Mmore $=3.05 ; F(1,92)=1.13, p=.290)$. In contrast, in the overt condition, participants reported greater intentions for a more personalized advertisement $($ Mless $=2.04$, Mmore $=4.12 ; F(1,92)=$ 17.16, $p<.001$ ), as we show in Figure 4.6. When respondents viewed the advertisement on $\mathrm{CNN}$, the interaction effect of personalization and information collection was not significant $(F(1,94)=.263, p=$ $.609)$. Participants in both the covert $($ Mless $=2.44$, Mmore $=3.87$; $F(1,94)=8.55, p=.004)$ and overt $($ Mless $=2.46$, Mmore $=4.26 ; F(1,94)$ $=10.64, p=.002)$ conditions noted significantly higher click-through 
intentions in the more versus less personalized condition. In the more personalized condition, we found no differences across the overt and covert conditions $\left(M_{\text {overt }}=4.26 ; M_{\text {covert }}=3.87 ; F(1,94)=\right.$ $.56, p=.455)$. Refer to page 97. 



\section{CHAPTER 5 \\ Conclusion}




\section{Synopsis}

The goal of this doctoral dissertation is to enrich our understanding of how sharing, amplified by the proliferation of social media, affects the discloser's behaviors. Turning to literature on information disclosure, I consolidate my three manuscripts under the disclosure decision model developed by Omarzu (2000; Figure 5.1); each manuscript corresponds to a stage in the model. This dissertation encompasses issues related to each stage in the process of disclosure decision-making and shows these issues not only impact what and how information is disclosed but also influence other behavioral effects, such as the discloser's short-term purchase behavior and long-term engagement.

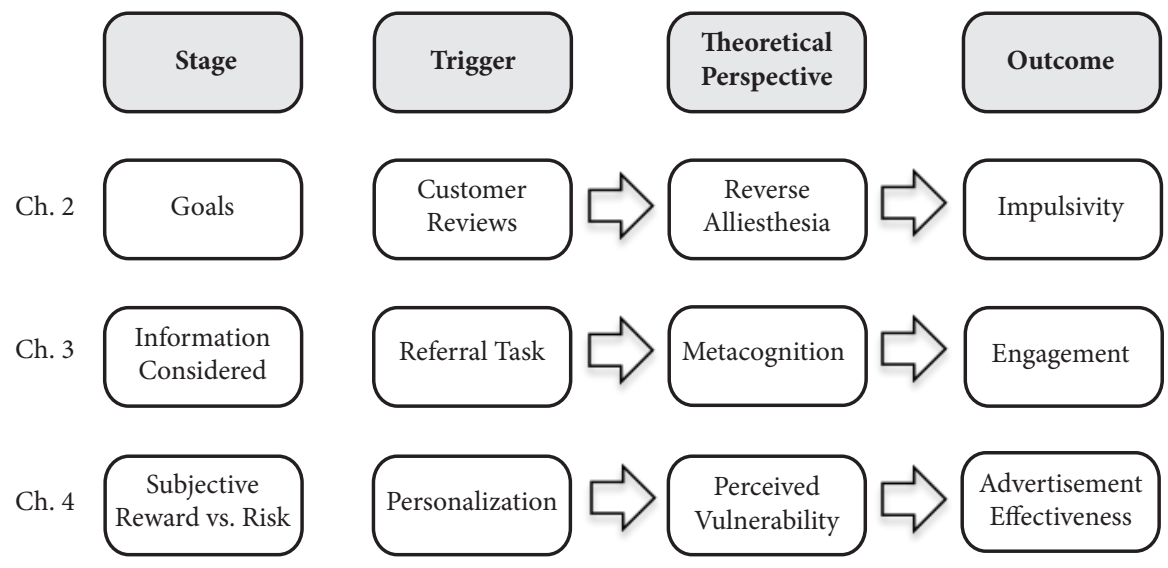

Figure 5.1

Dissertation Overview

In Chapter 2, I focus on how the presence of social cues within customer reviews activates the reward-seeking goal, particularly when the reviewer shares emotional information. I highlight the socially rewarding nature of customer reviews through a series of four experiments and a field study. I find sharing emotional information publicly, compared to expressing it in private, leads to an increase in impulsive behaviors (Studies $1 \mathrm{a}$ and $1 \mathrm{~b}$ ). I extend this finding beyond the experimental setting by demonstrating it in a field study among Amazon.com reviewers (Study 2). I find these impulsive outcomes brought about by a reward drive state can be quelled by prior exposure to other rewards such as praise (Study 3), and individuals who are 
more sensitive to social cues are more likely to be affected by the review-writing process (Study 4). Taken together, these findings provide evidence of the driving force of social rewards and show the negative consequences that can stem from sharing information within social networks.

The findings of Chapter 2 contribute to research on reverse alliesthesia by showing social rewards may also trigger impulsive behaviors. I further enrich theory by showing different types of shared information have differential social rewards attached to them, with emotional information triggering impulsive behaviors. Moreover, I also study how the social reward of praise can offset this negative effect and how individuals who strongly possess the trait of self-monitoring are more affected by review writing.

In Chapter 3, I observe situational cues and individual differences not only impact salient goals, but also have an effect on the type of information that is considered and reflected on. I study how this reflection (metacognition), triggered by writing feedback, has an impact on partner engagement within manufacturer-partner relationships, particularly among those who have a low learning orientation. In a series of three experimental studies collected from participants drawn from a Fortune 100 manufacturer, I find support for the proposition that writing feedback helps to engage low learning oriented partners to pursue additional learning compared to those who are asked to provide their feedback through rating (Study 1). I find this is due to the relevance of information that is reflected upon-when partners write feedback for the benefit of a similar other (Study 2) or write in a focused manner (Study 3) -making partners more confident and increasing their engagement behaviors, as measured by their pursuit of additional learning. Overall, these results demonstrate writing feedback stimulates reflection, which makes the writer certain and more determined to continue to pursue additional learning. This finding has profound implications for how vendors can integrate these insights into their enablement programs.

In Chapter 3, I also enhance research by showing how the feedback writing process can have an impact on writers' behaviors. I find this is a particularly effective tool among partners with low learning orientations because it helps them better engage in metacognitive thinking-not all metacognitive interventions are universally 
effective. Additionally, I find elaboration on relevant information helps partners to strengthen the certainty of their beliefs, as measured by objective text mining methods, with a lasting effect on partners' engagement behaviors.

In Chapter 4, I show along with the benefits of sharing come risks that may make the sharer more vulnerable. This manuscript focuses on how consumers react to the feeling of vulnerability made salient by personalization cues in advertising, by making them realize how the information was collected. In an experimental field study and secondary data, I show personalization does not have a linear relationship with click-through rates, which suggests it is not as straightforward as it may seem (Pre-Study 1); firms experience sharp drops in click-through rates when customers realize that firms used their information without their knowledge (Pre-Study 2). I find support for the propositions that covert information collection makes consumers feel more vulnerable and reduces the effectiveness of personalization strategies (Study 1), and that trust-building cues can mitigate these negative effects, particularly when the personalized advertisement is placed on a credible website (Study 2) or contains an information icon (Study 3). Consequently, this research provides insights into the personalization process and supports government calls to better disclose tracking, as it benefits both customers and firms.

The findings of Chapter 4 contribute to research by highlighting the centrality of both information collection and use in predicting personalization effectiveness. I extend research in this domain by applying psychological ownership theory to show decreases in personalization effectiveness are due to the affective feeling of vulnerability. I further enrich literature in the field by showing how trust-building strategies offset this effect.

\section{Areas of Future Research}

Each manuscript contains specific areas of future research. In this section, I aim to provide a broader scope of research derived from this dissertation by identifying three areas of future beneficial research that span the subjects of the three manuscripts.

First, each manuscript takes into account the presence of others within these digital platforms, whether it is considering others in the review/ 
feedback writing process (Chapter 2 and Chapter 3 ) or considering information collected from these social interactions (Chapter 4). However, in each of these manuscripts, the role of others is stagnant. Given that social media platforms enable social interaction, I believe integrating this vibrant social environment could greatly expand the insights gained from this dissertation. Research could consider the dynamic social environment as customers exchange information in real time. These interactions may strengthen ties and even lead customers to develop their own unique linguistic style (Ludwig et al. 2014). These factors could influence the findings of each of these manuscripts.

Second, the manuscripts in this dissertation do not take into account the dynamic effects of time on consumer behavior. Research that incorporates the time factor would greatly move forward our understanding of the theory, and build upon the insights within each manuscript. Specifically, with regard to Chapter 2, it would aid in further developing the theory of reverse alliesthesia by understanding how the reward drive persists when no rewarding stimuli is present to suppress it. With regard to Chapter 3, this approach could help us understand how long metacognitive effects last in impacting engagement behaviors, and what factors could help sustain them. With regard to Chapter 4, this could help us gain insight into whether customers may get accustomed to certain forms of data collection as they are constantly exposed to it, and, if this is the case, explain this process.

Third, the relevance of this dissertation hinges on advances in technology that have changed the way people share information with others. For instance, the prevalence of social media has allowed individuals to voice their opinions and personal experiences in real time to a limitless audience. This phenomenon has several implications for future research related to the manuscripts in this dissertation.

In Chapter 2, I note sharing emotional information through customer reviews has an impact on impulsive behaviors. However, customer reviews are only one of many digital platforms that allow individuals to express themselves. We see a myriad of other platforms that vary in function and motivation. Twitter users, for example, broadcast their information worldwide (Shi, Rui, and Whinston 2014) and provide both intrinsic and image-related utility (Toubia and Stephen 2013). 
LinkedIn provides users with the ability to professionally network, resulting in both economic and social benefits (Vock, van Dolen, and de Ruyter 2013). Because customers derive different types of rewards and have different motivations within each platform, it would be interesting to study how these factors interact and affect user behavior.

With regard to Chapter 3, new technologies may have implications for which types of information are considered and reflected upon in driving engagement behaviors. Moreover, they may also pave the way for new metacognitive interventions that stimulate self-awareness. For instance, technologies may provide real time information about the progress of the partners as they go through learning modules. This information may help partners monitor their learning and keep them engaged with the program.

In Chapter 4, we see new technologies also give rise to new forms of personal data collection (Čaić et al. 2015) such as location, human visuals via facial recognition, home-device usage, and health care status. These technologies allow firms to gather a variety of information, and combine it with existing information to develop unique insights that can be used to differentiate their customers and provide them with more personalized experiences (Hardy 2014). It would be interesting to understand how customers react to such technologies as they are seamlessly integrated into their lives, when it is difficult for them to know how this information was collected in the first place.

\section{Practical Relevance}

Emerging social platforms are enabling customers to voice their thoughts and feelings, and allowing firms to hear and respond to them. Each chapter of this dissertation provides several practical and relevant insights that result from this phenomenon. In this section, I present three concluding suggestions based on the findings.

First, firms should not underestimate the power of sharing. Sharing has a strong influence on customer buying behavior, and sentiment analysis of what is shared with other customers can help predict product success. But sharing can also have a profound effect on individual posters. As this research has shown, it can have both positive and negative effects. On one hand, it can drive brand engagement by 
helping posters make sense of their experiences. On the other hand, it can be detrimental to posters, as it may expose them to behaviors that threaten their well-being, place them in vulnerable situations, and make them feel exploited by firms. Managers can use the insights from this study to manage both the opportunities and the challenges that sharing may provide to the poster.

Second, there is great debate about who owns posted information. Many firms, such as Facebook, explicitly state in their Terms and Conditions that they hold the rights to the information and can use it in whatever way they deem fit. However, customers believe they hold the rights to their information (Stelter 2009). Regardless of whether firms have rights to this information, users who share content on their sites should be respected, given the appropriate courtesy of being explicitly informed about how their information will be used, and provided with appropriate controls to manage it. The findings of this dissertation show when firms inform their customers and provide them with controls, they reap benefits as their personalization strategies become more effective. These findings support government policies that encourage disclosure of tracking (Goel 2014).

Third, consumer welfare groups and governments should be wary about the growing use of social media. Currently, little is known about how it impacts users. Wilcox and Stephen (2013) have shown greater social network use leads to poorer self-control, particularly among those with strong ties; our findings contribute to this literature stream. Given the potentially negative consequences that may arise from social network use, more efforts are needed to further our understanding of these consequences at both an individual and societal level (i.e., overall health and spending). Moreover, these findings should be clearly communicated to consumers to provide them with greater awareness of the phenomenon, give them with more control, and help them make better decisions. 



\section{References}

Aaker, David A. and Phillip K. Brown (1972), "Evaluating Vehicle Source Effects," Journal of Advertising Research, 12 (4), 11-16.

Accenture (2010), "Next Generation Partner Relationship Management (PRM)." Retrieved on May 1, 2014 from http://www.accenture. com/SiteCollectionDocuments/ PDF/Accenture-Next-GenerationPartner-Management.pdf

Aguirre, Elizabeth, Dominik Mahr, Dhruv Grewal, Ko de Ruyter, and Martin Wetzels (2015), "Unraveling the Personalization Paradox: The Effect of Information Collection and Trust-Building Strategies on Online Advertisement Effectiveness," Journal of Retailing, 91(1), 34-49.

Andreasen, Alan R., Elizabeth Cooper-Martin, and N. Craig Smith (1994), "Who Is the Vulnerable Consumer? The Implications for Marketing and Public Policy of Objective and Subjective Consumer Vulnerability," Working paper.

Angwin, Julia (2012), "Online Tracking Ramps Up," The Wall Street Journal, June 17. Retrieved on September 25, 2012, from http://online.wsj. com/article/ SB100014240527023038364045774772491637833420.html

(2010), “The Web's New Gold Mine: Your Secrets," The Wall Street Journal. Retrieved on January 16, 2015, from http://www.wsj.com/ articles/ SB10001424052748703940904575395073512989404

Ansari, Asim and Carl F. Mela (2003), "E-Customization," Journal of Marketing Research, 40 (2), 131-145.

Anseel, Frederik, Filip Lievens, and Eveline Schollaert (2009), "Reflection as a Strategy to Enhance Task Performance After Feedback," Organizational Behavior and Human Decision Processes, 110 (1), 23-35. 
Applebee, Arthur N. (1984), "Writing and Reasoning," Review of Educational Research, 54 (4), 577-596.

Arnold, Mark J. and Kristy E. Reynolds (2009), "Affect and Retail Shopping Behavior: Understanding the Role of Mood Regulation and Regulatory Focus," Journal of Retailing, 85 (3), 308-320.

Arora, Neeraj, Xavier Dreze, Anindya Ghose, James D. Hess, Raghuram Iyengar, Bing Jing, Yogesh Joshi, V. Kumar, Nicholas Lurie, Scott Neslin, S. Sajeesh, Meng Su, Niladri Syam, Jacquelyn Thomas, and Z. John Zhang (2008), "Putting One-to-One Marketing to Work: Personalization, Customization, and Choice," Marketing Letters, 19 (3-4), 305-321.

Avey, James B., Bruce J. Avolio, Craig D. Crossley, and Fred Luthans (2009), "Psychological Ownership: Theoretical Extensions, Measurement, and Relation to Work Outcomes," Journal of Organizational Behavior, 30 (2), 173-191.

Avnet, Tamar, Michel Tuan Pham, and Andrew T. Stephen (2012), "Consumers' Trust in Feelings as Information," Journal of Consumer Research, 39 (4), 720-735.

Awad, Naveen Farag and M. S. Krishnan (2006), “The Personalization Privacy Paradox: An Empirical Evaluation of Information Transparency and the Willingness to be Profiled Online for Personalization," MIS Quarterly, 30 (1), 13-28.

Bagozzi, Richard P. and Youjae Yi (1988), "On the Evaluation of Structural Equation Models," Journal of the Academy of Marketing Science, 16 (1), 74-94.

Baker, Stacey Menzel, James W. Gentry, and Terri L. Rittenburg (2005), "Building Understanding of the Domain of Consumer Vulnerability," Journal of Macromarketing, 25 (2), 128-139.

Bandyopadhyay, Soumava (2009), "Antecedents and Consequences of Consumers' Online Privacy Concerns," Journal of Business and Economics Research, 7 (3), 41-48.

Barasch, Alixandra and Jonah Berger (2014), "Broadcasting and Narrowcasting: How Audience Size Affects What People Share," Journal of Marketing Research, 51 (3), 286-299. 
Bart, Yakov, Venkatesh Shankar, Fareena Sultan, and Glen L. Urban (2005), "Are the Drivers and Role of Online Trust the Same for All Websites and Consumers? A Large Scale Exploratory Study," Journal of Marketing, 69 (4), 133-152.

Baumeister, Roy F. and Mark R. Leary (1995), “The Need to Belong: Desire for Interpersonal Attachments as a Fundamental Human Motivation," Psychological Bulletin, 117 (3), 497-529.

___ Roy F. (1982), "A Self-Presentational View of Social Phenomenon," Psychological Bulletin, 91 (1), 3-26.

Becherer, Richard and Lawrence M. Richard (1978), "Self-Monitoring as a Moderating Variable in Consumer Behavior," Journal of Consumer Research, 5 (3), 159-162.

Belk, Russell W. (1988), "Possessions and the Extended Self," Journal of Consumer Research, 15 (2), 139-168.

Bell, Simon J., Bülent Mengüç, and Robert E. Wuding II (2010), "Salesperson Learning, Organizational Learning, and Retail Sales Performance," Journal of the Academy of Marketing Science, 38 (2), 187-201.

Bennett, Roger (2009), "Impulsive Donation Decisions During Online Browsing of Charity Websites," Journal of Consumer Behavior, 8 (2-3), 116-134.

Berger, Jonah and Katherine L. Milkman (2012), "What Makes Online Content Viral," Journal of Marketing Research, 49 (2), 192-205.

___ and Eric M. Schwartz, (2011), "What Drives Immediate and Ongoing Word of Mouth?," Journal of Marketing Research, 48 (5), 869-880.

-_- and Baba Shiv (2011), "Food, Sex and the Hunger for Distinction," Journal of Consumer Psychology, 21 (4), 464-472.

Berridge, Kent C. and Terry E. Robinson (1998), "What is the Role of Dopamine in Reward? Hedonic Impact, Reward Learning, or Incentive Salience?," Brain Research Reviews, 28 (3), 309-369.

Bhattacharya, C.B. and Sankar Sen (2003), "Consumer-Company Identification: A Framework for Understanding Consumers' Relationships with Companies," Journal of Marketing, 67 (2), 76-88. 
Brehm, Jack W. (1966). A Theory of Psychological Reactance. New York: Academic Press.

Brocato, E. Deanne, Clay M. Voorhees, and Julie Baker (2012), "Understanding the Influence of Cues from Other Customers in the Service Experience: A Scale Development and Validation," Journal of Retailing, 88 (3), 384-398.

Buss, Arnold H. (1983), "Social Rewards and Personality," Journal of Personality and Social Psychology, 44 (3), 553-563.

Čaić, Martina, Dominik Mahr, Elizabeth Aguirre, Ko de Ruyter, and Martin Wetzels (2015), “Too Close for Comfort": The Negative Effects of Location-Based Advertising," Advances in Advertising Research, (Vol. V). Springer Fachmedien Wiesbaden.

Canavan-Gumpert (1977), "Generating Reward and Cost Orientations Through Praise and Criticism," Journal of Personality and Social Psychology, 35 (7), 501-513.

Channel Marketer Report (2014), "Are You Optimizing Social Media For Your Channel?” April 14. Retrieved on February 4, 2015, from http://channelmarketerreport.com/2014/04/are-you-optimizingsocial-media-for-your-channel

Chellappa, Ramnath K. and Shivendu Shivendu (2010), "Mechanism Design for 'Free' but 'No Free Disposal' Services: The Economics of Personalization under Privacy Concerns," Management Science, 56 (10), 1766-1780.

Chevalier, Judith A. and Dina Mayzlin (2006), "The Effect of Word of Mouth on Sales: Online Book Reviews," Journal of Marketing Research, 43 (3), 345-354.

Cho, Kwangsu, and Charles MacArthur (2011), "Learning by Reviewing," Journal of Educational Psychology, 103 (1), 73-84.

Choi, Sejung Marina and Nora J. Rifon (2002), "Antecedents and Consequences of Web Advertising Credibility: A Study of Consumer Response to Banner Ads," Journal of Interactive Advertising, 3 (1), 12-24. 
Clark, Margaret S. and Carolyn Taraban (1991), "Reactions to and Willingness to Express Emotion in Communal and Exchange Relationships," Journal of Experimental Social Psychology, 27 (4), 324-336.

Collins, Nancy L. and Lynn Carol Miller (1994). "Self-Disclosure and Liking: A Meta-Analytic Review," Psychological Bulletin, 116 (3), 457-475.

comScore (2011), "U.S. Online Display Advertising Market Delivers 1.1 Trillion Impressions in Q1 2011," May 4. Retrieved on September 24, 2012, from http://www.comscore.com/Press_Events/Press_ Releases/2011/5/U.S._Online_Display_Advertising_Market_ Delivers_1.1_Trillion_Impressions_in_Q1_2011

Cozby, Paul C. (1973), “Self-Disclosure: A Literature Review," Psychological Bulletin, 79 (2), 73-91.

CSO Insights (2014), "Optimizing Channel Partner Sales Effectiveness." Retrieved on August 18, 2014 from http://www.treehousei.com/ contact/ resource.aspx?dlid=L7PZIZIKEF2EN\&dlnm $=$ White $\% 2 b$ Paper\%2b-\%2bOptimizing\%2bChannel\%2bPartner\%2bSales\%2b Effectiveness

Dekimpe, Marnik G., Katrijn Gielens, Jagmohan Raju, and Jacquelyn S. Thomas (2011), "Strategic Assortment Decisions in InformationIntensive and Turbulent Environments," Journal of Retailing, 87 (S1), S17-S28.

Deloitte (2012), “The Engagement Economy: How Gamification in Reshaping Business." Retrieved on June 15, 2014 from http://www. deloitte.com/view/en_US/ us/Insights/Browse-by-Content-Type/ deloitte-review/ c7cee86d96498310VgnVCM1000001956f00aRCRD. htm

Derlega, Valerian J., Sandra Metts, Sandra Petronio, Stephen T. Margulis (1993), Self-Disclosure. Newbury Park: CA: Sage.

Dijkstra, Arie (2005), "Working Mechanisms of Computer-Tailored Health Education: Evidence from Smoking Cessation," Health Education Research, 20 (5), 527-539. 
Dinev, Tamara and Paul Hart (2004), "Internet Privacy Concerns and Their Antecedents: Measurement Validity and a Regression Model," Behavior and Information Technology, 23 (6), 413-422.

Dubois, David, Derek D. Rucker, and Zakary L. Tormala (2011), "From Rumors to Facts, and Facts to Rumors: The Role of Certainty Decay in Consumer Communications," Journal of Marketing Research, 48 (6), 1020-1032.

Duggan, Maeve, Nicole B. Ellison, Cliff Lampe, Amanda Lenhart, and Mary Madden (2015), "Social Media Update 2014," Pew Research Center, January 9. Retrieved on February 4, 2015, from http://www. pewinternet.org/2015/01/09/social-media-update-2014

DutchNews.nl (2013), "Dutch Cookie Law to be Watered Down," May 20. Retrieved on August 13, 2013, from http://www.dutchnews.nl/news/ archives/2013/05/dutch_cookie_law_to_be_watered.php

Dweck, Carol S. (1986), "Motivational Processes Affect Learning," American Psychologist, 41 (10), 1040-1048.

- - and Ellen L. Leggett (1988), "A Social-Cognitive Approach to Motivation and Personality," Psychological Review, 95 (2), 256-273.

Elliot, Andrew J. and Marcy A. Church (1997), "A Hierarchical Model of Approach and Avoidance Achievement Motivation," Journal of Personality and Social Psychology, 72 (1), 218-232.

eMarketer (2013), "Amazon Earned Over $\$ 600$ Million in Ad Revenue Last Year," June 4. Retrieved on May 29, 2014 from http://www. emarketer.com/Article/ Amazon-Earned-Over-600-Million-AdRevenue-Last-Year/1009940

EMC $^{2}$ (2014), “The EMC Privacy Index.” Retrieved on February 4, 2015 from http://estonia.emc.com/collateral/brochure/privacy-indexglobal-in-depth-results.pdf

Essex, Mike (2011), "20 Ways to Get Reviews From Customers," Econsultancy.com, October 10. Retrieved on January 27, 2015 from https://econsultancy.com/blog/8109-20-ways-to-get-reviews-fromcustomers 
Evans, Christina, J., John R. Kirby, and Leandre R. Fabrigar (2003), "Approaches to Learning, Need for Cognition, and Strategic Flexibility among University Students," The British Psychological Society, 73 (4), 507-528.

Fitzsimons, Gavan J. and Donald R. Lehmann (2004), "Reactance to Recommendations: When Unsolicited Advice Yields Contrary Responses," Marketing Science, 23 (1), 82-94.

Flavell, John H. (1979), "Metacognition and Cognitive Monitoring: A New Area of Cognitive-Developmental Inquiry," American Psychologist, 34 (10), 906-911

Foirletta, Alicia (2012), "Social Media Playing a Starring Role in Partner Marketing," Channel Marketer Report, March 21. Retrieved on November 4, 2014 from http://channelmarketerreport.com/2012/03/ social-media-playing-a-starring-role-in-partner-marketing/

Ford, J. Kevin, Eleanor M. Smith, Daniel A. Weissbein, Stanley M. Gully, and Eduardo Salas (1998), "Relationships of Goal Orientation, Metacognitive Activity and Practice Strategies With Learning Outcomes and Transfer," Journal of Applied Psychology, 83 (2), 218-233.

Fornell, Claes and David Larcker (1981), "Evaluating Structural Equation Models with Unobservable Variables and Measurement Error," Journal of Marketing Research, 18 (1), 39-50.

Forrester (2013), "The Forrester WaveTM: Partner Relationship Management (PRM) Platforms, Q4 2013." Retrieved on November 4, 2014 from https://www.forrester.com/The+Forrester+Wave+P artner+Relationship+Management+PRM+Platforms+Q4+2013/ fulltext/-/E-RES91761

Förster, Jens (2012), "GLOMOSYS: The How and Why of Global and Local Processing," Current Directions in Psychological Science, 21 (1), 15-19. and Markus Denzler (2012), "Sense Creative! The Impact of Global and Local Vision, Hearing, Touching, Tasting and Smelling on Creative and Analytic Thought," Social Psychological and Personality Science, 3 (1), 108-117. 
Gable, Shelly L. and Harry T. Reis (2010), "Good News! Capitalizing on Positive Events in an Interpersonal Context," Advances in Experimental Social Psychology, 42, 195-257.

Gangestad, Steven W. and Mark Snyder (2000), "Self-Monitoring: Appraisal and Reappraisal," Psychological Bulletin, 126 (4), 530-555.

Garg, Nitika, Brian Wansink, and J. Jeffrey Inman (2007), “The Influence of Incidental Affect on Consumers' Food Intake," Journal of Marketing, 71 (1), 194-206.

Garson, G. David (2012), Hierarchical Linear Modeling: Guide and Applications. Thousand Oaks, CA: SAGE Publications, Inc.

Glogger, Inga, Rolf Schwonke, Lars Holzäpfel, Natthias Nückles, and Alexander Renkl (2012), "Learning Strategies Assessed by Journal Writing: Prediction of Learning Outcomes by Quantity, Quality, and Combinations of Learning Strategies," Journal of Educational Psychology, 104 (2), 452-468.

Goel, Vindu (2014), "Some Privacy Please? Facebook, Under Pressure, Gets the Message," The New York Times, May 22. Retrieved on February 4, 2015, from http://www.nytimes.com/2014/05/23/technology/ facebook-offers-privacy-checkup-to-all-1-28-billion-users.html

Golder, Peter N., Debanjan Mitra, and Christine Moorman (2012), "What Is Quality? An Integrative Framework of Processes and States," Journal of Marketing, 76 (4), 1-23.

Goldfarb, Avi and Catherine Tucker (2011), "Online Display Advertising: Targeting and Obtrusiveness," Marketing Science, 30 (3), 389-404.

Grant, Anthony M., John Franklin, and Peter Langford (2002), “The Self-Reflection and Insight Scale: A New Measure of Private SelfConsciousness," Social Behavior and Personality, 30 (8), 821-836.

Grewal, Dhruv, Kusum L. Ailawadi, Dinesh Gauri, Kevin Hall, Praveen Kopalle, and Jane R. Robertson (2011), "Innovations in Retail Pricing and Promotions," Journal of Retailing, 87 (S1), S43-S52.

Gupta, Pranjal, Manjit S. Yadav, and Rajan Varadarajan (2009), "How Task-Facilitative Interactive Tools Foster Buyers' Trust in Online Retailers: A Process View of Trust Development in the Electronic Marketplace," Journal of Retailing, 85 (2), 159-176. 
Harber, Kent D. and Dov J. Cohen (2005), "The Emotional Broadcaster Theory of Social Sharing," Journal of Language and Social Psychology, 24 (4), 382-400.

Hardesty, David M., William O. Bearden, and Jay P. Carlson (2007), "Persuasion Knowledge and Consumer Reactions to Pricing Tactics," Journal of Retailing, 83 (2), 199-210.

Hardy, Quentin (2014), "How Urban Anonymity Disappears When All Data is Tracked," The New York Times, April 19. Retrieved on June 30, 2014 from http://bits.blogs.nytimes.com/2014/04/19/howurban-anonymity-disappears-when-all-data-is-tracked/? module $=$ Search \&mabReward=relbias\%3As\%2C\%5B\%22RI\%3A6\%22\%2C \%22RI\%3A $18 \% 22 \% 5 \mathrm{D}$

Hawkings, Gary (2012), "Will Big Data Kill All But the Biggest Retailers?” Harvard Business Review, September 18. Retrieved on September 25, 2012, from http://blogs.hbr.org/cs/2012/09/ will_big_data_kill_ all_but_the.html

Hayes, Andrew F. (2013), "PROCESS: A Versatile Computational Tool for Observed Variable Mediation, Moderation, and Conditional Process Modeling," White paper. http://www.afhayes.com/public/ process2012.pdf

___(2009), "Beyond Baron and Kenny: Statistical Mediation Analysis in the New Millennium," Communication Monographs, 76 (4), 408-420.

Henderlong, Jennifer and Mark R. Lepper (2002), "The Effects of Praise on Children's Intrinsic Motivation: A Review and Synthesis," Psychological Bulletin, 128 (5), 774-795.

Hennig-Thurau, Thorsten, Kevin P. Gwinner, Gianfranco Walsh, and Dwayne D. Gremler (2004), "Electronic Word-of-Mouth Via Customer-Opinion Platforms: What Motivates Consumers To Articulate Themselves on the Internet," Journal of Interactive Marketing, 18 (1), 38-52.

Hicks, Robert A., Maralee J. Hicks, and Harold Mansfield (1969), "A MultiSolution Anagram Task," Psychological Reports, 24 (2), 671-674.

Higgins, E. Tory (2006), "Value from Hedonic Experience and Engagement," Psychological Review, 113 (3), 439-460. 
Hox, Joop (2002), Multilevel Analysis: Techniques and Applications. Mahwah, NJ: Lawrence Erlbaum Associates.

IBM Institute for Business Value (2012), "Winning Over the Empowered Consumer: Why Trust Matters." Retrieved on September 5, 2013 from http://www.nrf.com/modules.php? name=News\&op=viewlive\&sp_ id $=1343 \&$ \&arent_id $=960$ \&peer_rev $=1 \&$ nrf_or $=0$

Interactive Advertising Bureau (2012), “Internet Ad Revenues Hit \$31 Billion in 2011, Historic High Up 22\% Over 2010 Record Breaking Numbers," April 18. Retrieved on September 21, 2012, from http:// www.iab.net/about_the_iab/recent_press_releases/ press_release_ archive/press_release/pr-041812

Internet Advertising Bureau UK (2011), "Europe Commits to SelfRegulation," April 14. Retrieved on June 14, 2012, from http://www. iabuk.net/news/europe-commits-to-self-regulation.

Interactive Advertising Bureaux Europe (2011), "IAB Europe Urges EU Member States to Consider Negative Impact of an Overly Strict Consent for Cookies (and Other Storing Technologies)," June 10. Retrieved on July 6, 2012, from http://www.iabeurope.eu/publicaffairs/e-privacy-directive/cookiedemosite-061011.aspx

Jacobs, Janis E. and Scott G. Paris (1987), "Children's Metacognition About Reading: Issues in Definition, Measurement, and Instruction," Educational Psychologist, 22 (3\&4), 255-278.

James, William (1981). The Principles of Psychology: Volume I, Cambridge, MA: Harvard University Press.

John, Leslie K., Alessandro Acquisti, and George Loewenstein (2011), "Strangers on a Plane: Context-Dependent Willingness to Divulge Sensitive Information," Journal of Consumer Research, 37 (5), 858-873.

Jost, John T., Arie W. Kruglanski and Thomas O. Nelson (1998), "Social Metacognition: An Expansionist Review," Personality and Social Psychology Review, 2 (2), 137-154.

Karmarkar, Uma R. and Zakary L. Tormala (2009), "Believe Me, I Have No Idea What I'm Talking About: The Effects of Source Certainty on Consumer Involvement and Persuasion," Journal of Consumer Research, 36 (6), 1033-1049. 
Kaufman, Micha (2012), "The Power of Sharing in the Internet Economy," Forbes, November 30. Retrieved on May 28, 2014 from http://www. forbes.com/sites/ michakaufman/2012/11/30/the-power-of-sharingin-the-internet-economy

Kenton, Chris (2014), "Engaging Channel Partners with Social Media," SocialRep, April 4. Retrieved on February 4, 2015, from http://www. socialrep.com/blog/ engaging-channel-partners-social-media

Kharif, Olga (2012), "Social-Media Ad Spending to Jump to $\$ 9.8$ Billion in 2016," Bloomberg, May 15. Retrieved on October 10, 2012, from http://www.bloomberg.com/news/2012-05-15/social-media-adspending-to-jump-to-9-8-billion-in-2016.html

Kim, Kyongseok and Jooyoung Kim (2011), “Third-Party Privacy Certification as an Online Advertising Strategy: An Investigation of the Factors Affecting the Relationship between Third-Party Certification and Initial Trust," Journal of Interactive Marketing, 25 (3), 145-158.

Kim, B. Kyu and Gal Zauberman (2013), “Can Victoria’s Secret Change the Future? A Subjective Time Perception Account of Sexual-Cue Effects on Impatience," Journal of Experimental Psychology, 142 (2), 328-335.

Kitroeff, Natalie (2014), "Why That Video Went Viral," The New York Times, May 19. Retrieved on February 4, 2015, from http://www.nytimes. com/2014/05/20/science/why-that-video-went-viral.html?_r=0

Klein, Perry D. (1999), "Reopening Inquiry into Cognitive Processes in Writing-To-Learn," Educational Psychology Review, 11 (3), 203-270.

Kohli, Ajay K., Tasadduq A. Shervani, and Goutam N. Challagalla (1998), "Learning and Performance Orientation of Salespeople: The Role of Supervisors," Journal of Marketing Research, 35 (2), 263-274.

Kotler, Philip (2011), "Reinventing Marketing to Manage the Environmental Imperative," Journal of Marketing, 75 (4), 132-135. 
KPMG (2011), "Leading Practices in Effective Channel Management." Retrieved on May 1, 2014 from https://www.kpmg.com/DK/da/ nyheder-og-indsigt/nyhedsbreve-og-publikationer/publikationer/ brancher/ice/Documents/leading-practices-in-effective-channelmanagement.pdf

Kuhrt, Bonnie L. and Pamela J. Farris (1990), "Empowering Students through Reading, Writing, and Reasoning," Journal of Reading, 33 (6), 436-441.

Lane4 (2012), “Talent Tactics: How Can You Plug the Talent Gap?” June. Retrieved on June 4, 2014 from http://www.lane4performance.com/ NewsDetail.aspx itemid $=970 \&$ itemTitle $=$ Talent + Tactics\&sitesectio nid $=92 \&$ sitesectiontitle $=$ White + Papers

Lastovicka, John L., Lance A. Bettencourt, Renée Shaw Hughner, and Ronald J. Kuntze (1999), "Lifestyle of the Tight and Frugal: Theory and Measurement," Journal of Consumer Research, 26 (1), 85-98.

Laurenceau, Jean-Philippe, Lisa Feldman Barrett, and Paula R. Pietromonaco (1998), "Intimacy as an Interpersonal Process: The Importance of Self-Disclosure, Partner Disclosure, and Perceived Partner Responsiveness," Journal of Personality and Social Psychology, 74 (5), 1238-1251.

Lee, Jaehoon and L. J. Shrum (2012), "Conspicuous Consumption Versus Charitable Behavior in Response to Social Exclusion: A Differential Needs Explanation," Journal of Consumer Research, 39 (3), 530-544.

Lerouge, Davy, and Luk Warlop (2006), "Why It Is So Hard to Predict our Partner's Product Preferences: The Effect of Target Familiarity on Prediction Accuracy," Journal of Consumer Research, 33 (3) , 393-402.

Li, Lan, Xiongyi Liu, and Allen L. Steckelberg (2010), “Assessor or Assessee: How Student Learning Improves by Giving and Receiving Peer Feedback," British Journal of Educational Technology, 41 (3), 525-536.

Li, Xiuping (2008), "The Effects of Appetitive Stimuli on Out-of-Domain Consumption Impatience," Journal of Consumer Research, 34 (5), 649-656. 
Li, Zhan G. and Rajiv P. Dant (1999), "Effects of Manufacturers' Strategies on Channel Relationships," Industrial Marketing Management, 28 (2), 131-143.

Long, J. Scott, and Jeremy Freese (2006), Regression Models for Categorical and Limited Dependent Variables using Stata. College Station, TX: Stata Press.

Ludwig, Stephan, Ko de Ruyter, Dominik Mahr, Martin Wetzels, Elisabeth C. Brüggen, and Tom de Ruyck (2014), "Take Their Word for It: The Symbolic Role of Linguistic Style Matches in User Communities," MIS Quarterly, 38 (4), 1201-1217.

-_ Ko de Ruyter, Mike Friedman, Elisabeth Bruggen, Martin Wetzels, and Gerard Pfann (2013), "More than Words: The Influence of Affective Content and Linguistic Style Matches in Online Reviews on Conversion Rates," Journal of Marketing, 77 (1), 87-103.

Lwin, May O., Andrea J.S. Stanaland, and Anthony D. Miyazaki (2008), "Protecting Children's Privacy Online: How Parental Mediation Strategies Affect Website Safeguard Effectiveness," Journal of Retailing, 84 (2), 205-217.

Magnifico, Alecia Marie (2010), "Writing for Whom? Cognition, Motivation, and a Writer's Audience," Educational Psychologist, 45 (3), 167-184.

Maritz (2013), "How to Create True Loyalty in the Channel." Retrieved August 8, 2014 from http://www.maritzmotivation.com/ /media/ Files/MaritzMotivationSolutions/White-Papers/How-to-CreateTrue-Loyalty_rev.ashx

(2012), "The Power of Play: How Gamification Will Drive the Evolution of Channel Loyalty." Retrieved on June 5, 2014 from http://www.maritzmotivation.com/ /media/Files/MaritzDotCom/ White\%20Papers/Motivation/The-Power-of-Play_How-GamificationWill-Drive-the-Evolution-of-Channel-Loyalty.pdf

McAuley, Julian and Jure Leskovec (2013), "Hidden Factors and Hidden Topics: Understanding Rating Dimensions with Review Text," Proceedings of the 7th ACM Conference on Recommender Systems, 165-172. 
McCann Worldwide (2011), "The Truth About Privacy," Retrieved on July 10, 2012, from http://truthcentral.mccann.com/truth-studies/\#thetruth-about-privacy.

Mikulincer, Mario and Orna Nachshon (1991), "Attachment Styles and Patters of Self-Disclosure," Journal of Personality and Social Psychology, 61 (2), 321-331.

Milne, George R., Shalini Bahl, and Andrew Rohm (2008), "Toward a Framework for Assessing Covert Marketing Practices," Journal of Public Policy and Marketing, 27 (1), 57-62.

Miyazaki, Anthony D. (2008), "Online Privacy and the Disclosure of Cookie Use: Effects on Consumer Trust and Anticipated Patronage," Journal of Public Policy and Marketing, 27 (1), 19-33.

Monetate (2012), "Maximize Online Sales with Product Recommendations." Retrieved on February 4, 2015, from http://content.monetate. $\mathrm{com} / \mathrm{h} / \mathrm{i} / 12311883$-maximize-online-sales-with-productrecommendations\#axzz2IdJfsKau

Montgomery, Alan. L. and Michael D. Smith (2009), "Prospects for Personalization on the Internet," Journal of Interactive Marketing, 23 (2), 130-137.

Moon, Youngme (2000), "Intimate Exchanges Using Computers to Elicit Self-Disclosure from Consumers," Journal of Consumer Research, 26 (4), 323-339.

Mothersbaugh, David L., William K. Foxx II, Sharon E. Beatty, and Sijun Wang (2012), "Disclosure Antecedents in an Online Service Context: The Role of Sensitivity of Information," Journal of Service Research, 15 (1), 76-98.

Mudambi, Susan M. and David Schuff (2010), "What Makes a Helpful Online Review? A Study of Customer Reviews on Amazon.com," MIS Quarterly, 34 (1), 185-200.

Muller, Dominique, Charles M. Judd, and Vincent Y. Yzerbyt (2005), "When Moderation Is Mediated and Mediation Is Moderated," Journal of Personality and Social Psychology, 89 (6), 852-863. 
Murthi, B.P.S. and Sumit Sarkar (2003), "The Role of the Management Sciences in Research on Personalization," Management Science, 49 (10), 1344-1362.

National Employment Savings Trust (2013), "Impulse-Buy Brits Spend E6.2 Billion on Things They Don’t Use." Retrieved on November 14, 2014 from http://www.nestpensions.org.uk/ schemeweb/NestWeb/ includes/public/news/Impulse-buy-Brits.html

National Retail Federation (n.d.), "Comments of The National Retail Federation and Shop.org Before the Federal Trade Commission on Preliminary FTC Staff Report: 'Protecting Consumer Privacy in an Era of Rapid Change' A Proposed Framework for Businesses And Policymakers." Retrieved on September 4, 2013, from http://ftc.gov/ os/comments/privacyreportframework/00419-58061.pdf

Naylor, Rebecca Walker, Cait Poynor Lamberton, and David A. Norton (2011), "Seeing Ourselves in Others: Reviewer Ambiguity, Egocentric Anchoring, and Persuasion," Journal of Marketing Research, 48 (3), 617-631.

Netemeyer, Richard G., William O. Bearden, and Subhash Sharma (2003). Scaling Procedures: Issues and Applications, Thousand Oaks, CA: Sage Publications.

Nielson (2013), “Top 10 List for Global Web Parent Companies,” May. Retrieved on August 13, 2013, from http://www.nielsen.com/us/ en/top 10s.html.

___ (2012), "State of the Media: The Social Media Report." Retrieved on November 27, 2014 from http://www.nielsen.com/us/en/insights/ reports/2012/state-of-the-media-the-social-media-report-2012.html

Nitkin, Jana and Alexandra M. Freund (2010), "When Wanting and Fearing Go Together: The Effect of Co-Occurring Social Approach and Avoidance Motivation on Behavior, Affect, and Cognition," European Journal of Social Psychology, 40 (5), 783-804.

Omarzu, Julia (2000), "A Disclosure Decision Model: Determining How and When Individuals Will Self-Disclose," Personality and Social Psychology Review, 4 (2), 174-185. 
Oracle (2009), "Maximizing Revenues Through Your Indirect Channels." Retrieved on February 4, 2015, from http://www.oracle.com/us/ products/applications/ siebel/039712.pdf

Palmatier, Robert W., Rajiv P. Dant, and Dhruv Grewal (2007), "A Comparative Longitudinal Analysis of the Theoretical Perspectives of Interorganizational Relationship Performance," Journal of Marketing, $71(4), 172-194$

__ _ _ _ _ _ a and Kenneth R. Evans (2006), "Factors Influencing the Effectiveness of Relationship Marketing: A Meta-Analysis," Journal of Marketing, 70 (4), 136-153.

Pan, Yue and George M. Zinkhan (2006), "Exploring the Impact of Online Privacy Disclosures on Consumer Trust," Journal of Retailing, 82 (4), 331-338.

Paul, Lauren Gibbons (2013), "Driving Channel Partner Loyalty and Performance," Bloomberg Business Week Research Services, February. Retrieved March 27, 2015 from http://www.sap.com/bin/sapcom/ en_ca/downloadasset.2013-03-mar-12-13.sap-partneredge-channelpartner-loyalty-program-bloomberg-businessweek-pdf.html

Pavlou, Paul A. (2011), "State of the Information Privacy Literature: Where We Are Now and Where We Should Go?" MIS Quarterly, 35 (4), 977-988.

—_, Huigang Liang, and Yajiong Xue (2007), “Understanding and Mitigating Uncertainty in Online Exchange Relationships: A Principal-Agent Perspective," MIS Quarterly, 31 (1), 105-136.

Pennebaker Conglomerates, Inc. (n.d.). In LIWC: Linguistic Inquiry and Word Count. Retrieved April 23, 2014 from http://www.liwc.net/ index.php

Pennystockslab (2015), “The Internet in Real-Time." Retrieved on February 4, 2015, from http://pennystocks.la/internet-in-real-time

Peters, Kim and Yoshihasa Kashima (2007), "From Social Talk to Social Action: Shaping the Social Triad with Emotion Sharing," Journal of Personality and Social Psychology, 93 (5), 780-797. 
Pierce, Jon L., Tatiana Kostova, and Kurt T. Dirks (2001), "Toward a Theory of Psychological Ownership in Organizations," Academy of Management Review, 26 (2), 298-310.

Preacher, Kristopher J., Derek D. Rucker, and Andrew F. Hayes (2007), "Addressing Moderated Mediation Hypotheses: Theory, Methods, and Prescriptions," Multivariate Behavioral Research, 42 (1), 185-227.

PwC (2012), "Advancing Digital Commerce Capabilities to Drive Financial Value: Perspective and Benchmarking Framework." Retrieved on January 27, 2015 from http://www.strategyand.pwc.com/global/home/ what-we-think/reports-white-papers/article-display/advancingdigital-commerce-capabilities-drive

Rapp, Adam, Lauren Skinner Beitelspacher, Dhruv Grewal, and Douglas E. Hughes (2013), "Understanding Social Media Effects Across Seller, Retailer, and Consumer Interactions," Journal of the Academy of Marketing Science, 41 (5), 547-566.

_-_, ——, Niels Schillewaert, and Thomas L. Baker (2012), "The Differing Effects of Technology on Inside vs. Outside Sales Forces to facilitate Enhanced Customer Orientation and Interfunctional Coordination," Journal of Business Research, 65 (7), 929-936.

- Michael Ahearne, John Mathieu, and Niels Schillewaert (2006), "The Impact of Knowledge and Empowerment on Working Smart and Working Hard: The Moderating Role of Experience," International Journal of Research in Marketing, 23 (3), 279-293.

Raudenbush, Stephen W. and Anthony S. Bryk (2002), Hierarchical Linear Models: Applications and Data Analysis Methods (Vol. 1). Sage.

Rime, Bernard (2007), "The Social Sharing of Emotion as an Interface Between Individual and Collective Processes in the Construction of Emotional Climates," Journal of Social Issues, 62 (2), 307-322.

Rossi, Peter E., Robert E. McCulloch, and Greg M. Allenby (1996), “The Value of Purchase History Data in Target Marketing," Marketing Science, 15 (4), 321-340.

Rousseau, Denise M., Sim B. Sitkin, Ronald S. Burt, and Colin Camerer (1998), "Not So Different After All: Cross Discipline View of Trust," Academy of Management Review, 23 (3), 393-404. 
Rucker, Derek D., Zakary L. Tormala, Richard E. Petty, and Pablo Briñol (2014), "Consumer Conviction and Commitment: An AppraisalBased Framework for Attitude Certainty," Journal of Consumer Psychology, 24 (1), 119-136.

Rust, Roland T., and Tuck Siong Chung (2006), "Marketing Models of Service and Relationships," Marketing Science, 25 (6), 560-580.

Schlosser, Ann E., Tiffany Barnett White, and Susan M. Lloyd (2006), "Converting Web Site Visitors into Buyers: How Web Site Investment Increases Consumer Trusting Beliefs and Online Purchase Intentions," Journal of Marketing, 70 (2), 133-148.

Schmidt, Aaron M. and J. Kevin Ford (2003), "Learning within a Learner Control Training Environment: The Interactive Effects of Goal Orientation and Metacognitive Instruction on Learning Outcomes," Personnel Psychology, 56 (2), 405-429.

Schunk, Dale H. (2005), "Self-Regulated Learning: The Educational Legacy of Paul R. Pintrich," Educational Psychologist, 40 (2), 85-94.

Sengupta, Jaideep and Rongrong Zhou (2007), "Understanding Impulsivity Eaters' Choice Behaviors: The Motivational Influences of Regulatory Focus," Journal of Marketing Research, 44 (2), 297-308.

Shamdasani, Prem N., Andrea J. S. Stanaland, and Juliana Tan (2001), "Location, Location, Location: Insights for Advertising Placement on the Web," Journal of Advertising Research, 41 (4), 7-21.

Shankar, Venkatesh, J. Jeffrey Inman, Murali Mantrala, Eileen Kelley, and Ross Rizley (2011), "Innovations in Shopper Marketing: Current Insight and Future Research Issues," Journal of Retailing, 87 (S1), S29-S42.

Sheldon, Oliver J., David Dunning, and Daniel R. Ames (2014), "Emotionally Unskilled, Unaware, and Uninterested in Learning More: Reactions to Feedback About Deficits in Emotional Intelligence," Journal of Applied Psychology, 99 (1), 125-137.

Shen, Anyuan and A. Dwayne Ball (2009), "Is Personalization of Services Always a Good Thing? Exploring the Role of Technology-Mediated Personalization (TMP) in Service Relationships," Journal of Services Marketing, 23 (2), 79-91. 
Shi, Zhan, Huaxia Rui, and Andrew B. Whinston (2014), "Content Sharing in a Social Broadcasting Environment: Evidence from Twitter," MIS Quarterly, 38 (1), 123-142.

Shiv, Baba and Alexander Fedorikhin (1999), "Heart and Mind in Conflict: The Interplay of Affect and Cognition in Consumer Decision Making," Journal of Consumer Research, 26 (3), 278-292.

Shu, Suzanne B. and Joann Peck (2011), "Psychological Ownership and Affective Reaction: Emotional Attachment Process Variables and the Endowment Effect," Journal of Consumer Psychology, 21 (4), 439-452.

Singer, Natasha (2010), "Shoppers Who Can't Have Secrets," The New York Times, May 1. Retrieved on September 25, 2012, from http://www. nytimes.com/2010/05/02/ business/ 02stream.html

(2012), "E-Tailer Customization: Convenient or Creepy?" The New York Times, June 23. Retrieved on July 18, 2012, from http://www. nytimes.com/2012/06/24/ technology/e-tailer-customization-whatsconvenient-and-whats-just-plain-creepy.html? ref=natashasinger

Sitzmann, Traci and Katherine Ely (2010), "Sometimes You Need a Reminder: The Effects of Prompting Self-Regulation on Regulatory Process, Learning, and Attrition," Journal of Applied Psychology, 95 (1), 132-144.

Snyder, Mark (1974), "Self-Monitoring of Expressive Behavior," Journal of Personality and Social Psychology, 30 (4), 526-537.

Somuncuoglu, Yesim and Ali Yildirim (1999), "Relationship between Achievement Goal Orientations and Use of Learning Strategies," Journal of Educational Research, 92 (5), 267-277.

Song, Ji Hee and George M. Zinkhan (2008), "Determinants of Perceived Web Site Interactivity," Journal of Marketing, 72 (2), 99-113.

Spiller, Stephen A., Gavan J. Fitzsimons, John G. Lynch Jr., Gary H. McClelland (2013), "Spotlights, Floodlights, and the Magic Number Zero: Simple Effects Tests in Moderated Regression," Journal of Marketing Research, 50 (2), 277-288. 
Sporat, Ethan, Dana Lynn Driscoll, and Allen Brizee (2012), "Aristotle's Rhetorical Situation," Purdue University Online Writing Lab, April 27. Retrieved on November 42014 from https://owl.english.purdue. edu/owl/resource/625/03/

Stelter, Brian (2009), "Facebook Users Ask Who Owns Information," The New York Times, February 16. Retrieved on February 4, 2015, from http:// www.nytimes.com/2009/02/17/technology/internet/17facebook.html

Stewart, Katherine J. (2003), "Trust Transfer in the World Wide Web," Organization Science, 14 (1), 5-17.

Streitfeld, David (2012), "For a \$2 a Star, an Online Retailer Gets 5-Star Product Reviews," The New York Times, January 26. Retrieved on January 27, 2015 from http://www.nytimes.com/2012/01/27/ technology/for-2-a-star-a-retailer-gets-5-star-reviews.html?_ $\mathrm{r}=3$ \&pagewanted $=$ all

Sujan, Harish, Barton A. Weitz, and Nirmalya Kumar (1994), "Learning Orientation, Working Smart, and Effective Selling," Journal of Marketing, 58 (3), 39-52.

Sundar, S. Shyam and Sampada S. Marathe (2010), "Personalization versus Customization: The Importance of Agency, Privacy, and Power Usage," Human Communication Research, 36 (3), 298-322.

Tam, Kar Yan and Shuk Ying Ho (2006), "Understanding the Impact of Web Personalization on User Information Processing and Decision Outcomes," MIS Quarterly, 30 (4), 865-890.

Tamir, Diana I. and Jason P. Mitchell (2012), "Disclosing Information About the Self Is Intrinsically Rewarding," Proceedings of the National Academy of Sciences of the United States of America, 109 (21), 8038-8043.

Tausczik, Yla R. and James W. Pennebaker (2010), "The Psychological Meaning of Words: LIWC and Computerized Text Analysis Methods," Journal of Language and Social Psychology, 29 (1), 24-54.

The New York Times (2011), "The Psychology of Sharing." Retrieved on August 18, 2014 from http://nytmarketing.whsites.net/mediakit/pos 
Tolchinski, Paul D., Michael K. McCuddy, Jerome Adams, Daniel C. Ganster, Richard W. Woodman, and Howard L. Fromkin (1981), "Employee Perceptions of Invasion of Privacy: A Field Simulation Experiment," Journal of Applied Psychology, 66 (3), 308-313.

Tormala, Zakary L. and Derek D. Rucker (2007), "Attitude Certainty: A Review of Past Findings and Emerging Perspectives," Social and Personality Psychology Compass, 1 (1), 469-492.

Toubia, Olivier, and Andrew T. Stephen (2013), "Intrinsic vs. ImageRelated Utility in Social Media: Why Do People Contribute Content to Twitter?." Marketing Science, 32 (3), 368-392.

Tucker, Catherine (2012), "The Economics of Advertising and Privacy," International Journal of Industrial Organization, 30 (3), 326-329. - (2014), "Social Networks, Personalized Advertising, and Privacy," Journal of Marketing Research, 51 (5), 546-562.

Turow, Joseph, Jennifer King, Chris Jay Hoofnagle, Amy Bleakley, and Michael Hennessy (2009), "Americans Reject Tailored Advertising and Three Activities that Enable It," Working Paper. Retrieved on April 17, 2012, from http://ssrn.com/abstract=1478214.

Urban, Glen L., Cinda Amyx, and Antonio Lorenzon (2009), "Online Trust: State of The Art, New Frontiers, and Research Potential," Journal of Interactive Marketing, 23 (2), 179-190.

van den Bergh, Bram, Siegfried Dewitte, and Luk Warlop (2008), "Bikinis Instigate Generalized Impatience in Intertemporal Choice," Journal of Consumer Research, 35 (1), 85-97.

VandeWalle, Don, Steven P. Brown, William L. Cron, and John W. Slocum, Jr. (1999), "The Influence of Goal Orientation and Self-Regulation Tactics on Sales Performance: A Longitudinal Field Test," Journal of Applied Psychology, 84 (2), 249-259.

van Kleef, Gerben A. (2009), "How Emotions Regulate Social Life: The Emotions as Social Information (EASI) Model," Current Directions in Psychological Science, 18 (3), 184-188. 
van Prooijen, Jan-Willem, Johan C. Karremans, and Ilja van Beest (2006), "Procedural Justice and the Hedonic Principle: How Approach Versus Avoidance Motivation Influences the Psychology of Voice," Journal of Personality and Social Psychology, 91 (4), 686-697.

Veenman, Marcel V. J., Bernadette H. A. M. van Hout-Wolters, and Peter Afflerbach (2006), "Metacognition and Learning: Conceptual and Methodological Considerations," Metacognition Learning, 1 (1), 3-14.

Verhoef, Peter C., Rajkumar Venkatesan, Leigh McAlister, Edward C. Malthouse, Manfred Krafft, and Shankar Ganesan (2010), "CRM in Data-Rich Multichannel Retailing Environments: A Review and Future Research Directions," Journal of Interactive Marketing, 24 (2), 121-137.

Vesanen, Jari (2007), "What is Personalization? A Conceptual Framework," European Journal of Marketing, 41 (5), 409-418.

Vock, Marlene, Willemijn Van Dolen, and Ko de Ruyter (2013), "Understanding Willingness to Pay for Social Network Sites," Journal of Service Research 16 (3), 311-325.

Vohs, Kathleen D., and Ronald J. Faber (2007), "Spent Resources: SelfRegulatory Resource Availability Affects Impulse Buying," Journal of Consumer Research, 33 (4), 537-547.

Voss, Christopher A., Aleda V. Roth, Eve D. Rosenzweig, Kate Blackmon and Richard B. Chase (2004), "A Tale of Two Countries' Conservatism, Service Quality, and Feedback on Customer Satisfaction," Journal of Service Research, 6 (3), 212-230.

Vuong, Quang H. (1989), "Likelihood Ratio Tests for Model Selection and Non-Nested Hypotheses," Econometrica, 57 (2), 307-333.

Wadhwa, Monica, Baba Shiv, and Stephen Nowlis (2008), "A Bite To Whet the Reward Appetite: The Influence of Sampling on Reward-Seeking Behaviors," Journal of Marketing Research, 45 (4), 403-413.

Wan, Echo Wen, Derek D. Rucker, Zakary L. Tormala, and Joshua J. Clarkson (2010), "The Effect of Regulatory Depletion on Attitude Certainty," Journal of Marketing Research, 47 (3), 531-541. 
Wang, Guangping, and Richard G. Netemeyer (2002), “The Effects of Job Autonomy. Customer Demandingness, and Trait Competitiveness on Salesperson Learning, Self-Efficacy, and Performance," Journal of the Academy of Marketing Science, 30 (3), 217-228.

Wang, Sijun, Sharon E. Beatty, and William Foxx (2004), "Signaling the Trustworthiness of Small Online Retailers," Journal of Interactive Marketing, 18 (1), 53-69.

Weber Shandwick (2013), "Buy It, Try It, Rate It.” Retrieved on January 27, 2015 from http://www.webershandwick.com/news/article/buyit-try-it-rate-it-the-power-of-consumer-reviews

White, Tiffany Barnett, Debra L. Zahay, Helge Thorbjprnsen, and Sharon Shavitt (2008), "Getting Too Personal: Reactance to Highly Personalized Email Solicitations," Marketing Letters, 19 (1), 39-50.

Wilcox, Keith and Andrew T. Stephen (2013), "Are Close Friends The Enemy? Online Social Networks, Self-Esteem, and Self-Control," Journal of Consumer Research, 40 (1), 90-103.

Wolfinbarger, Mary and Mary C. Gilly (2003), "eTailQ: Dimensionalizing, Measuring, and Predicting eTail Quality," Journal of Retailing, 79 (3), 183-198.

Worthy, Morgan, Albert L. Gary, and Gay M. Kahn (1969), "Self-Disclosure as an Exchange Process," Journal of Personality and Social Psychology, 13 (1), 59-63.

Zhang, Jie and Michel Wedel (2009), "The Effectiveness of Customized Promotions in Online and Offline Stores," Journal of Marketing Research, 46 (2), 190-206.

ZS Associates (2014), "Voice of Partner Programs from Hardware to Software Companies Leave Many IT Channels Flat." Retrieved on September 22, 2014 from http://www.zsassociates.com/about/ news-and-events/voice-of-partner-programs-from-hardware-andsoftware-companies--leave-many-it-channel-partners-flat.aspx 


\section{Appendix}

\section{APPENDIX A}

Chapter 2: Audience and Review Type Manipulation

We would like you to write down your objective [personal] assessment of the short video biography on the space below. Comment about the quality of the sound, the editing, the length, and the content. As you write, do not let your personal feelings or opinions influence your factual assessment of the video. [Comment about how the film made you feel and what thoughts went through your head as you watched the clip. As you write, let your personal feelings and opinions guide your personal assessment of the video.]

This will help you reflect on your experience, which is required for the next task. No one, not even the experimenters, will see what you have written. [Your review of the video will be shared with members of the film academy at our university. This will help them understand the importance of composition on various types films.]

Please spend at least 3 minutes to write the assessment. After this time, you will be able to proceed to the next page. 


\section{APPENDIX B}

\section{Chapter 3: Pretest}

Design, Participants, and Procedure. The pretest used an experimental design and included 108 first-year undergraduate students, who received course credit in return for their participation. One hundred six students (Mage $=21$ years; $45 \%$ female) completed the experiment and were randomly assigned to either the reviewing or rating group. They chose a course they had already taken and wanted to provide a referral on, then wrote a review in the space provided or rated the course on a 1-10 scale.

We informed the students that the university was conducting a poll about how many undergraduate students were interested in pursuing a master's degree. They indicated, on a seven-point Likert scale $(1=$ "strongly disagree," 7 = "strongly agree") how much they agreed with the sentence, "I am interested in pursuing a Master's Degree after I complete my Bachelors program." Next, students completed a range of personality questions, including a six-item LO scale adapted from Elliot and Church $(1997 ; \alpha=.812)$. For the analysis, we took the average of the six items, and higher values indicated higher LO.

Results. We pretested $\mathrm{H} 1$, namely, that reviewing a learning experience increases interest in further learning among low LO participants, with a regression in which interest in pursuing a master's degree was the dependent variable, and the referral manipulation (reviewing $=1$; rating = $0)$, $\mathrm{LO}(\mathrm{M}=5.59, \mathrm{SD}=.78, \min =1, \max =7)$, and their interactions were the independent variables. We found significant main effects of referral $(\beta=3.85 ; t(102)=2.131 ; p=.035)$ and $\mathrm{LO}(\beta=.72 ; t(102)=3.094 ; p=$ .003). Thus, reviewing (vs. rating) and having a higher LO both led to increases in students' interest in pursuing additional learning. In support of our hypothesis, we also found a significant interaction between referral and LO at a $10 \%$ level $(\beta=-.56 ; t(102)=-1.759 ; p=.082)$.

As suggested by Spiller et al. (2013), we applied Johnson and Neyman's test to decompose the interaction and identify the range(s) of LO for which the simple effect of the manipulation was significant. The test revealed a significant positive effect of reviewing on interest in further learning for any participant with a LO score below $5.9\left(\beta_{\mathrm{JN}}=.53 ; t=1.983 ; p=.05\right)$ but not for participants with a LO score above 5.9. 


\section{APPENDIX C}

\section{Chapter 4: Information Collection Manipulation}

In the first quarter, Facebook delivered more banner ads to its users than any other Web publisher. They surpassed Microsoft as the market leader, according to the marketing research firm DEK Group.

DEK found that Facebook's share of the display market grew to 20\% in April 2011, up from 10\% in April 2010. In an interview, Guy Bresett, Facebook's vice president for advertising and global operations, said growth in the company's ad business is "steep" and "really healthy"

Mr. Bresett said marketers are coming to Facebook because of the company's ad targeting capabilities. Users are aware that they grant Facebook access to their personal information when they open an account with the social networking site. Facebook informs its users how it analyzes their data to create personalized advertisements. [Facebook steadily follows its users over the social networking site and partner sites, and records their individual activities without their awareness. Facebook conceals from its users how it analyzes their data to create personalized advertisements.] 


\section{APPENDIX D}

Chapter 4: Scenario

Imagine that you are a member of the social networking site Facebook. You are an active user, and you communicate to all your friends through this medium.

Please picture that you have to drive to work every day. This morning, your car broke down, and you brought the car to the garage only to find out that it was broken beyond repair. You face a dilemma. You know that you do not have enough money saved up to replace the car, but also that you need a car to get to work.

You remember that one of your friends has recently taken out a car loan. Please picture yourself sending a private message to your friend through Facebook. You tell your friend that you need to take out a loan to finance your new car. You ask if your friend can provide you with more information about it. 


\section{APPENDIX E}

\section{Chapter 4: Vulnerability Development Scale}

From a thorough review of literature, we concluded that instruments available to measure vulnerability did not apply readily to our study. For example, Dinev and Hart (2004) measure individual perceptions of vulnerability as a general understanding of the risks involved when information is revealed during specific contexts, rather than the affective feeling triggered by such instances. Therefore, we followed established procedures and adopted a four-step scale development approach (Netemeyer, Bearden, and Sharma 2003): construct definition and content domain, generating and judging measurement items, designing and conducting studies to develop and refine the scale, and finalizing the scale.

First, in a series of 50 qualitative interviews, we identified that vulnerability went beyond an understanding of risk to include affective feelings of discomfort, as the following quotes represent:

- "An email from my girl friend for example dealing about a bicycle trip was connected to an advertisement about bicycles. This was a bit unpleasant because an email is pretty much an electronic mail which should be private."

- "Well, actually I did observe it that sometimes when you are online and then you suddenly see or receive information and advertisements of which you think: hey I like that! And then I do ask myself how they know this. Because for example this advertisement is about shoes that I saw on a totally different webpage. And actually I think that is rather strange and also a bit frightening. I wonder how far it goes."

- "I just sometimes think its kind of freaky, because you click on a website, and then on Facebook you get ads of websites you have previously visited, and then I'm like; okay, it's kind of freaky that they know I have visited that website and that they now make an ad out of that."

."someone is breaking into my private sphere ... it is unpleasant."

The interviews revealed an affective feeling associated with information collection, further clarified by the theory of psychological ownership 
and a subsequent sense of vulnerability. These theoretical insights helped construct the definition of the vulnerability construct.

Second, we integrated the results of the qualitative study and supporting theory to generate a list of 15 scale items that could reliably measure perceived vulnerability. Then 101 students participated in an open-ended elicitation task (Hardesty, Bearden, and Carlson 2007). As part of the task, each participant listed all words associated with vulnerability. Three judges coded the items by evaluating the degree to which each item was representative of the definition of vulnerability. If less than two-thirds of the judges did not affirm an item, we removed it. This process led to the retention of seven items.

Third, we conducted a pilot test with 108 students; for item reduction efforts, college students are an acceptable population (Netemeyer, Bearden, and Sharma 2003). In LISREL 8, we ran an exploratory factory analysis, and the modification index values indicated a single-factor model with five items (Lastovicka et al. 1999). The model revealed a small chi-square value $\left(\chi^{2}=2.13 ; \mathrm{df}=5 ; p=.831\right.$ ), and a good fit (root mean square error of approximation $<.01$, goodness-of-fit index $=.99$, adjusted goodnessof-fit index $=.98$, normed fit index $=.99)$. The corrected item-to-total correlations were all above .50 (Brocato, Voorhees, and Baker 2012), as well the interitem correlations (Netemeyer, Bearden, and Sharma 2003). The Cronbach's alpha was .864.

Fourth, our main studies demonstrate the discriminant, convergent, and nomological validity of the measure. Specifically, we conducted a study that contained a cognitive response measure (privacy) together with perceived vulnerability $(n=39)$. The average variance extracted (AVE) of the perceived vulnerability construct was greater than .50 (Bagozzi and Yi 1988; AVE $=.764)$, and the composite reliability $(\mathrm{CR})$ exceeded the recommended minimum of .7 (Fornell and Larcker 1981; CR = .941). In support of discriminant validity, the AVE of perceived vulnerability was greater than the shared variance between perceived vulnerability and privacy $\left(\mathrm{AVE}=.764>\mathrm{r}^{2}=.230\right)$. Perceived vulnerability and privacy are not only moderately correlated $(\mathrm{r}=-.480 ; p=.002)$ but also move in similar directions, as predicted by theory (lower values indicate higher privacy concerns). This relationship, as well as those between perceived vulnerability and the constructs in Studies 1 and 2, provide support for our measure of perceived vulnerability. 


\section{Valorization Addendum}

This dissertation focuses on the consequences of sharing information online. It places particular emphasis on the positive and negative outcomes for the individual who is sharing information, an approach that is increasingly relevant as growing numbers of individuals are drawn to social networking sites that allow them to share their experiences and engage in relevant content. In this section, I discuss the relevance of each of the manuscripts in this dissertation to managers and policy makers.

\section{Chapter 2: Sharing is rewarding}

This manuscript discusses the negative consequences that may arise from the use of social media, in line with recent research that finds participation in social networking sites results in debt and higher levels of body mass index (Wilcox and Stephen 2013). Despite the negative consequences that may stem from sharing information online, we see a growing number of people who post, tweet, and blog about their lives. There are also trends to integrate these social networks with purchase functions to increase sales. These developments are particularly troubling, and because customers are likely unaware of them. Industry associations should take it upon themselves to develop more specific guidelines for making customers more aware of the consequences of their online decisions. One finding of this manuscript that can help inform such guidelines is reviewers who write in an emotional manner are susceptible to impulsive behaviors. Therefore, firms can develop tools that integrate text mining to better identify reviewers who are more prone to writing in an emotional manner, and develop targeted strategies to manage them.

Firms can address this issue by integrating praise into their feedback systems and presenting it to customers immediately after they have submitted a review. However, one drawback to this approach is 
customers may become accustomed to, or skeptical of, certain praise messages (Henderlong and Lepper 2002). Managers responsible for the social media functions of their companies must therefore take great care to make these messages as authentic as possible, and tailor them to individual accomplishments. Because individuals derive social rewards from a variety of sources, managers can also consider other socially rewarding feedback such as acknowledging and thanking the reviewers for their contributions.

Another initiative a firm can implement is the development of nonpublic channels that enable customers to communicate directly with the firm. Many firms already integrate such systems, such as private chat functions or simple "contact us" sections, into their websites. While these systems are typically used to manage complaints, they could also be used as a means for customers to express their personal feelings and opinions of products. Such insights could not only help the firm gain valuable product knowledge, but also mitigate impulsive behaviors that may result from expressing this information in a public forum.

\section{Chapter 3: $A(R e)$ View of myself}

This manuscript addresses a key issue that many manufacturers face: a lack of engagement within Channel Partner Programs (CPPs). Although participation in CPPs benefits both channel partners and manufacturers, a general lack of motivation on the part of some channel partners seems to prevent both parties from mutually benefitting from CPPs. The findings from this study suggest several ideas for increasing engagement and promoting CPPs through the use of review systems.

First, manufacturers should consider incorporating intrinsic motivators that might supplement their existing incentive programs. Extrinsic incentive programs that reward partners with luxury items or vacation destinations when they participate in learning modules might help motivate partners, but they can also be easily matched by competitors (Lane4 2012) and generally lack the elements that create engaging, meaningful experiences (Deloitte 2012). Review systems seem to be a powerful tool to trigger unmotivated channel partners to engage in reflective thinking, which motivates them to 
take on additional learning modules. Therefore, I recommend such review systems be incorporated into CPPs.

Second, although reflective thinking brought about by writing reviews is a powerful behavioral motivator, it is limited in that it is effective only for partners who are not already intrinsically motivated to learn. To optimize the behavioral outcomes of reviewing, manufacturers should find ways to focus on essential information within the reviews, relevant to low learning oriented partners' personal experience with learning modules, in the task instructions. Similar to suggestions put forward by ZS Associates (2014), I recommend review tasks be customized to appeal to different segments of channel partners with distinct needs. For example, manufacturers could identify segments (such as those with low learning orientation) through a survey question, then invite certain channel partners to review modules while highlighting the benefits of these reviews for their peers.

Third, to increase partners' certainty, manufacturers should encourage their partners to draw conclusions about how learning programs have helped them. Reflective thinking is a key method, but certainty could also increase if channel partners read negative and positive appraisals from other business partners, or discern that a majority of other business partners hold similar perspectives (Rucker et al. 2014). Other methods for increasing certainty include sending e-mails that affirm what the channel partners learned a few days after they have completed a learning module or sharing the thoughts expressed by other channel partners about the learning module. Because of its strong, lasting impact on engagement, manufacturers should measure certainty, possibly using unobtrusive text mining methods similar to those in our study, to help them evaluate and predict their partners' behaviors.

Fourth, managers can advance the social functionalities of their CPPs to facilitate knowledge exchanges among business partners. They can develop and maintain communities that help channel partners discuss their experiences with the CPPs. These platforms would not only foster reflective thinking, as channel partners share their experiences, but also boost the degree of certainty among other channel partners when the partners encounter testimonials from their peers. However, for these functionalities to work effectively, managers must also educate their channel partners on how to effectively use such 
tools, and provide them with support to ensure smooth adaptations (Ahearne, Jelinek, and Rapp 2005).

\section{Chapter 4: Unraveling the personalization paradox}

This manuscript highlights a growing issue that society is facing as technological advances make data collection ubiquitous and difficult to trace. The Internet is a prime example of this: as customers browse the Internet, firms collect their behavioral information and present them with personalized advertisements. However, as many customers are unaware their information is being collected, this lack of awareness may impact the effectiveness of firms' personalization attempts. This study offers valuable insights for firms engaging in such online personalization. Retailers, the most active group using such advertising strategies, should recognize personalization is not always effective; they should strategically vary their personalization efforts by carefully selecting which pieces of information to use. For example, firms might rely on information that is generally relevant to a customer but not overly or personally targeted, particularly if they have gathered the information from online social networks. The firms should carefully assess the level of information sensitivity and how closely the information is tied to each consumer's identity. Both elements determine consumer acceptance of a personalization strategy.

Additionally, online retailers should practice transparency with regard to when and how consumer data is being collected. Increased media attention and the spread of personalization practices mean consumers are increasingly aware that firms collect their information, online and offline. When they receive personalized advertising, consumers are likely to express more skepticism toward the retailer, especially if the company cites information they did not explicitly consent to provide. Consumers believe they own personal information; if retailers gain access to it, they must inform customers about their data collection strategies and seek implied consent, in the form of consumers' continued usage. Because customers must consciously consent, retailers should be proactive in providing comprehensible, visible notifications of their information collection practices.

Despite the importance of such information policies, it is difficult to implement proactive communications in all circumstances and across 
the various complex relationships on the Web (e.g., among online publishers, retailers, and data brokers). For targeted advertising in social media, firms might benefit from placements on trustworthy websites or from the use of an informational icon included directly in their advertisements. The icons have been advocated by industry associations as a best practice solution (Internet Advertising Bureau UK 2011) but have not yet been universally implemented. My findings indicate the need for wider adoption; such tools can offset negative reactions to personalized advertising, enhance website credibility, and make personalized advertising more acceptable.

Finally, there has been much debate between government and industry regarding how to handle customer data. Policies have recently been implemented within the European Union to require firms such as Google to increase their transparency, and improve the information they provide to customers regarding how their information is collected and used (BBC 2015). These policies support the findings of this research and show both customers and companies benefit as personalization initiatives become more effective. Other policy makers should follow suit, and encourage more transparency from such firms.

\section{REFERENCES}

Ahearne, Michael, Ronald Jelinek, and Adam Rapp (2005), "Moving Beyond the Direct Effect of SFA Adoption on Salesperson Performance: Training and Support as Key Moderating Factors," Industrial Marketing Management 34 (4), 379-388.

BBC (2015), "Google Agrees Privacy Policy Changes with Data Watchdog," January 30. Retrieved on February 4, 2015, from http://www.bbc.com/news/ technology-31059874

Deloitte (2012), “The Engagement Economy: How Gamification is Reshaping Business." Retrieved on June 15, 2014 from http://www.deloitte.com/ view/en_US/ us/ Insights/Browse-by-Content-Type/deloitte-review/ c7cee86d96498310VgnVCM1000001956f00aRCRD.htm. 
Henderlong, Jennifer and Mark R. Lepper (2002), "The Effects of Praise on Children's Intrinsic Motivation: A Review and Synthesis," Psychological Bulletin, 128 (5), 774-795.

Internet Advertising Bureau UK (2011), "Europe Commits to SelfRegulation," April 14. Retrieved on June 14, 2012, from http:// www.iabuk.net/news/europe-commits-to-self-regulation.

Lane4 (2012), “Talent Tactics: How Can You Plug the Talent Gap?” June. Retrieved on June 4, 2014 from http://www.lane4performance. $\mathrm{com} /$ NewsDetail.aspx?itemid $=970 \&$ itemTitle $=$ Talent + Tactics $\&$ sitesectionid $=92 \&$ sitesectiontitle $=$ White + Papers .

Rucker, Derek D., Zakary L. Tormala, Richard E. Petty, and Pablo Briñol (2014), "Consumer Conviction and Commitment: An Appraisal-Based Framework for Attitude Certainty," Journal of Consumer Psychology, 24 (1), 119-136.

Wilcox, Keith and Andrew T. Stephen (2013), "Are Close Friends The Enemy? Online Social Networks, Self-Esteem, and Self-Control," Journal of Consumer Research, 40 (1), 90-103.

ZS Associates (2014), "Voice of Partner Programs from Hardware to Software Companies Leave Many IT Channels Flat.” Retrieved on September 22, 2014 from http://www.zsassociates.com/ about/news-and-events/voice-of-partner-programs-fromhardware-and-software-companies--leave-many-it-channelpartners-flat.aspx 


\section{Summary}

\section{IT'S ALL ABOUT THAT POST: \\ OPPORTUNITIES AND CHALLENGES OF SHARING INFORMATION ONLINE}

We live in an information sharing society that thrives because of technologies that enable individuals to broadcast their thoughts and experiences through social media. Users spend a significant amount of time communicating with others through these technologies. But we know little about how sharing information online affects the individuals who post information. In this dissertation, I confront this research gap by studying positive and negative consequences of sharing information online.

The first manuscript, "Sharing is Rewarding," examines how writing emotional reviews affects reviewer behaviors. Drawing on the theory of reverse alliesthesia, we find the act of sharing personal opinions is itself a rewarding experience that may cause reviewers to behave impulsively. Firms can minimize the occurrence of impulsive behaviors and their negative consequences by praising reviewers immediately after their writing tasks, because social approval provides the reviewers with rewards. However, not all individuals are equally affected; participants who are more sensitive to social cues seem particularly susceptible to these negative effects.

The second manuscript, "A (Re)View of Myself," investigates how writing reviews about previous learning experiences triggers unmotivated channel partners to participate in additional learning modules. In line with metacognition theory, we find review writing serves as an effective metacognitive intervention that heightens belief certainty about knowledge acquisition and spurs channel partners 
to pursue further learning. However, these findings are contingent on two boundary conditions: (1) writing for the benefit of peers rather than the manufacturer and (2) a focused rather than broad perspective of the learning content.

The third manuscript, "Unraveling the Personalization Paradox," takes the research a step further by studying the effects that occur when firms collect and use information shared by customers online to provide them with personalized advertisements. In line with psychological ownership theory, we find that customers perceive they own their information and feel vulnerable when their information is collected and used without their consent. When firms collect information overtly, participants exhibit greater click-through intentions in response to personalized advertisements than when firms collect information covertly. Trust-building marketing strategies (transferring trust from another website or signaling trust with informational cues) can offset this negative effect. 


\section{Curriculum Vitae}

Elizabeth Aguirre was born in Makati, Philippines on the 17th of November 1986. She attended primary and secondary education in Assumption College in the Philippines. Afterwards, she obtained her Bachelors of Science degree in Management with a major in Communication Technology Management from the Ateneo de Manila University, Philippines in May 2008, having spent one semester at the National University of Singapore, Singapore. She completed her Master's degree in Strategic Marketing at Maastricht University, the Netherlands in August 2010. In October 2010, she started working as a $\mathrm{PhD}$ fellow at the Marketing \& Supply Chain Management department within the School of Business and Economics at Maastricht University, under the supervision of Prof. Dr. Ko de Ruyter, Prof. Dr. Martin Wetzels, Prof. Dr. Dhruv Grewal and Dr. Dominik Mahr. She currently continues to work at Maastricht University as a postdoctoral scholar. 